This PDF is a simplified version of the original article published in Internet Archaeology. Enlarged images and video which support this publication can be found in the original version online. All links also go to the online version.

Please cite this as: Petersson, B. and Burke. D. et al. Experimental Heritage as Practice: Approaching the Past through the Present at the Intersection of Art and Archaeology, Internet Archaeology 55.

\title{
Experimental Heritage as Practice: Approaching the Past through the Present at the Intersection of Art and Archaeology
}

Bodil Petersson, Danny Burke, Maria Kerin, Mary Nunan, Michael Walsh, Helle Kvamme, Patricia McKenna, Ros Ó Maoldúin, Déirdre Carr and Stefan Bergh

\section{Summary}

This article presents the emerging transdisciplinary practice of Experimental Heritage as performed within an ongoing Irish-Swedish research project involving artists and archaeologists. The project is undertaken simultaneously in western Ireland and southeastern Sweden. It explores the chosen Irish and Swedish landscapes of Clare and Öland, their similarities and differences, with the aid of combined and integrated artistic and archaeological practices. The starting points for common explorations are: stone and water, movement and time/the multitemporal, and the tangible and intangible aspects of landscape experience. In a transdisciplinary process, we explore new ways of combining art, archaeology and heritage within and between these landscapes.

One path towards fulfilling the aims is to explore art, archaeology and heritage through the senses. A phenomenological landscape perspective and an eco-cultural approach is combined with Performance Studies and movement-based practice. These perspectives and methodologies are paired with artistic and archaeological approaches to research, such as those conducted through poetry, music, performance, visual arts, physical surveys, mapping and excavations. 


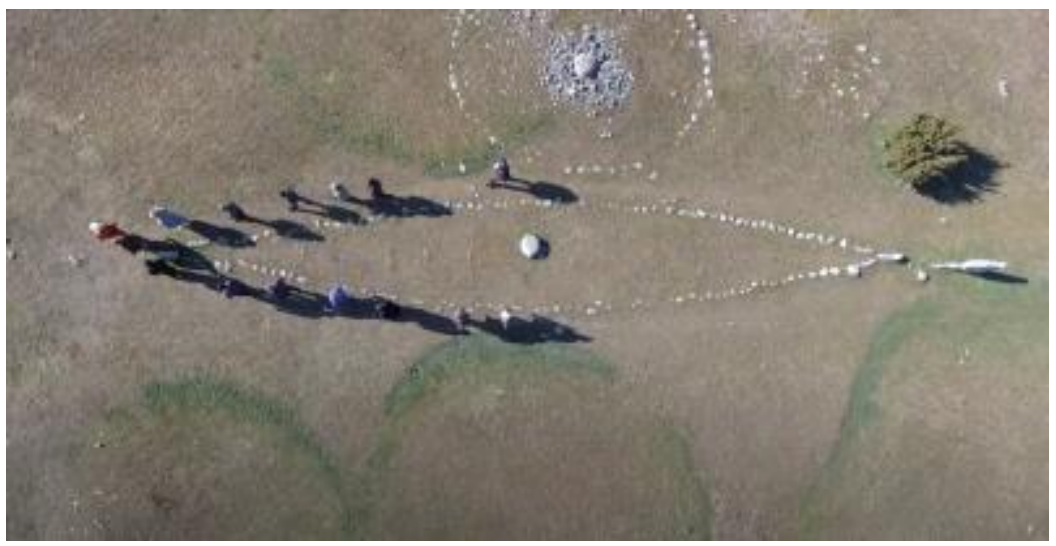

Still from Moving the Ship video

Methods of working have developed from walking in the landscape to sketching, through visuals, sound and movement, group dialogue, team building and exploring the materiality of making. Group movement-based workshops are used to support receptivity and inner listening for decision making through somatic principles and the senses. The project encourages transdisciplinary as well as translocal practice to arrive at new approaches and perspectives on how the past matters to us in the present and how it might have an impact on the future.

To achieve both transdisciplinary and translocal ways of working through art and archaeology/heritage, we need to expand beyond conventional art and archaeology/heritage research, communication and presentation within the well-known framework of universities, cultural history museums and art institutions. The constraints of these conventions are substituted by alternative settings in the landscape. This landscape-based practice includes method development across disciplines, times and geographic distances. It also includes collaborations with people from local communities that can contribute their perspectives, experiences and stories to the explorations.

The advantage of Experimental Heritage as practice in the landscape is its ability to challenge our current worldview to better understand other times and cultures as well as our own. This in turn provides us with new tools to create alternative futures resting on care and respect for the need for diversity and breaking not only with boundaries set up between nature and culture but also hierarchies of centre and periphery. We intend to find out more about the multitemporal layers in the landscapes surrounding us and how they relate to our inner landscapes of multitemporal perception. The combination and equal roles of artists and archaeologists as well as the contributions of researchers and members of the local communities in this work is crucial. Equality and diversity encourage transdisciplinary knowledge development. 


\section{Introducing Experimental Heritage 1.1 Experimental Heritage as transdisciplinary and translocal practice}

This article describes an experiment, and the ongoing project is a journey of exploration into new and alternative practices combining art, archaeology and heritage in a landscape setting (Figure 1). The experiment contains aspects of the specific and controlled as well as of the uncertain and uncontrolled, the unrestrained. Experiment is a term used both within science and within the arts and humanities, with quite different meanings depending on the discipline. We have chosen this term to signify our efforts.

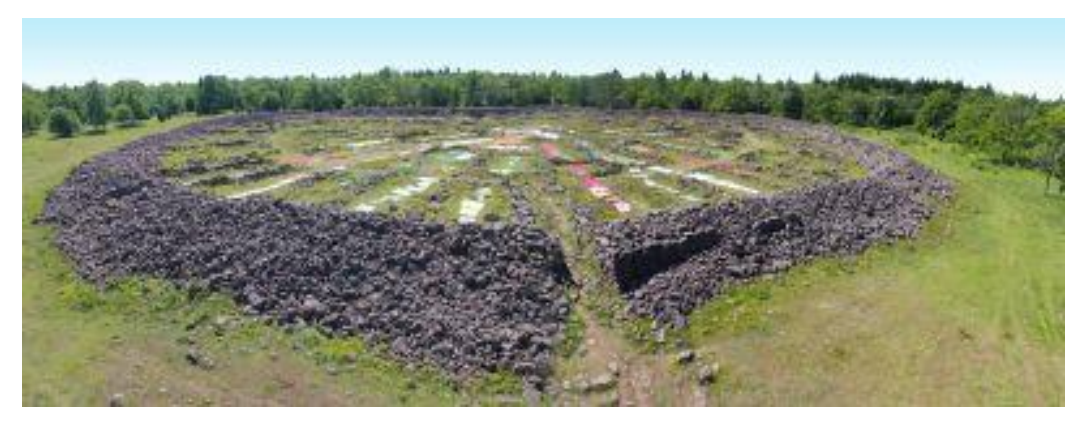

Figure 1: The Experimental Heritage practice combines art, archaeology and heritage in a landscape setting. Photo of the Iron Age Ismantorp fortress on Öland, Sweden, containing the ongoing Experimental Heritage blanket project inside its walls. Photo by Helle Kvamme and Sisters of Sättra, July 2017

The word experiment, as we use it, is closely connected with exploration and with striving towards finding new approaches. We explore new ways of examining relations between landscapes, humans, time and existence, and for that purpose we choose to work in a transdisciplinary as well as a translocal manner within the areas of our common interest; in this case art, archaeology and landscape. Archaeology is used in its widest sense, thereby not restricted to a specific period or time frame in the past but instead as a methodological approach to the tangible as well as intangible aspects of people, places and things past and present.

Experimental Heritage as practice aims to challenge our current worldview to better understand other times as well as other cultures. Our experiences will, in turn, provide us with new tools to create alternative futures rooted in respect for the need for diversity. We create a combined art and archaeology practice of care and respect. One path towards this aim is the exploration of art, archaeology and heritage through all senses, where a phenomenological point of departure, together with movement-based practice and performative action in the landscape are used. These methods are used in combination with other artistic and archaeological tools and expressions. Two rural landscapes, one western Irish and one south-eastern Swedish, are linked in this process. The explorations take as their departure point some fundamental concepts uniting these landscapes at a general level: stone and water, movement and time/the multitemporal, and tangible and intangible aspects of the explored areas. 


\subsection{Previous explorations}

This research approach, which we now call Experimental Heritage, began to emerge in 2014 in Sweden and has been continuously evolving since then. In the years 2016-18 a transdisciplinary project involving artists and archaeologists was undertaken on the Swedish island of Öland in the Baltic Sea. The Öland project, and the enthusiasm it created, was triggered by the idea of merging different traditions of working within landscape, and of combining the participants' experiences of these different landscapes. The efforts and results of this project are described in somewhat more detail below (see also www.experimentelltkulturarv.se). The Öland explorations led to a wish to expand the project idea and to try new ways of working with the transdisciplinary aspects of art and archaeology, aiming to merge the traditions of these two disciplines and to try to work in a translocal way with two different geographic areas: Öland in south-eastern Sweden and Clare in western Ireland (Figure 2).

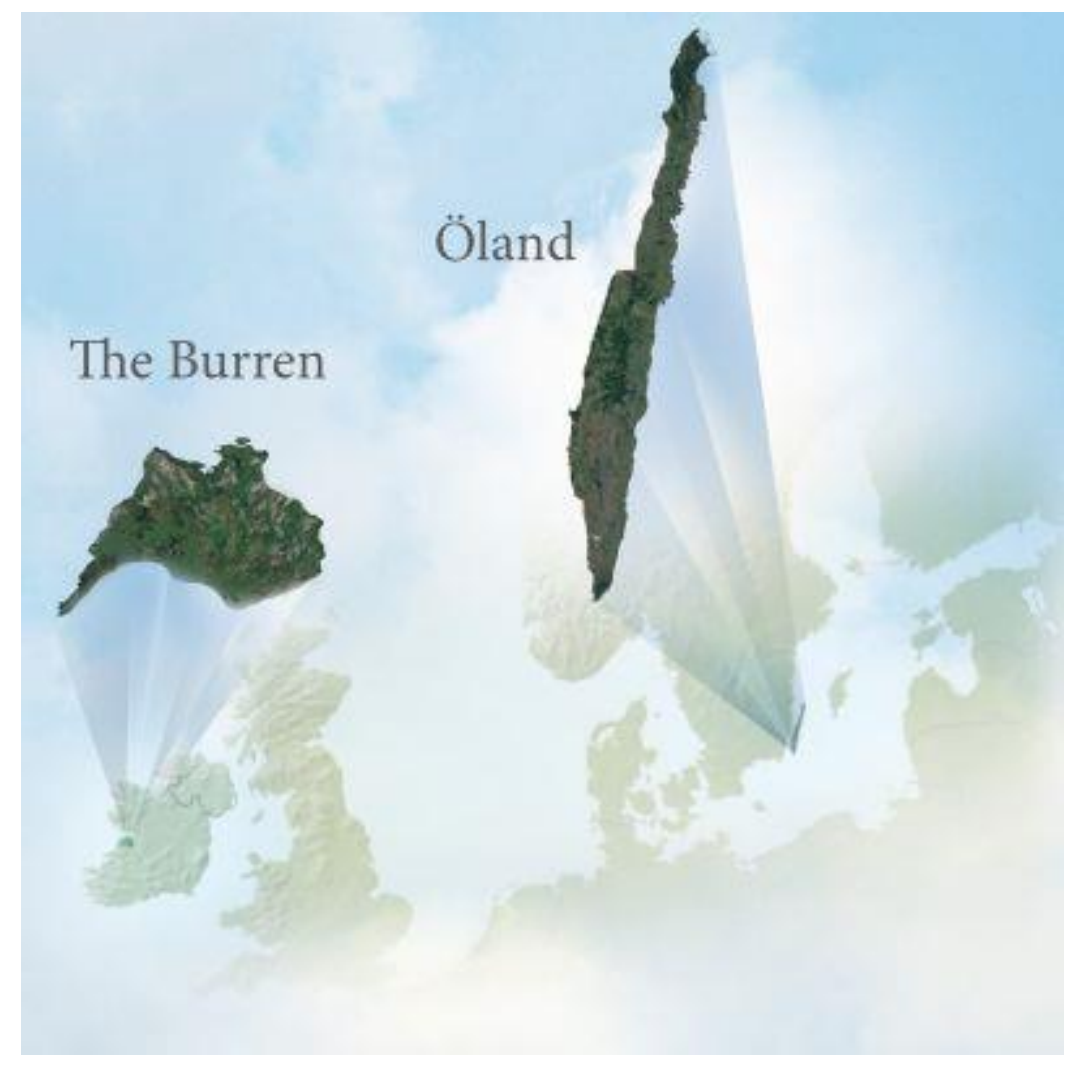

Figure 2: Map showing the location of the landscapes of Öland, south-eastern Sweden, and the Burren area of County Clare, western Ireland. Map by Michael Walsh 2019

\subsection{Process orientated approach}

To develop the Experimental Heritage approach, we formulate our themes together. The work performed is process orientated. (The use of the word 'process' here does not refer to 'process art'. We use the word to signify the way we are creating and performing together without the immediate aim of reaching an end result.) We work through process rather than aiming for measurable and quantitative outcomes. The process is intended to produce not a quantifiable end product but a refinement of understanding. We see the development of this process itself as the explicit aim. The approach can be seen as an 
alternative to the pressure to adapt arts and humanities research and community activities to inappropriate capitalist value systems that unfortunately are dominating the mindset of the present globalised world. This dominant system has a tendency to reduce existential matter and translate it into a language of markets and products, and this makes the system unsuitable because it is at the same time reducing and simplifying what it means to be human in the world - and it is the more complex dimensions of being human in the world that arts and humanities research as well as community activities often revolve around.

\subsection{The Karum-Creevagh collaboration and contributors}

Two groups have formed in Sweden and Ireland respectively, the Karum and the Creevagh groups (see www.experimentalheritage.com). The names relate to features and sites in the respective landscapes of Sweden and Ireland. Karum is a place name on Öland, Sweden. The suffix -rum, meaning open space, and the -rum names are localised to the south-eastern part of Sweden and on Öland. It emanates from the Viking Age or the Middle Ages (Wahlberg 2016). In the specific area it names a landscape of the alvar kind, as well as being the name of a grave field in the area dated to the Bronze Age and the Iron Age, between c. 1700 BCE-500 CE (Figure 3).

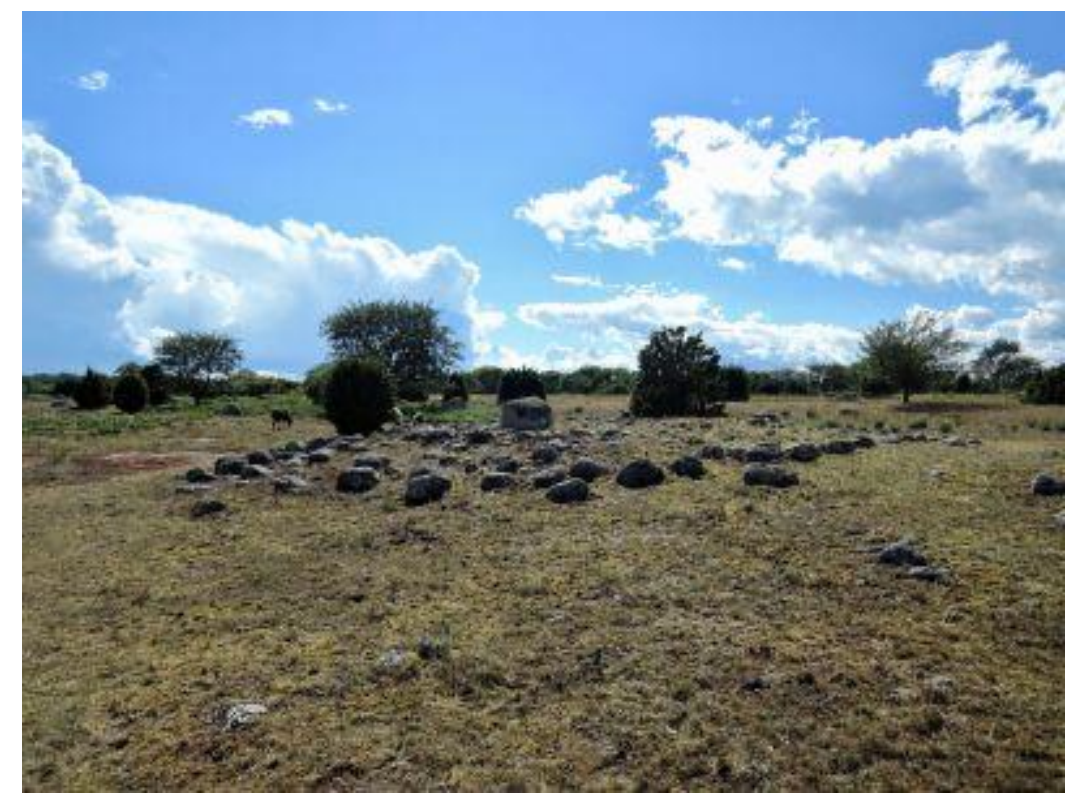

Figure 3: The Karum landscape of the alvar kind, with stone monuments belonging to the grave field with the same name and situated on the island of Öland, Sweden, and dated to the Bronze Age and Iron Age period. Photo by Bodil Petersson, July 2017

Creevagh/Craobhach similarly names an Irish townland in the karstic Burren area of County Clare. Craobhach is the toponym in the Irish language, meaning 'branchy', probably descriptive of the scrubby land with lots of hazel. The name is also given to a wedge tomb situated in this townland (Figures 4-5). In order to give some kind of time frame, similar wedge tombs on nearby Roughan Hill date from the Chalcolithic to Early Bronze Age periods, 2400-1700 BCE (Ros Ó Maoldúin pers. comm.). Wedge tombs are a feature of the archaeology of the region and there are around 80 in the area of the 
Burren alone, and in the whole of Ireland there are over 500 (www.burrengeopark.ie; Schulting et al. 2008). The naming of the groups has the purpose of relating us more strongly to landscape features both natural and cultural, as the combination of nature and culture is at the very heart of our explorations together.

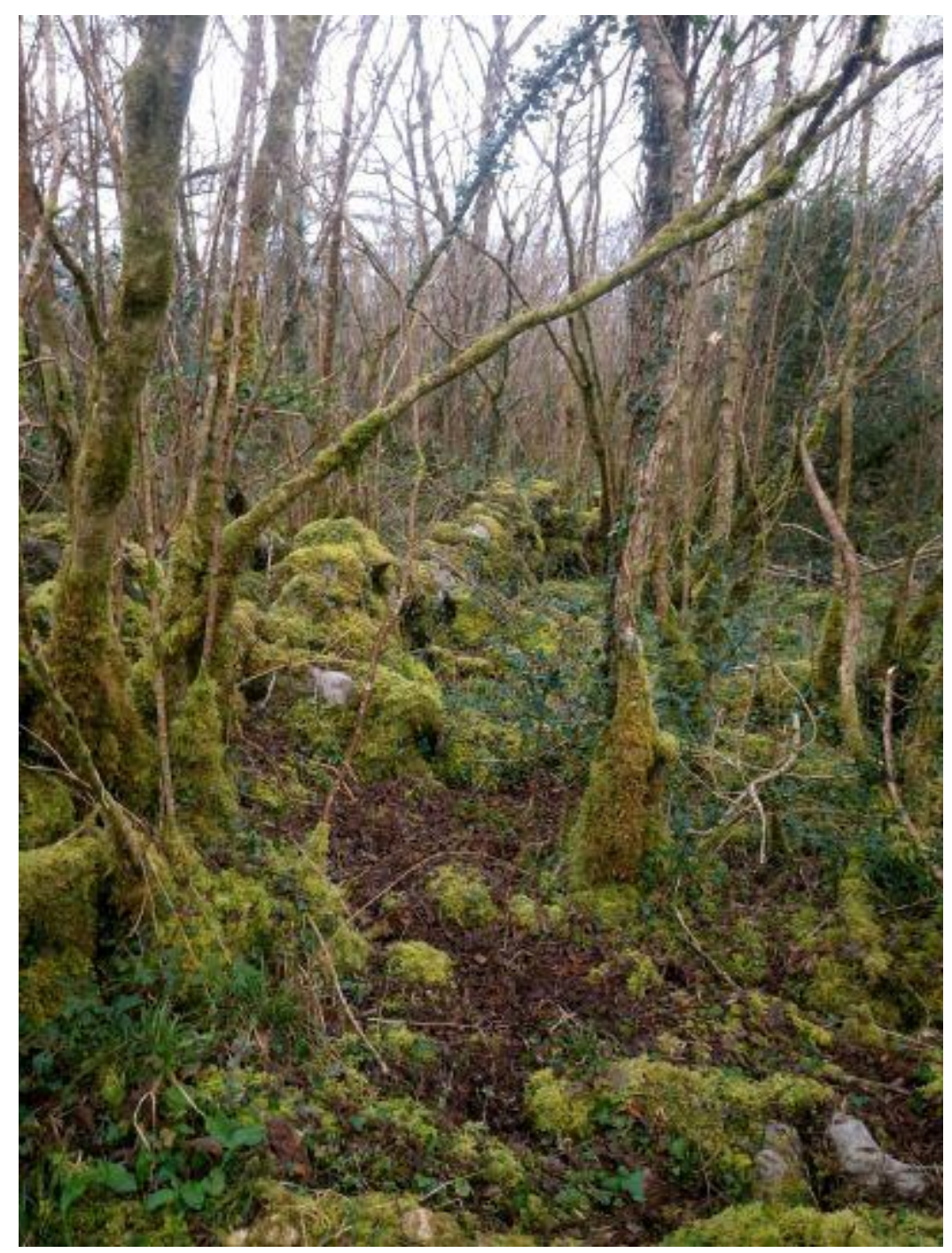

Figure 4: Creevagh/Craobhach, scrubby land with lots of hazel. Photo by Danny Burke 2019

The Karum and Creevagh groups perform studies of our respective landscapes as well as interacting and working together in translocal landscape studies, with translations and transformations between the landscapes and their contents. The work is transdisciplinary, actively and intentionally combining art and archaeology and thereby enhancing the emergence of new and hitherto unknown approaches. Methods applied in the field are a phenomenological approach combined with movement-based practice where the body and its movements are central to experiencing the landscapes. 


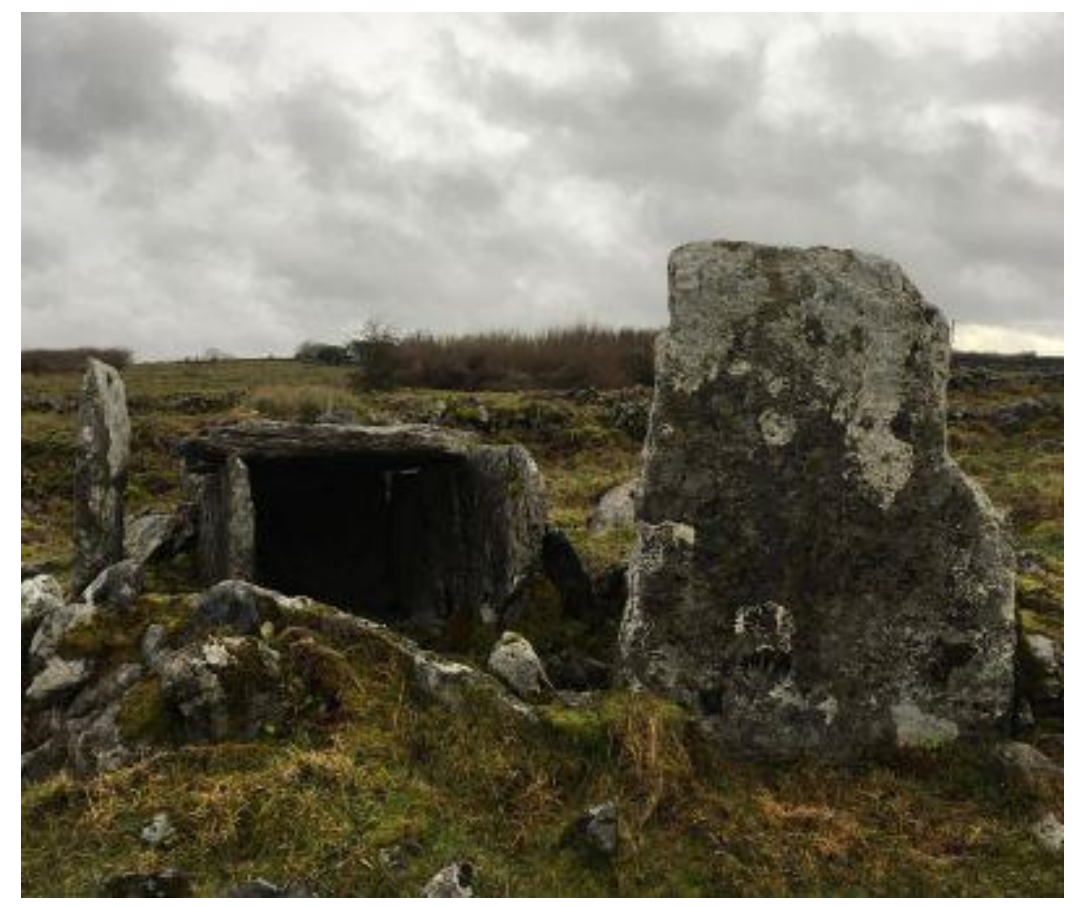

Figure 5: The Creevagh wedge tomb in the townland with the same name in County Clare, Ireland. This kind of tomb is roughly dated from the Chalcolithic to Early Bronze Age period. Photo by Bodil Petersson, December 2018

Involved in this work are researchers and practitioners within the fields of art, archaeology and heritage. The project also has participants from natural sciences and communication. Contributing are researchers, practitioners and community groups of practising artists, culture workers and archaeologists as well as those interested in archaeology. Some of the participants are connected to smaller companies or non-profit associations, and all of us are taking part as individuals with an interest in the project and its way of working.

\subsection{Approaching the experimental}

Essential to Experimental Heritage explorations is the creation of processes that evoke interest in archaeology, heritage and themes concerning the past, the present and the future, through a combined art and archaeology effort. This project is developing art and archaeology as an integrated and transdisciplinary practice. The ambition is to stand free from established archaeological as well as established artistic restrictions and boundaries. We also aim to stand free from conventional timeline and diachronic thinking. Specifically, our goals are also transdisciplinary and the multitemporal. We wish to establish and restore relationships between ourselves as humans, our surrounding world of landscapes and places and different ways of life and traditions through time, and to find embodied paths towards sustainable existence and living in the world. We aspire to find out more about the multitemporal layers in the landscapes surrounding us and how they relate to our inner landscapes of multitemporal perception. In the combined world of art and archaeology the layers can metaphorically be thought of as the painter's work on the canvas as well as the archaeologist's uncovering of layers in the soil. 
The intention is to use the past and traditions lingering among humans and within landscapes, to understand ourselves and the present, and to make use of these experiences for sustainable future needs. It is obvious that continuous modernist approaches have failed to provide us as humans with tools to overcome environmental, technological and relational problems. We are convinced that this project and its approach to rural landscape and ways of working is an important complement to the urban perspective that is often the focus when it comes to discussions about sustainability for the future. Strangely, the focus on matters of sustainability in debate and research is often linked to urban settings, because of a bias in academia and intellectual life in favour of urban environments with their concentration of cultural entities and because rural areas are often seen as more 'natural' and therefore perhaps more intact than urban settings. We see the landscape and the rural setting as a pathway to approach other values and ways of life.

There is also the question of doing research in society as a collaborative effort together with communities. One of the main strands of this project is collaboration with communities, and also to integrate into the work the oral histories of the areas and knowledge held within families of the local people (Figure 6).

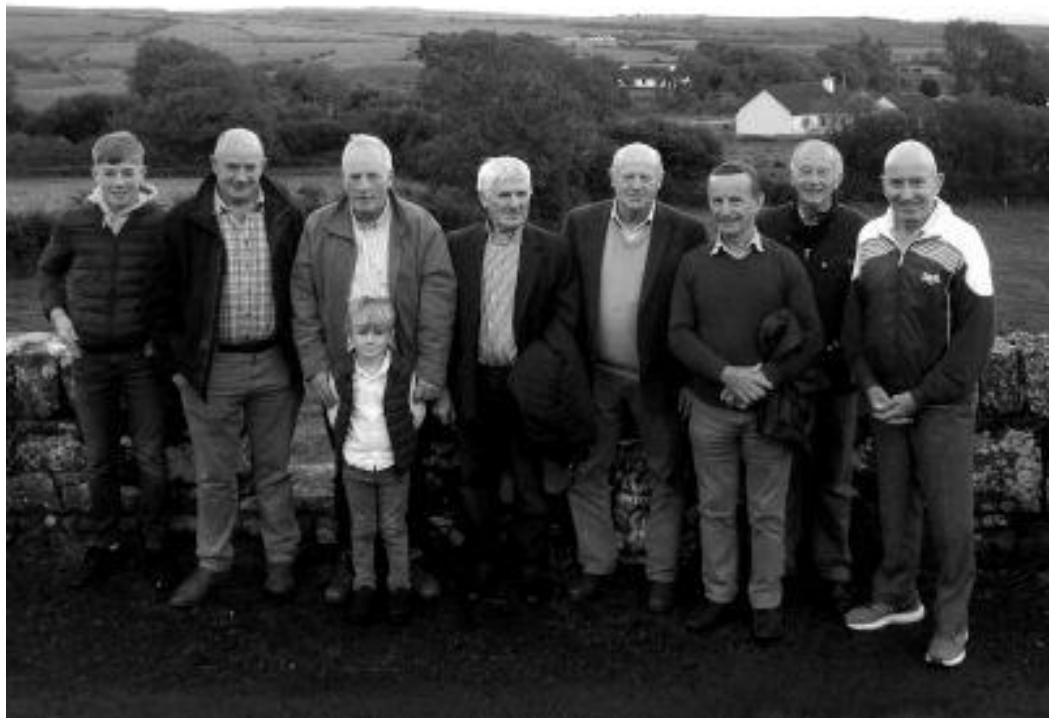

Figure 6: Members of the Kilshanny community and custodians of the monuments and ritual landscape of Kilshanny, photographed after a religious ceremony celebrating St Augustine's Holy Well. Photo: Danny Burke 2019

Both art and archaeology have in recent years been challenged to make efforts towards relevance to society, and one such example might be obtained through engaging with communities of different kinds (Mouffe 2008; Smith and Waterton 2009; Crehan 2011; Atalay 2012). To open up the work for those in the surrounding communities interested in the questions raised by this project is a way to interact in a sincere way with people, even if it sometimes also generates more questions. 
A general intention of this project is thus to view the past as a place that is relevant to the present and from which lessons can be learned. The idea is supported by experiences collected from both past and present situations, peoples, places, traditions and things.

\subsection{Multitemporal enquiries}

We are working in the spirit of creating an experimental, multitemporal and process-led approach to a field of research combining art, archaeology and heritage. The explicit intentions are:

- to change disciplinary perspectives and viewpoints

- to deliberately mix times and places

- to deconstruct hierarchies of different kinds

- to dissolve the artificial separation of nature and culture

- to emphasise the process as an important main result

We have formulated the following exploratory ambitions as questions, deriving from the above-mentioned explicit purposes:

- What happens when we merge perspectives from art and archaeology into a mutual and joint examination of landscapes, their structures and their related peoples, finds and remains from both the distant past and the more recent past?

- What happens when we merge past and present times in our experiences of the traces of past times in the landscape, without special attention to timelines and instead focusing on moments in time, the multitemporal, and on the past as it occurs at this very moment in the present?

- What happens when we work similarly with two clearly separate areas of Europe in this effort, and take as a point of common departure the unifying concepts of landscape, stone and water, movement and time? In which ways are these concepts useful for connecting these areas?

- Does the rural point of departure and choice of landscapes in this project have the possibility to affect how we approach, understand and talk about both present and past societies that are not urban but instead rural or village based?

- How might the multitemporal experience of landscapes and their contents be conceived and expressed through the joint and consequently integrated effort of artists, archaeologists and surrounding communities?

- What is the relationship between process and result? In what sense can Experimental Heritage as practice promote the intention that the process itself is the main result?

The result of efforts in new directions might appear uncertain, as expressed by artist and anthropologist Robert Willim:

As a researcher, you seldom state that your research might be out of control. But all creative practices, including art and anthropology, are to some degree [an] excursion into the unknown. The question is instead to what degree you articulate your lack of control or frame uncertainties. (Willim $\underline{2013}, 84$ )

The approach is to combine past and present, archaeology, art and the senses, to better understand the circumstances that we humans inherit. 
This enquiry is not solely about art and archaeology, it is about our being and existence - as humans, in the world and in the landscapes, both general and specific, from past to present and into the future. In such an enquiry the participants in the project need to have this question coming from within, and the team of artists and archaeologists has, through preceding activities together in the landscape and through practice-orientated workshops, found a common path, yet with room for diversity. The process itself demands a specific rhythm to it, a fluctuation between groups and individuals, between different landscapes and cultures, between times, and between practices known and unknown, so that new questions arise and several potential pathways towards answers might emerge to be considered.

\section{Theoretical and Methodical Considerations}

\subsection{Process and practice}

In undertaking Experimental Heritage explorations at the intersection of art and archaeology, it is crucial to be aware of the tension between the intellectual and the emotional, the tangible and intangible, the permanent and the fluid, past and present, disciplinary and interdisciplinary, local and global. Our efforts are directed towards theories and methods that appear to us to support this kind of awareness. The intention is that the chosen direction will have the possibility to contain and support practices that overcome discipline-rooted borders, limitations and constraints. To avoid the risk of limitation, we have chosen to work together across disciplinary borders from the start and thereby try to overcome the risks in practice, by subsequently creating and performing together.

In the formation of this process and practice-orientated work towards a new set of theories and methods in a spirit of transdisciplinarity, the shared artistic and archaeological processes have been allowed to take shape organically. An explicit aim with this way of working from practice, without any overarching method statement, is to leave room for the unexpected (cf. Narmo 2011). This way of exploring relates both to the experimental and to the transdisciplinary and allows for new directions and perspectives to emerge.

The project is working towards a process and practice perspective where it is the doing of things that is the aim, not mainly the results or outcomes in the form of end products of artistic and archaeological work (Schatzki et al. 2001; Schön 2003; Nelson 2013 ). Our approach to the past is unavoidably as well as purposefully rooted in the present. We aim to find out more about the layers of time, to critically consider how our current worldview might affect how we think about and act in relation to past societies. This rootedness in the present calls for certain theoretical and methodological approaches that clearly take departure in ourselves and the present situation.

\subsection{Why art and archaeology}

Archaeologists and artists work together in this Experimental Heritage setting to develop a common ground for transdisciplinary practice. We explore new ways to understand the 
past and its meaning to us. With the landscape as a shared lens, archaeologists and artists access the past together through embodied explorations. Archaeologists work with their bodies. With faint and elusive traces of other times they try to uncover information about such times, life forms and thoughts that can be accessed either through digging the ground, or through undertaking archival studies and other research efforts within a range of fields entangled with the study of past societies. Artists likewise approach the world through their bodies. By experiences created in the present they enter enquiries and interpretations going in different directions in both time and space. As the artists are introduced to new materials and perspectives through interaction with archaeologists, the artists' experiences in the present are then interwoven with the experience of past times through enquiries by archaeologists. The combined experiential effort of artists and archaeologists strongly relies upon embodied practice, as the focus of both is to gain insights into the tangible as well as intangible aspects of both the present and of past times (Figure 7).

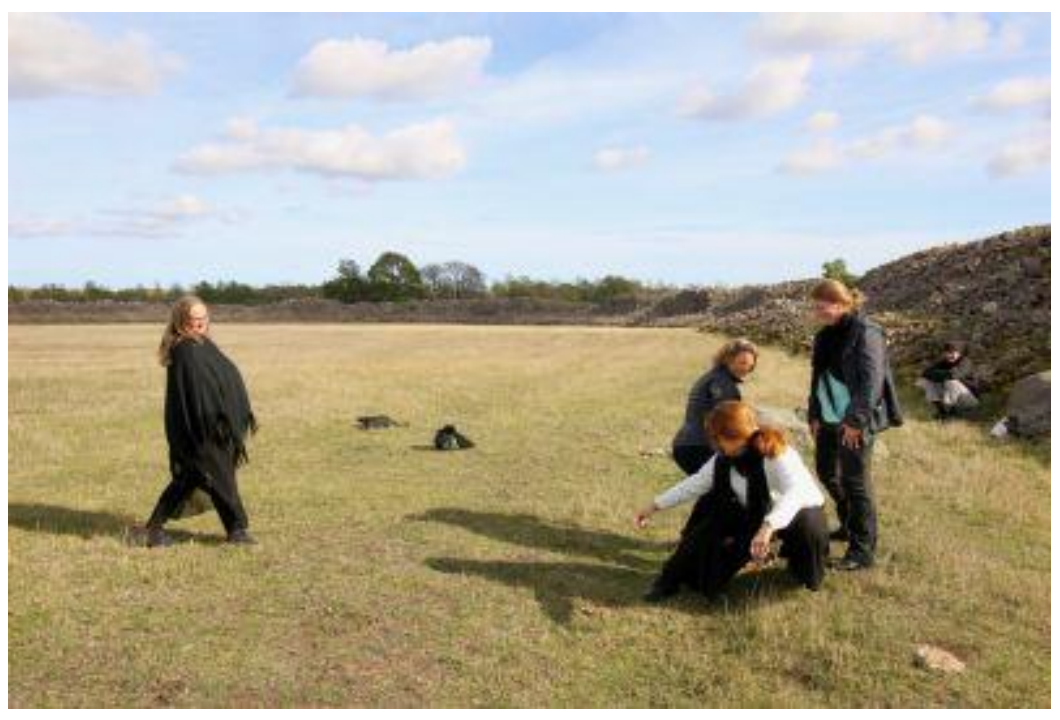

Figure 7: A group of artists and archaeologists exploring aspects of past and present through embodied practice at an Iron Age Öland site called Gråborg. Photo by Michael Walsh 2019

It is important for today's secular rational archaeologist to bear in mind that the sites and communities being investigated today were probably steeped in ritual: perhaps burial sites, perhaps sites of inauguration or other elements at the core of territoriality, perhaps sites of veneration of ancestors or propitiation of deities, perhaps sites of gatherings. As evidenced by contemporary indigenous peoples, such sites tend to be characterised by deeply ritualised behaviours. In most traditional societies, ritual is not just reserved for major life events, it permeates the daily life of the members of the community, so ritual must be considered even in the context of domestic sites (Figure 8). 


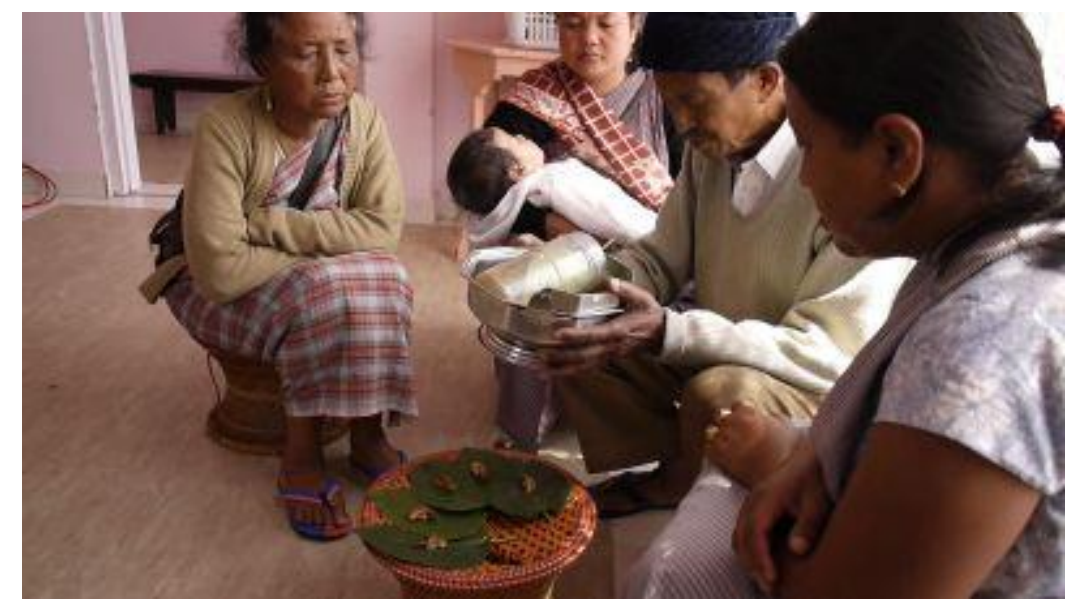

Figure 8: The Lyngdoh of Nongkrem performing a domestic ritual on the occasion of a family member purchasing a new car. The ritual included the cutting and 'reading' of areca-nuts as offerings to the ancestors. The areca-nuts can be seen laid on betel leaves, a combination that is widely chewed as a mild stimulant in the day-to-day life of Hynniewtrep people in Meghalaya, India. Photo: Danny Burke 2013

In matrilineal Hynniewtrep society in the Northeast Indian state of Meghalaya, for example (see Arbenz 2012, 21-23), which retains many long-held traditions and a stillpractised indigenous religion, an older brother or uncle of the female head of the family will often act as ritualist in the domestic setting, while at village and state level, ritual is conducted by the lyngdoh or myntri (Burke 2014). The ritualists in these cases perform the role of creating a narrative for the event they preside over, and progressing the participants through that event, and in so doing provide a framework in which individual and community can safely navigate through potentially dangerous and disruptive emotional situations (Figures 9-10). 


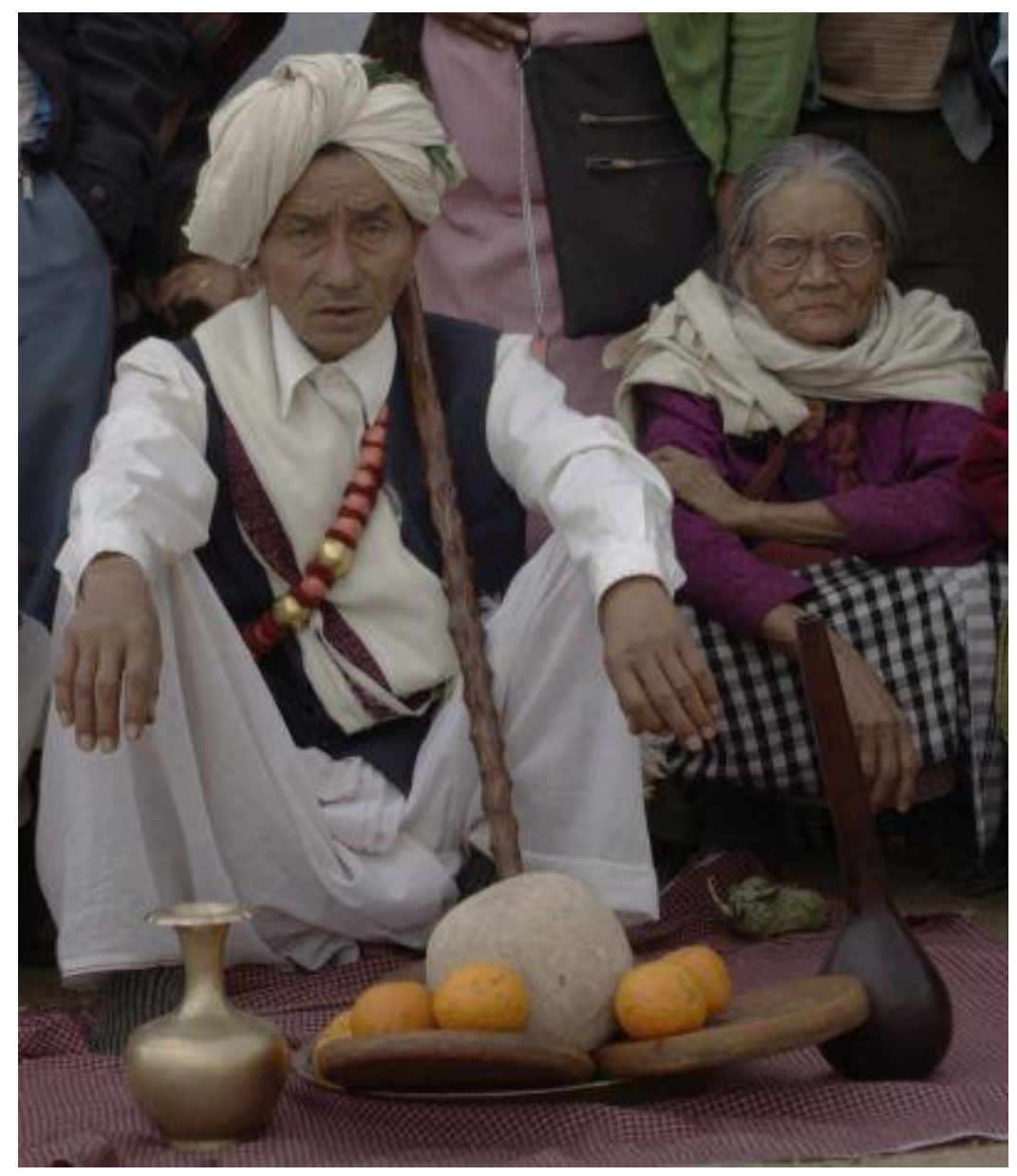

Figure 9: The Doloi of Nongbah Elaka performing part of a state-level ritual. The gourd on the right contains rice-spirit, the brass vessel water, the oranges are locally grown and the flat discs under the oranges are rice breads. Photo by Danny Burke 2013

For modern western society, on the other hand where religion is largely defunct and there is a dearth of inherited ritual compared to more traditional societies, an important role for the artist can be to support the creation of new narratives, directly in cinema, theatre, performance art and more obliquely in music, thereby providing a framework for a conducted exploration of, among other things, mood and emotion, whether for the individual or the group. 


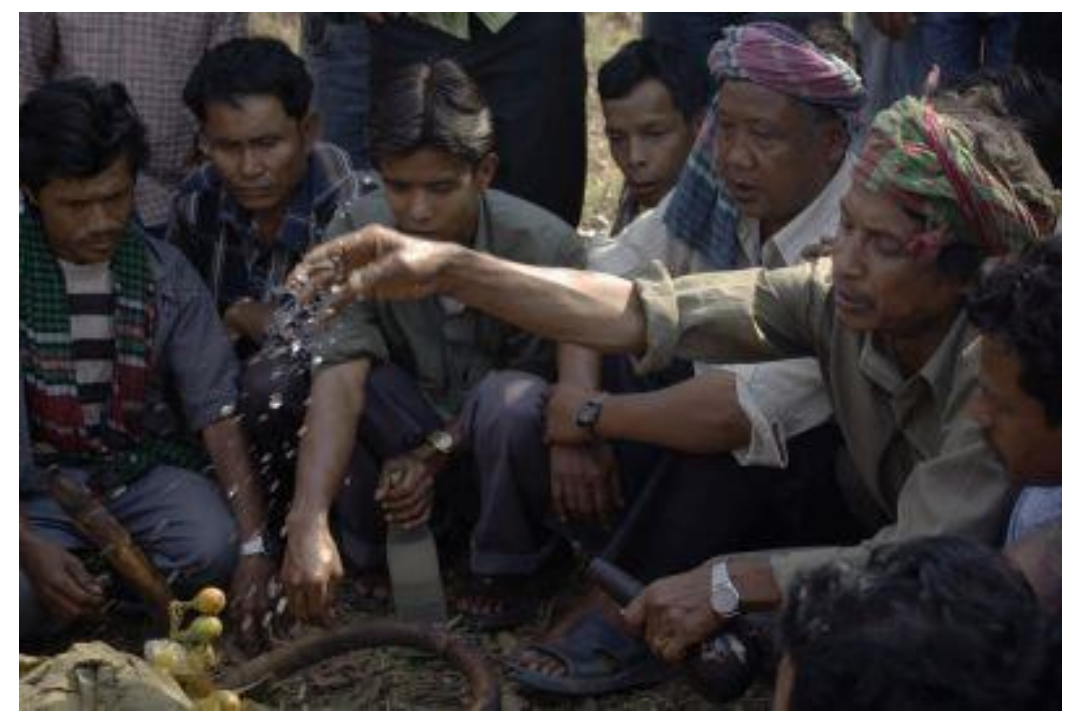

Figure 10: In this photo the elders of Lamin village in the War area of the Jaintia Hills, India, are concluding the rituals in a clan-level ceremony at the insertion of the cremated remains of a member of the Passah clan. Rice spirit is being scattered on offerings to the ancestors which include food items and betel-nuts. Photo by Danny Burke 2013

This is an arena that makes for a potentially highly fruitful collaborative process including both rationality and emotion. As archaeologists and artists together explore the chosen multitemporal landscapes and sites associated with ritual, gatherings and liminal events, the participants help each other to understand new aspects of ritualised landscape and thereby create the necessary consciousness of the ever-present ritualism in earlier dayto-day life. Archaeologists, who traditionally rely on evidence-based rationality, can through this collaboration have their understanding of the past deepened, enriched and transformed by exposure to and combination with artistic perspectives that will include the sensory and the emotional, perspectives under-expressed in archaeological thinking (Figure 11).

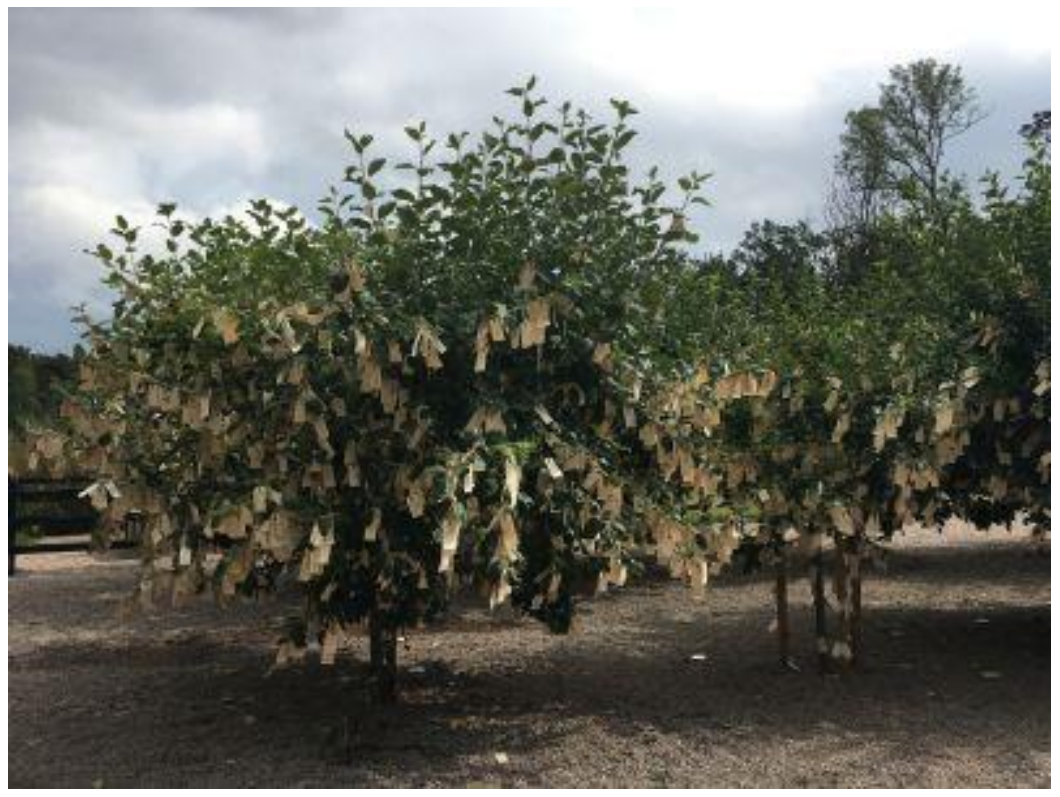

Figure 11: Artwork named 'Wish Tree' in Wanås art park, southern Sweden, where visitors are invited to write their wishes on paper and hang them in the trees to move in 
the wind. Example of artistic addition of sensory/emotional perspectives to a specific site. Photo by Bodil Petersson 2019

Since archaeology emanates from an academic setting with certain claims to a scientific approach, archaeologists cannot usually approach the ritual aspects of the past on their own. Together with artists the approach might be easier to perform for archaeologists, since artists have fewer constraints in relation to scientific research and can act more freely in relation to that specific tradition. On the other hand, artists' enquiries and work can get access to additional and previously unexplored perspectives through collaboration with archaeologists. The difference between the disciplines and their traditions can work as an inspirational source for both artists and archaeologists in the sense that such differences promote seeing things from new angles and thereby encourage movements in new directions together.

As artists and archaeologists in this project are trying to avoid the tradition of institutional practice in order to create new ground to perform work together, there is also tension. Archaeological as well as artistic work are often strongly dependent upon individual achievements. The individualistic performance prevalent in both environments might make it difficult to focus on collaborative achievements before individual ones, since both artists and (academic) archaeologists are used to work in settings where work is rewarded mostly on an individual basis. As we wish to change this focus, the challenge for movement in new directions in this project is to try to move from individual to collaborative performance and community sharing. We do not wish to eliminate individual performances but the aim is to keep the group as well as surrounding communities informed and involved.

In the project several of the participant artists are dancers, and the movement approach is crucial to the group. In a landscape setting, archaeologists have one certain way of moving and approaching the past through acts of excavating, mapping and archiving. Artists/dancers have other ways of approaching the past through movement, dance and embodied action. The artists' performative ways of working constitute an interesting basis for the meetings between archaeologists and artists directly in the landscape and on site, exploring the possibilities of preverbal landscape experience (Figure 12). The meetings may even evoke the significance of dance in the lives and rituals of traditional societies.

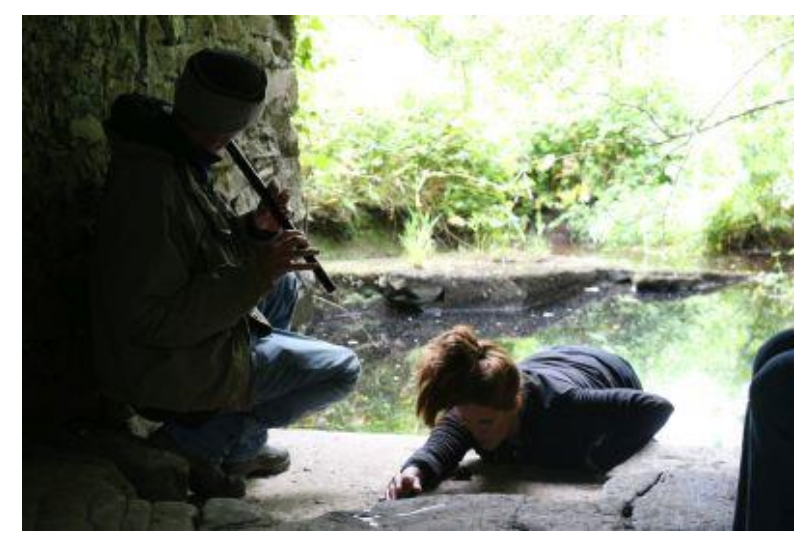

Figure 12: Dance/movement/music performance exploring the possibilities of preverbal landscape experience. Maria Kerin and Danny Burke within the Experimental Heritage project under the bridge by Dealagh river in Clare, Ireland. Photo by Michael Walsh 2019 


\subsection{Phenomenological perspectives}

In our time of technological representations of the world, the act of physically being in the landscape and literally getting in touch with it becomes even more important. Coming generations will most certainly continue to relate to landscape as filtered through mobile electronic devices, as is already the reality today. Much interaction is ruled by digital applications providing information about landscape features or intended for gaming situations in the landscape. Such experiential technology is sometimes called 'Augmented Reality'. We wish to contest the reality part in this augmentation and explore further our human need to get physically in touch with the world surrounding us to be able to care for it and to experience and understand its dimensions and meanings. Moving with our own bodies in the landscape seems obvious for many artists and archaeologists, since both groups might relate physically to the environment. It is essential with movement, to also see, hear, smell, feel, taste. This becomes even more tempting in the age of technology, where our sensing has become even more limited to seeing and hearing than it was before.

Phenomenology has thus emerged as a useful framework for many artists and archaeologists as we work together. The work of the philosopher Maurice Merleau-Ponty is of interest, in particular his ideas about the body, the senses and their role for human perception (Merleau-Ponty 2002, originally published in 1945). As both artists and archaeologists are familiar with concepts relating to phenomenology, it is attractive to both parties as a direction with its physicality and direct relationship with the body and its sensory as well as sensual experience.

From an archaeological point of view, it is primarily the connection between body, landscape and stone that has been the focus for extensive archaeological work with phenomenological perspectives. The archaeologist Christopher Tilley published $A$ Phenomenology of Landscape - places, paths and monuments in 1994, where he explored landscapes, movements and monuments with his own body (Tilley 1994). Some years later the phenomenological perspective was further developed in The Materiality of Stone: explorations in landscape phenomenology (Tilley and Bennett 2004). This was part one in a series of three books exploring landscape phenomenology, the other two books in the series being Body and Image (Tilley 2008) and Interpreting Landscapes: Geologies, Topographies, Identities (Tilley 2016, originally published in 2010).

Another approach that doesn't directly reference phenomenology but is moving in the same area is taken by archaeologist Richard Bradley, in his study of 'natural places' (Bradley 2000). He explores landscape perception and how people move in and use natural landscape features, mostly for ritual or sacred purposes.

From an artistic point of view several works have been informed by phenomenological thinking and method. Some of the works are connected with specific art forms (Brodsky 2002), others with landscape studies (Unwin 2008) similar to the ones performed within Experimental Heritage. The works have in common that they are inspired by phenomenology in the spirit of Merleau-Ponty. The studies share a multisensory approach and embodied practice, as well as the connection with contemporary art and performance. In the case of artist Bren Unwin's work, there is an explicit relationship with cultural anthropology and landscape studies, and the artist has 
made use of works by archaeologist Christopher Tilley and anthropologist Tim Ingold in her work, which is interesting and inspiring for this project as well.

To expand on phenomenological perspectives integrated in the project method, we pay attention to the importance of walking the landscapes, boating the waters and additionally sensing the environments in all imaginable ways (Figure 13).

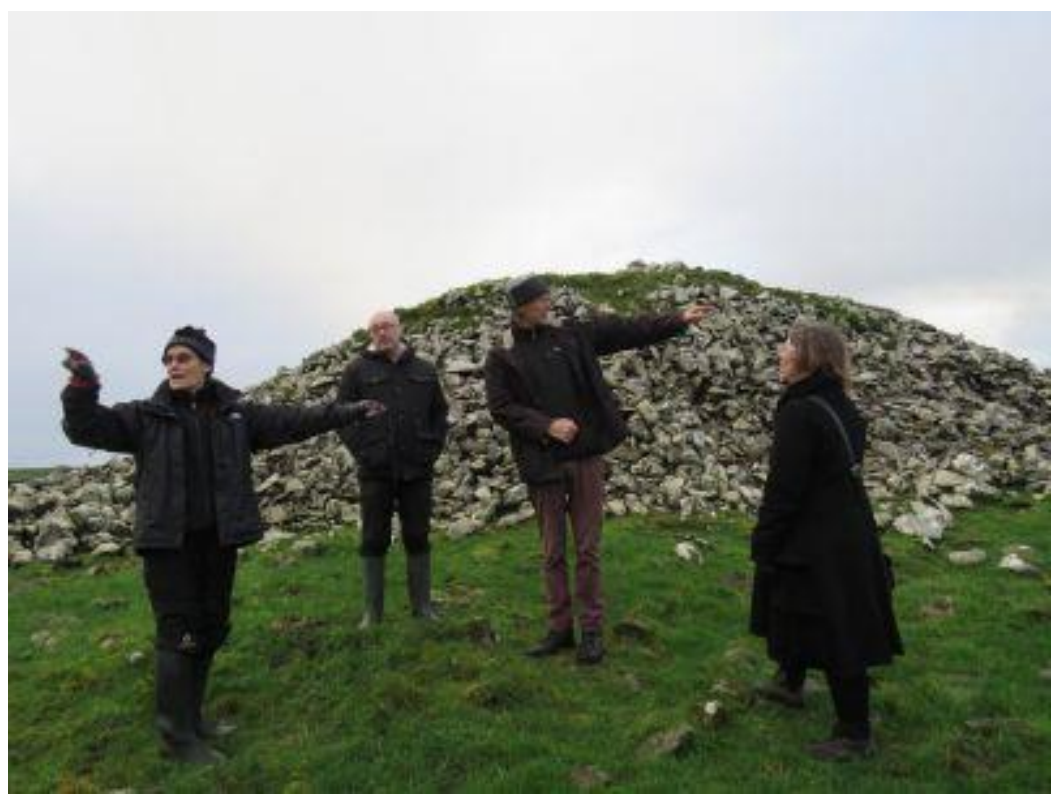

Figure 13: Artists and archaeologists within Experimental Heritage Swedish-Irish Explorations exploring the environments of Carn Connachtach in Kilshanny parish, western Ireland. Photo by Michael Walsh 2018

Within the artistic and literary fields, the term impressionism has been used to frame a concept of subjective naturalism, a practice often performed outdoors and with the purpose of catching the moment, often in a landscape setting. It is about registering impressions and presenting those in an immediate way, with the purpose of showing rather than telling a coherent story. Details come to the fore rather than the whole, and a dynamic flow rather than structure is characteristic for this kind of expression. There is a directness about the perception of the world, and the purpose is to find nuance and express sensory input from new angles (Lund 1993). Through impression, spontaneous patterns appear, organised and interpreted afterwards in an associative manner. This approach can be seen as related to the phenomenological approach: the ambition to experience directly with the body in the landscape. The word 'impression' is evoked here as it might be of some guidance in understanding the broader scope and ambition of this work.

\subsection{Non-representational theory}

Another theory that points towards practice and embodied experience is the 'nonrepresentational theory' developed within human geography, which began in the mid1990s. One of the leading researchers in this field is Nigel Thrift. The theory focuses upon practices and performance and is related to phenomenology. The human body is seen as closely related to things in the world, the body being what it is just because of the surrounding matter (Thrift 2008, 10). This position arises in our process, with a focus 
on human bodies being and acting in landscape settings: moving, performing, listening and experiencing; the essence of the process is thereby its development from practice into theory and not the other way around.

In relation to non-representational theory, Thrift also works with concepts of emotion and affect, something that strengthens the reason why this theoretical approach suits this project well (Thrift 2004), since we also work with sensory and emotional experiences directly referring to how we move and act in landscape settings.

\subsection{The ecocultural approach}

As the focus of this project is on landscape and movement in landscape, the Experimental Heritage way of working aims to create new ways of interacting with landscape, as well as restoring an understanding of interactions in other times and cultures. To actually move in the landscape enhances the possibility of understanding how culture affects landscape over time. It also reveals things the other way around, namely how nature and landscape affect the shape and form of culture. Through landscape-based practice a respectful manner towards both nature and culture might be restored. Throughout history, with an accelerating pace in the 20th and 21st centuries, a seemingly rational and efficient land use has evolved, where traces of past times are often rapidly erased as a consequence of the goal of modernist efficiency.

Ecoculturalism pertains to how culture adapts to ecological settings and then how individuals act in relation to such an ecocultural situation (Berry 2003, 98). Every landscape contains and carries its own characteristics of both nature and culture through time. Traces of past times naturally become weaker as time goes by but today this process is faster, not only as a result of the passage of time but also because of active human erasure and active environmental reshaping. We wish to take a closer look at the remaining traits. Relationships with landscape and movements in landscape over time reveal attitudes and traditions. But as we distance ourselves from physical experience with our own bodies in real environments and instead tend to create digital replacements where planning and development takes place, the interaction between us and the surrounding landscapes gradually decreases. We no longer experience with our bodies the impact we have through our actions. The project and its participants aim towards enhanced embodied perception of the landscape - historical and present.

Related to the ecocultural is the ecopsychological philosophy. It explores the relations between humans and nature through bridging ecology and psychology. One main idea is to highlight sensuous and emotional bonds between humans and nature, thereby making the links between nature and culture obvious. Humans are here seen as part of nature itself and in need of a positive relationship with it. The senses and emotions of humans are seen as being enhanced if they are connected with nature, the influence of nature upon humans is conceived of as healing. The connection between humans and nature in this approach also creates environmental benefits through people that are more connected with nature and therefore more caring through the existing sensuous and emotional bonds. The ecopsychological direction is also of interest here since in some parts it enters the realm of phenomenology (Abram 1996; Vakoch and Castrillón 2014).

The reason why ecocultural and ecopsychological perspectives are at the core of this project is the explicit ambition to combine perspectives on nature, culture and society. 
We do not see it as fruitful to separate these categories; instead we try to enhance our holistic understanding by creating one and the same lens for nature, culture and the social. There is a modernist epistemology behind the separation of nature and culture (Tilley 2016, 36), and therefore it is our aim to create a practice that is not separating the world in a way that we think is counterproductive to our understanding of it.

One of the limitations with archaeology and the archaeological method is that it is mostly about recognising cultural traits, to find the traces of culture as opposed to nature (Tilley 2016, 36). At the same time some archaeologists, for example Richard Bradley, have worked with the concept of an archaeology of natural places, in the light of these places having sacred significance to people in the past (Bradley 2000). The attempts by both Bradley and Tilley in trying to make archaeology a way to approach nature and culture at the same time, point towards how these efforts actually emerge from and are contained within landscape studies. It is within landscape studies that the interest arises. Another research area working with landscape is human geography, and within this research direction there are several works that aim to combine nature, culture and social aspects. This direction of interest shows how relevant it is to change focus towards a more holistic view in the ecocultural direction (cf. Alex et al. 2017). Therefore, we strive towards a perspective combining ecology with cultural studies.

\subsection{Performance Studies}

Perspectives from the interdisciplinary field of Performance Studies will inform the research. In this field the term 'performance' is broadly defined. It includes not only the study and practice of artistic performances but also of other social, political and cultural events, rituals and ceremonies.

Performance Studies is a way to approach what people actually do (perform) during activities (cf. Schechner 2013). For this project Performance Studies is seen as necessary, embracing the practices performed by us working in between art and archaeology. What happens when we undertake activities to show ourselves and the surrounding community something relating to art and archaeology?

This field is related to cultural studies, to culture, body and identity. It has a critical view on history and the present and an inbuilt postcolonial and in-between way of working at the intersection of disciplines that goes across established borders and actually makes active use of the crossing of borders. This is suitable for the process developing within Experimental Heritage.

Interestingly for this project, working in areas well known by the participants in the project, and unlike anthropological studies, 'the other' may as well be our own culture that is under study. It is not the aim to be neutral; the whole point is to be involved and biased, but also to be able to see one's own position and relation to others in a cultural act (Schechner 2013, 2).

Projects labelled as Performance Studies are often acting against hierarchies, and they oppose capitalist, global forces. The direction is considered suitable for exploring margins, minorities, the subversive, the strange, and the colonised (Schechner 2013, 4, 25). This also makes the theoretical approach and methodical way of working in Performance Studies a good tool for this project as it is aiming towards sustainability. 
Performance Studies can be useful to explore culture, ritual, and unique expressions (Schechner 2013, 20). Therefore, it is especially good for exploring the intangible aspects of archaeology, heritage and the past.

The being in-between, or the liminal aspect, is crucial to the approach within Performance Studies (Schechner 2013, 24), so it is definitely of value to be in-between subjects and practices such as art and archaeology, trying to explore the interfaces between different practices and groups within cultures past and present. This also indicates the usefulness for this project of this way of approaching things.

The diversity of approaches within Performance Studies also includes dance (Lepecki 2006) and feminist approaches (Phelan 1993), which makes Performance Studies even more relevant in relation to this project, which engages several artists related to the contemporary dance and movement theme and explorations.

\subsection{Posthumanism}

The posthuman perspectives have a clear role in the explorations of the relationship between nature and culture that is obvious in non-urban settings. In urbanised areas most remains can be explained as culturally created expressions of human life. But when it comes to non-urban areas there are many more connections to be made between nature and culture, and nature-culture is not that easily separated. The posthuman and its critique towards the anthropocentric perspectives dominant in society is also a reason for adopting this perspective, which is considered to be approaching the more-than-human. To explain how humans interact with landscape, nature, stone, water, movement and time, there is a need to consider, among other things, the role of nonhumans as agents, the limitations of human thinking, and also in part the technological development as an aspect of the posthuman (cf. Hayles 1999).

In a themed book on the topic of posthuman attunements, the concept of attunements and its different aspects is explored in depth. It is concluded that the posthuman can be used as a tool for creative listening; that is, listening in between the cultural and natural worlds. It is specifically pointed out that it is not about a romantic view of attunement as a tool only to understand and align to the positive but also as an approach to find dissonances (Brigstocke and Noorani 2016). This is also relevant for this project, since the view on heritage in society in many cases contains romantic views as well as contested and dissonant heritage (Tunbridge and Ashworth 1996).

\subsection{Movement-based practice}

Integral to the Experimental Heritage process is creating pathways to connectivity across different academic disciplines and diverse practices. How can we communicate with each other, experts in separate disciplines? We are using movement-based practice with special emphasis on somatic practice principles as a tool to strengthen our attentiveness, awareness, listening to ourselves and others, listening and sensing through layers of time, opening our fields of perception to the unknown.

Somatic movement principles and various contemporary dance techniques offer very specific pathways to connect and communicate. Using techniques from different movement-based practices including Bonnie Bainbridge Cohen's Body Mind Centering, 
Janet Adler's Authentic movement, Joan Davis' Maya Lila, Antoinette Spillane's Still Point Guide and Alexander techniques, we work with our individual physicalities to communicate our interpretations of the world, working with "the body as the site of knowledge" (Cancienne and Snowber 2003, 237).

Collaboration is at the core of the Experimental Heritage process, unfolding the space for two diverse disciplines of art and archaeology to work together. Movement-based methods in an embodied creativity process are used initially to nurture the sense of safety and trust between us, spiralling outwards from receptivity (Beausoleil 2014). How do professionals open themselves to new ways of listening and working together? As receptivity can be a challenge, we are trying to make that transition to active listening to support our collaborative efforts so that we can bring ourselves as well as our disciplines, and our cultural biases, to build trust between us for connectivity, that leads us 'beyond current problematic dualisms and ways of thinking' (Schatzki et al. 2001, 1).

Movement-based practice also informs individual art practices and feeds into the collaborative projects unfolding from this unique transdisciplinary process as experienced in the Experimental Heritage performance Moving the ship, presented later in this article. Integrating choreography in our research process "shifts the perception that we have bodies to the reality that we are bodies" (Cancienne and Snowber 2003, 239)

\subsection{Postcolonial perspectives}

Postcolonial thinking is both a response to and rooted in the colonial. Cultures of the peripheries often managed to maintain some degree of autonomy in pre-colonial and colonial times due to their remoteness from centres of power. In some cases interested colonial-era administrators (for example J.P. Mills, and J.H. Hutton, British colonial administrators in Northeast India who are well-known for their ethnographic work in the region) were sensitive to the fragility of peripheral traditional societies, and authors such as Verrier Elwin, who initially went to India as an Anglican priest and missionary and became an advocate for non-interference with their traditional ways of living (Elwin 1943). Elwin's biographer writes that two years living with the Gond people of central India convinced Elwin 'that the tribals had to be protected from the corrosive influences of the outside world' (Guha 1999, 97).

The cultures of many of these peripheral communities are today more endangered, in this supposedly postcolonial era, by, among other things, a rampant and all pervasive digitally driven globalisation. Under this globalisation, which could in fact be seen as being the latest incarnation of colonialism, the tendency is that humanity adapts to a one-size-fits-all lifestyle, not allowing for meaningful individual expression or for regional cultural uniqueness as something enriching and essentially human. The trajectory towards this human mono-culture is presumably weakening instead of strengthening the conditions required for sustainable human existence. Local and regional specificity and uniqueness need to be protected and promoted and these aims are explicitly supported in this project.

\subsection{Community-based practice}


The gap between academic research and its impact on and meaning to society is a fact. This has led in recent years to the practice of community involvement. Not least in archaeology there has been considerable interest in community-based perspectives and practice, partly as a consequence of the allocation of money to perform communitybased studies, partly because it also makes it possible for archaeologists to share their otherwise quite anonymous work with a wider community and to get input from local communities and indigenous groups to the ongoing work (Atalay 2012). This involvement might in the best of worlds be an act of reciprocal information transfer, so that the community takes part in research and the researchers take part in community knowledge. Some dissonance has appeared, for a variety of reasons, in communitybased projects (Smith and Waterton 2009). Relating to artistic work there can be a question of the artist being prevented from unfolding her/his own idea of arts practice if too much attention has to be directed towards community needs and specific agendas relating to, for example, political issues. Within this project the act of encouraging local communities to contribute to this Experimental Heritage effort by sharing their traditions, stories and experiences from the specific landscapes is crucial and valued.

\section{Concepts}

\subsection{Recurring expressions}

Throughout this work there are some recurring expressions that need some explanation regarding how we use them within the framework of this project and its explorations. We choose to explain concepts that carry significance relating to the overall project ambitions.

\subsection{Experimental}

The experimental angle is chosen because of its double meaning. It is both controlled and free, and it might be both scientific and artistic. It is possible to perform controlled experiments as well as it is to do them in an uncontrolled, not so restrained manner. The meaning of the word is formally hinting towards the untested, the not yet established, the innovative, inventive, and alternative. In a general sense we incline towards a more artistic use of the concept and its thereby connected practice, but we wish not to limit ourselves to one single definition but to remain open-minded.

\subsection{Transdisciplinary}

The 'trans' in transdisciplinary is to be understood as the upheaval of borders between subjects, and that the aims are towards new directions of working, transgressing borders and integrating disciplines to new forms and functions. This is as opposed to the definition of, for example, 'inter', where the subjects and disciplinary frameworks are kept separated even if they interact and help each other. We are working towards new and integrated practices outside established institutions, and that in itself contains a striving towards the development of new transdisciplinary methods. It is not possible to achieve a transdisciplinary state immediately. A project like this has to be allowed to take its time to evolve. We rely upon a process-led practice to achieve shared experiences that eventually lead us beyond disciplinary borders towards a shared practice. The 
transdisciplinary approach is not an end in itself but a sincere way to express the serious strivings towards an upheaval of traditional approaches and in favour of new, shared directions and collaborations. The intention is to move beyond disciplines in search of a renewed understanding of the world.

\subsection{Translocal}

In this project we have also chosen to work according to the concept of translocality (cf. Brickell and Datta 2011). Even if we are critical towards the effects of capitalism and globalisation, we are aware that today's situation does not take away the more positive interconnectedness that exists between places and of different reasons. Depending on where people live their lives, educate themselves, settle or in other ways interact between areas in the world, a sense of connection might appear. This is the case in this project, as it all started with personal engagements, networking and exchanges between groups of artists, archaeologists and culture workers. By the time we explored a range of similarities between the two areas at the extreme west and east of Europe and found it suitable to connect them in project work, not least because a kind of physical connectivity was also to be seen through the materiality of stone and water. At the same time there are differences, for example in the approach to landscapes in Sweden and Ireland and in what ways people have access to them. In Sweden there is the Allemansrätten, the law-bound right to access land even if it is privately owned. In contrast Ireland, in common with many other areas in the world, has privately owned areas where access to landscape is restricted and depends on the goodwill of the landowners and their possible positive response to whatever use is proposed for the landscape if access is to be allowed.

\subsection{Stone and water}

The Karum and Creevagh groups found the connection between Sweden and Ireland through the symbolic and physical relationship with stone and water inspiring. The participants within this collaboration are all in one way or another taking the concepts and realities of stone and water as shared starting points. Because of the properties of these materials, matters concerning both movement and time as well as multitemporal aspects can be easily and similarly explored and linked. Stone and water represent the intangible within the tangible and vice versa. Immediately it is easy to think of the permanence of stone and the fluidity of water. At the same time the eroding limestone of the Burren and Öland transforms itself with the aid of water through the ages and is thereby found to be fluid as well. Water is also something eternally essential for life and therefore suggests permanence. There is as well a common megalithic tradition of stone monuments represented in the two places that are connected by the sea. The themes of stone and water support the connectedness between parts of the project as well as between people and places.

\subsection{Movement and time/the multitemporal}

As well as working with moving bodies through landscapes, between Ireland and Sweden, and in relation to the different moving materialities of stone and water, we work with the movement from past to present and future and back again. The relations and movements between these different times are actively studied and used in the project, 
and we thereby encourage the experiencing and contemplation of several time layers simultaneously, which might be conceived of as the multi-temporality of a specific place, landscape or situation.

\subsection{Tangible - intangible}

Artists and archaeologists are actively engaging with both tangible and intangible, material and immaterial aspects of life. Archaeology is traditionally strongly connected with the study of the material traces of the past. But in recent decades there has been a shift towards exploring also the intangible aspects of life in the past such as belief systems, religion, rituals and social structures. In addition, genetic research, which is becoming more and more important in our understanding of past movements of people, can be conceived of as being at once tangible and intangible: intangible in its lack of immediacy and its partly uncertain results, but made tangible through scientific methodology and practice.

Unlike archaeology, artistic exploration sees less of a dichotomy between tangible and intangible. Embodied practices of moving through the landscapes and experiencing traces from past times might create common points of departure for understanding relationships between tangible and intangible aspects of other times.

\subsection{Somatic - embodied}

As it is an important direction for dancers and performance artists within contemporary art forms, we have chosen to put extra emphasis on somatic movement and embodied practice. This technique is important for the perspectives and practices mirrored in phenomenology and Performance Studies. It also echoes and evokes the somatic and embodied practices of past times as performed, for example, through ritual, procession and dance. It is our intention to develop the somatic and embodied approach into a conscious tool for archaeologists as well. Throughout the project the ambition is to 'trans-act' in a way so that the theories, methods and practices of art and archaeology mix and form a new way of doing things.

\subsection{Rural - peripheral}

The rural point of departure is core to the project and its way of working. Through performing in rural landscapes, this project aims to affect how we approach, understand and talk about present as well as past rural and village-based societies. The rural is a conscious, absolute and crucial point of departure that hopefully affects the work done and the interpretations that follow from it.

When the rural is compared with the urban, the rural is often seen as backward and stagnant while the urban is related to progress and development. In recent years some nuances are discernible, as the discussion has changed from a rural-urban dichotomy towards the idea of an interrelationship and a recognition of the interdependence between rural and urban (Davoudi and Stead 2002), but the urban remains the contemporary academic norm. 
If heritage is considered in a landscape perspective, the setting is somewhat different. Rural and heritage can be seen as parallel in a sense, since both are strongly connected with tradition. Less mobility and change create a strength in the more traditional rural ways of life, relations, inheritance, the handling of farmland and care for lineage. It follows that the relations and bonds between the present and the past are much stronger in rural areas. Tradition, both material and immaterial, remains vibrant, making rural life richer in terms of heritage. Because of less mobility and a stronger local living tradition, the oral transmission of these traditions is also much stronger. One problem concerning heritage in rural areas though, is that farming can be harmful to heritage: ancient remains can be damaged or destroyed as a result of changing and modernising farming practices. In the Swedish countryside there have been huge changes in the structure of farmland through state administrative actions throughout the 18th-19th century that have radically changed the more ancient rural structures and organisation in most areas. On the other hand, in the area under investigation in County Clare, field boundaries have remained largely unchanged since the earliest detailed mapping in the first half of the 19th century.

Certain characteristics, such as visible remnants of rural as well as ritual landscapes, structures and sites, together with more intangible aspects such as traditions of land use, are discernible in such unchanged areas, since these areas, to a much greater degree, retain traces of the past and show lines from past to present (cf. UNESCO World Heritage List online with, among other examples, the world heritage represented by the agricultural landscape of Southern Öland). These areas, owing to their unchanged nature, show a certain stability, retaining elements of tradition in their land use. We are specifically interested in the areas of tradition and stability in this sense. They underline the links between the past, expressed as heritage and tradition, the present, and respect for the environment for the future. Today, globally, this perspective of respect is found most frequently among indigenous groups inhabiting rural areas. For example, Bruce Pascoe (2018) describes in detail with an archaeological time perspective the Australian Aboriginal connectedness with and understanding of their environment, giving several convincing examples of indigenous pre-colonial, longenduring and respectful symbiosis between humans, their land, and its flora and fauna, and a practice indicating a consciousness of sustainability emanating from traditional land use and experience from far back in time.

Urban life today is increasingly physically and spiritually detached from the rural. Understanding where, for example, food comes from, can be limited in urban dwellers, and in their urban existence they are insulated from the agricultural and natural cycle of the year, from the land that feeds them and from an understanding of the connections from past through the present to the future mentioned above, on which their future also depends. Combined with the long-term perspective stretching back several thousand years to the first farmers in the Neolithic, and to life in the past, there are interesting multitemporal, sensory and psychological connections to be made with an unspoken and perhaps sometimes even unbroken continuity of lifeways in farming communities.

Another expression to consider in connection with rural is the term peripheral. In today's dominant discourse in favour of the urban, the concept of periphery is likewise seen as the opposite of progress, but our intention is to question the urban-centred narrative and to explore the riches of rural and peripheral. Peripheral is at the edge, revolving around, it is outer and freer, less competitive and exterior to the hierarchies and power structures of the increasingly globalised urban world. In many cases the rural and peripheral areas are in some ways left to their own devices, which in turn strengthens their ability to 
create and maintain alternative views of the world, rooted in their rural environments, without representatives of centralised power intervening and restraining these worldviews.

\subsection{A practice of care in a landscape setting}

To summarise, we conclude with the ambition of striving towards a practice of care in relation to the combined nature/culture work performed in this project. We see the timelessness of the rural in opposition to the constant change of the urban; the rural maintaining identity through connections with the past, parallel to how urban centres tend to tear down and rebuild themselves in an ongoing headlong rush towards globalised homogeneity. We are aiming to make our ways from present to past and back again a tool for sustainable relations in the world. We wish the effects of the work to range from the past via the present and into the future. We resist globalisation and capitalism through our practice. We promote local and rural perspectives. We strive towards the re-enchantment and enrichment of cultures, and of an increased awareness of mixed natural and cultural diversity. We celebrate the peripheral. We strive to establish a practice set in the present that cares for the past and informs the future.

\section{Previous and Current Research Combining Art and Archaeology 4.1 Introducing the combination}

When archaeology is mentioned together with art, two different angles come to mind. One is archaeology combined with art in dealing with art forms from the past that are considered by archaeologists to be expressions of artistic work. Here might be included Palaeolithic cave art, Neolithic or Bronze Age rock art, Greek art, medieval art and similar elements of the archaeological record: paintings, carvings, sculptures, clay objects, patterns on ceramics, ceramic forms, and specific objects that are sculpted in artistic ways. It might also include objects that are supposed to have been used as objects in art forms relating to intangible practices - for example music and theatre in the past and therefore these objects qualify as objects symbolising art. The concept of art in these cases is partly contested. For example, the rock art may also be discussed as being an integral part of ritual and worship in earlier societies and therefore it should perhaps not immediately be interpreted as primarily an expression of art. This debate about art and archaeology has existed since archaeology was established as a subject in the 19th century, among other reasons, because early European archaeology was strongly connected with the subject of art history, especially in relation to archaeological sites in the Mediterranean area, notably belonging to ancient Greece and Rome.

A more recent angle is that of archaeology approaching contemporary art forms as a means to find alternative ways of expression and interpretation in archaeology today. The contemporary art forms involved are not limited to any traditional format. They include dance, music, theatre and performance, as well as other formats such as painting, sculpture and textile work. This contemporary art approach is used to broaden the scope of a combined artistic and archaeological interpretation and understanding. It 
might also make way for multidisciplinary and transdisciplinary approaches with the aim of renewing perspectives and understanding of the past in the present.

\subsection{Researching together}

In recent decades academic researchers in many fields have begun to approach artistic enquiry, and together with artists have been exploring the possibilities of new combined efforts to understand the world (Ehn 2012; Gibbs 2014; Larsson Pousette 2017;

Gkartzios and Crawshaw 2019). An important attraction between science/research and art is the possibility of reaching the hitherto unknown about being in the world, with the hope of restoring relationships between humans inhabiting this world and all its forms of life, and to enhance respect for the world as a whole. A 2019 report on sociological work together with contemporary artists, stated that while there is still limited evidence of how arts research can contribute to an overall increased understanding of the world (Saratsi et al. 2019, 2), there is a general recognition that artists, through contemporary art, often highlight important issues. This report suggests ways in which collaboration with the arts might enhance research perspectives:

- Arts offer a distinct way of understanding the world and ourselves

- Arts can provoke; they can unsettle norms and challenge prevailing wisdoms

- Arts can be political; they can illuminate problems and expose values and choices

- Arts can educate, inspire and persuade

- Arts can open up new perspectives through imagination

- Arts can help us to live with uncomfortable truths

- $\quad$ Arts can help us to adapt to new realities (Saratsi et al. 2019, 3)

Other positive effects of collaboration that are highlighted in the report are a holistic approach and a sincere sense of experimentation in the work process (Saratsi et al. 2019, 25). We agree with these insights and find these parallel results encouraging in relation to what our Experimental Heritage project has experienced throughout its duration as we will describe in some depth later in this text. Before we describe our own work, however, we highlight some previous collaborations between archaeology and the arts.

\subsection{Archaeology and contemporary art}

Since this Experimental Heritage project explicitly works with the combination of contemporary art and archaeology, the following describes contemporary art and archaeology projects and contemplations that have occurred within the past 60 years, focusing on the last 20 years as a result of increased interest in the combination in recent decades.

\subsection{Comparative vandalism (1961)}

In 1961, the artist Asger Jorn founded Skandinavisk Institut for Sammenlignende Vandalisme, SISV (Scandinavian Institute of Comparative Vandalism in English). The intention of the institute was, through a close collaboration between art and archaeology, to create the basis for mapping and processing Nordic folk art as a specific expression 
that had existed continuously through time ever since the early Stone Age of huntergatherers. The centre was led by Jorn as artist and involved archaeologists and art historians from the Nordic countries. A fundamental idea was the existence of a connection between expressions of folk art through time as a continuum, traced back as far as Indo-European origins. Jorn thought that even religious changes such as the advent of Christianity didn't intrude upon this continuity (Østergaard Pedersen $\underline{2015}$, 39ff). A curator of a recent exhibition about Asger Jorn and his work wrote:

Hypothetically, there could be an undercurrent of singular visual styles stretching from the Migration Period and the Vandals, undercurrents which are hard to categorise. Could folk art put us in direct contact with artistic intentions that have been lost in modernity? ( https://www.modernamuseet.se/stockholm/en/exhibitions/comparative-vandalism/)

Jorn and SISV were concerned about the question of centre and periphery. Traditional art was seen as too focused on Mediterranean antiquity as a yardstick, and as a contrast the Nordic area was seen as uncivilised, barbarian and without any aesthetic sense. Peripheries such as Scandinavia were treated as inferior and therefore marginalised in a hierarchical sense. The concept of folk art was primary for SISV, art as visual culture developing through people, not as an elite undertaking towards singular finished art works of specific value. The SISV was driven by a wish to research non-authoritative art expressions through time (Østergaard Pedersen 2015, 39ff).

It is an interesting challenge to cross boundaries of culture and thought, art and science, as well as the concept of vandalism, where the artist imposes more recent layers and interventions upon, in this case, the photographs of Nordic folk art. Thereby traditional concepts of time are abandoned (Figure 14). 


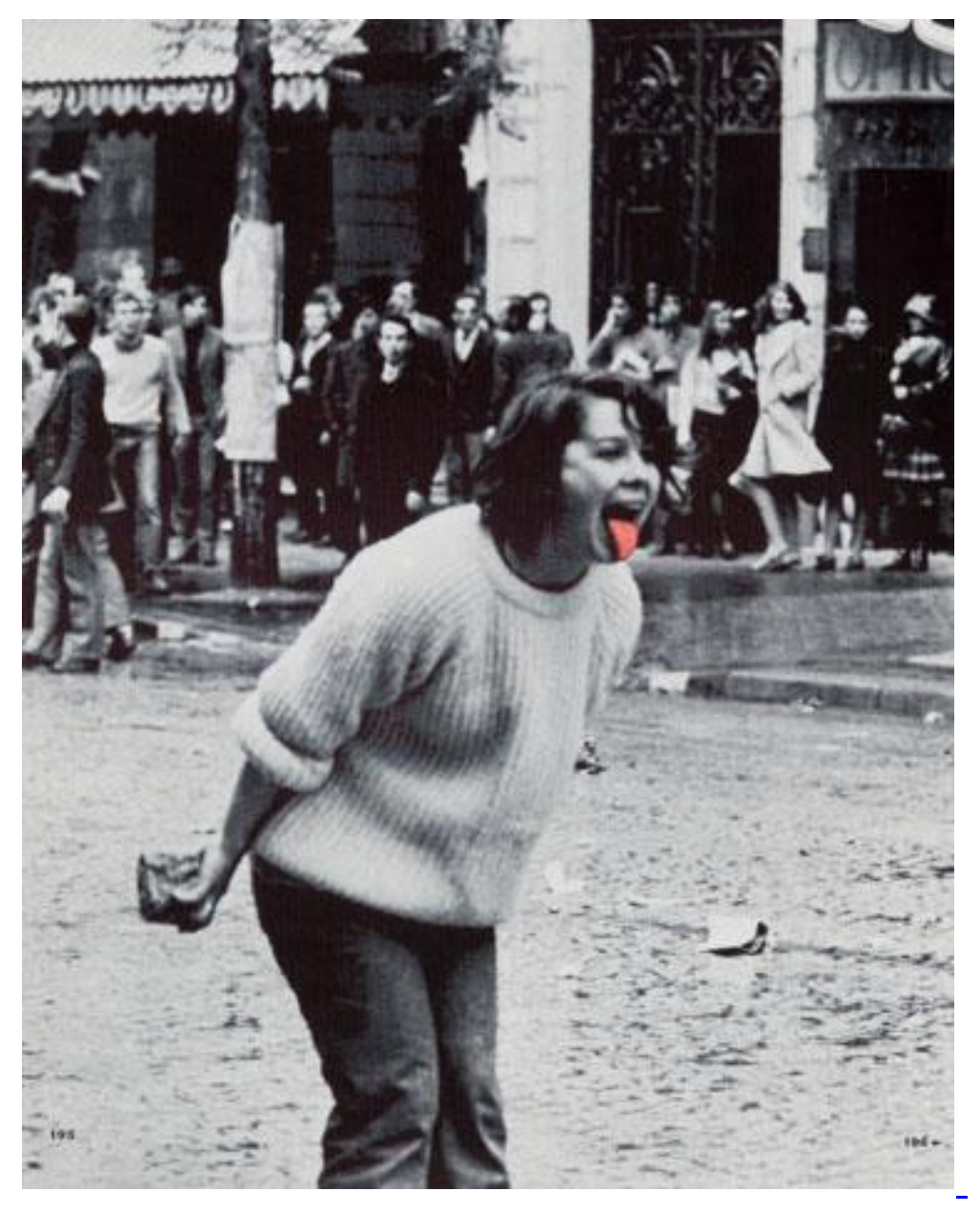




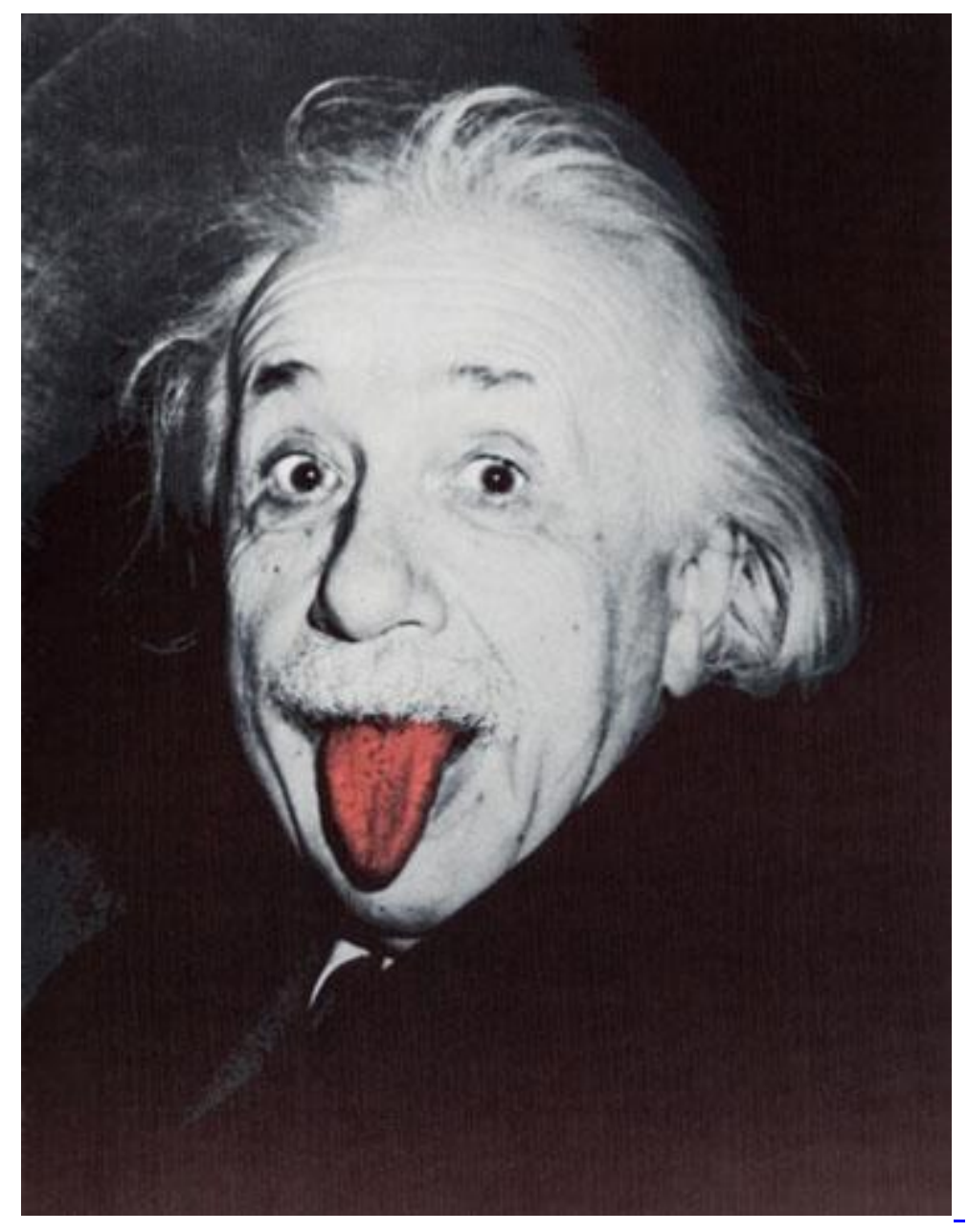




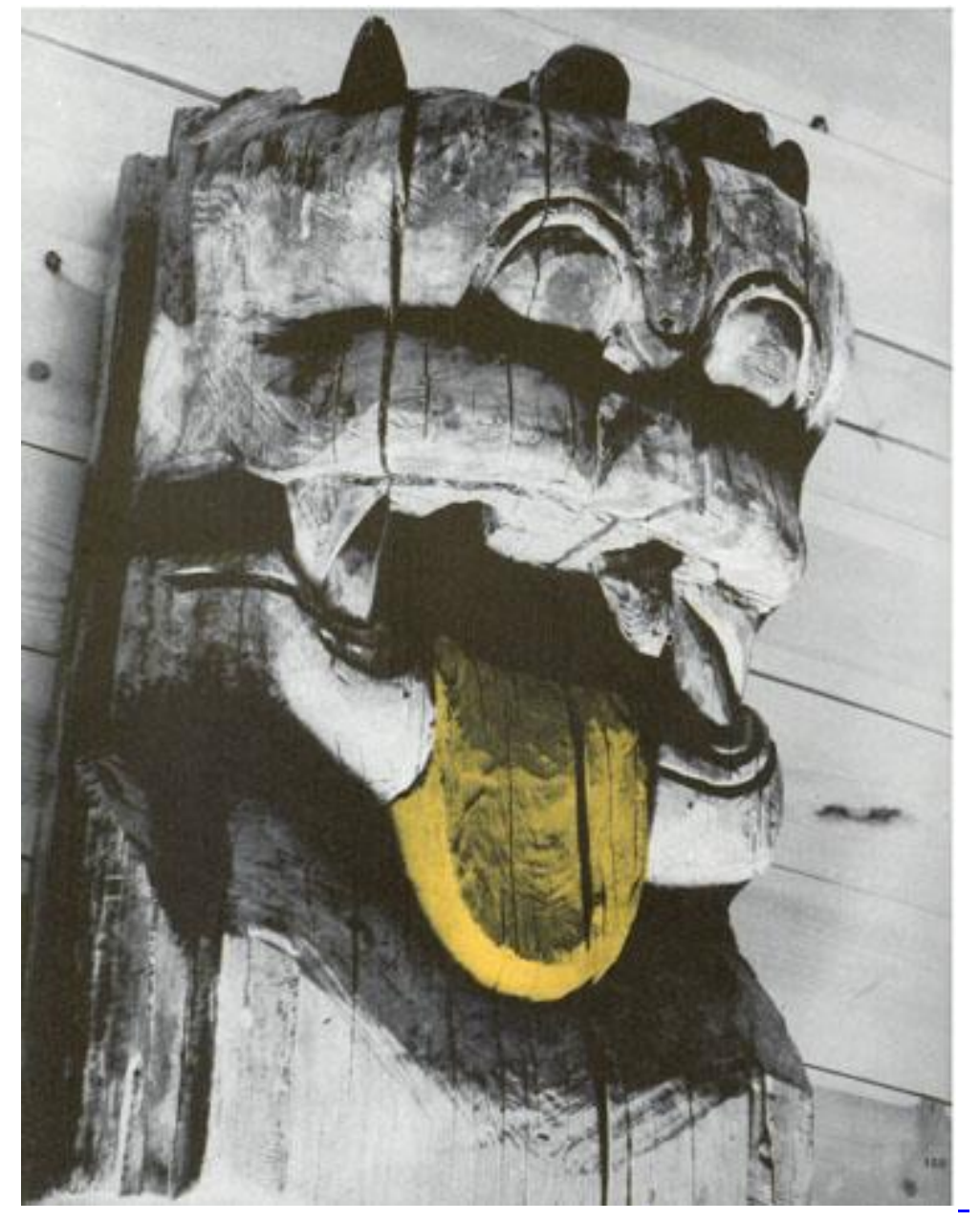




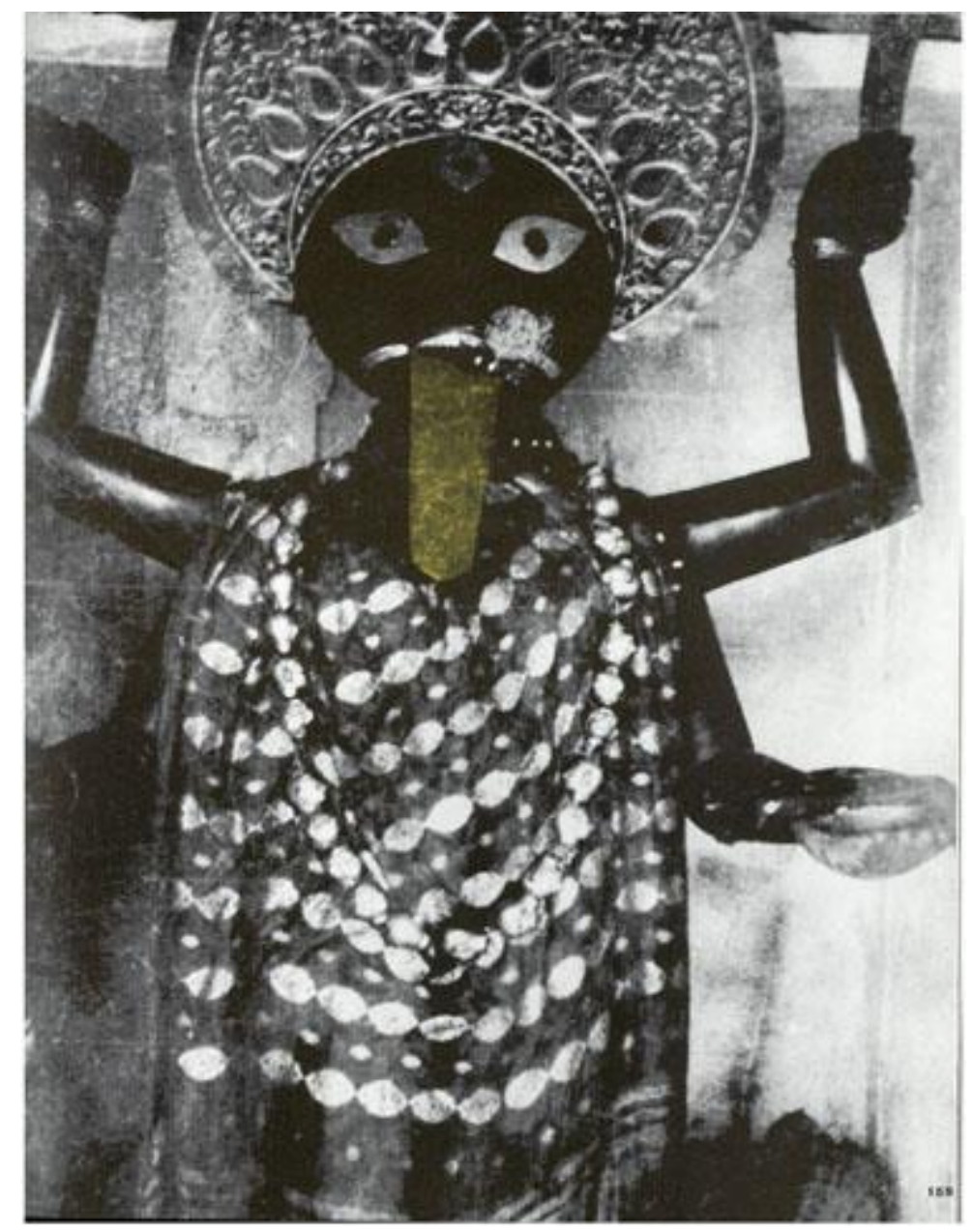

Figure 14: Comparisons without the constraints of chronology or geography. Photo from the publication La langue verte et la cuite. Étude gastrophonique sur la marmythologie musiculinaire by Asger Jorn and Noël Arnaud (1968) depicting a student rebel, Albert Einstein, motif from a Norwegian stave church and a Hindu figure. (c) Donation Jorn, Silkeborg

The work of the SISV resulted in an extensive photo collection, but the book series, planned to consist of more than 30 books, was never realised: just two books were published, one on the topic of ancient church graffiti (Jorn 1964), and another on Romanesque stone sculpture (Cinthio et al. 1995).

\subsection{Figuring it Out (2003)}

Archaeologist Colin Renfrew writes in the postscript to his book Figuring it Out that 'We are daughters and sons of time' (Renfrew 2003, 190). His ambition in this work is to find out more about the parallel visions of artists and archaeologists. The questions are general and all-encompassing and concern the human condition: Where do we come from? What are we? Where are we going? The book describes more than just those projects where the author himself has been involved in working with artists. It is also a presentation of the then (2003) state of collaborative approaches between (visual) artists and archaeologists. The book is an interesting statement since it is written by an established archaeologist, declaring that the study of human life is worth nothing if we do not take artistic expression into account (Figures 15-16). He is explicit about his wish to 
work with the human condition and that this cannot be done without art (Renfrew $\underline{2003}$, 194).

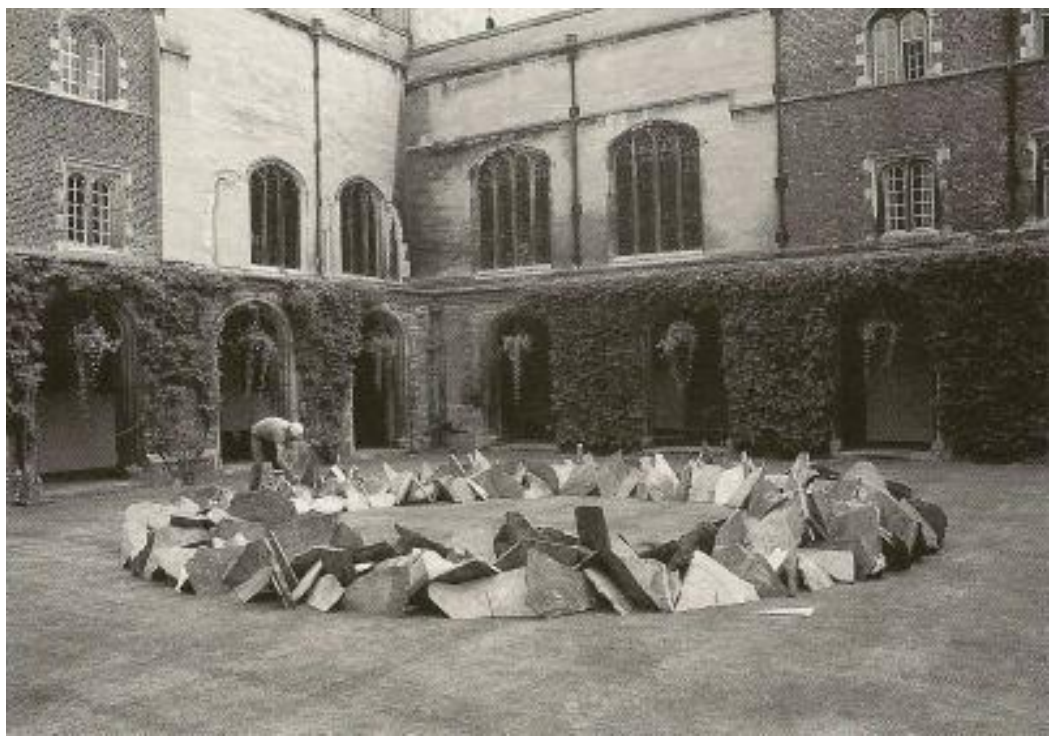

Figure 15: Perennial forms, art work by Richard Long, Jesus College, Cambridge (Renfrew 2003, 39). Photo by Colin Renfrew (used with permission).

Renfrew considers works of a group of contemporary artists that are engaged with their physical surroundings, the ultimate parallel to the archaeological interest in the material aspects of human life. The publication of this book was liberating for archaeology and its relation to contemporary art. With a renowned and established archaeologist declaring how much art, even the contemporary kind, means to our understanding of the human condition, these aspects became accepted within the realm of archaeology. Renfrew's work, while not adopting explicitly transdisciplinary approaches, nevertheless makes use of the combination of art and archaeology to discuss the human condition.

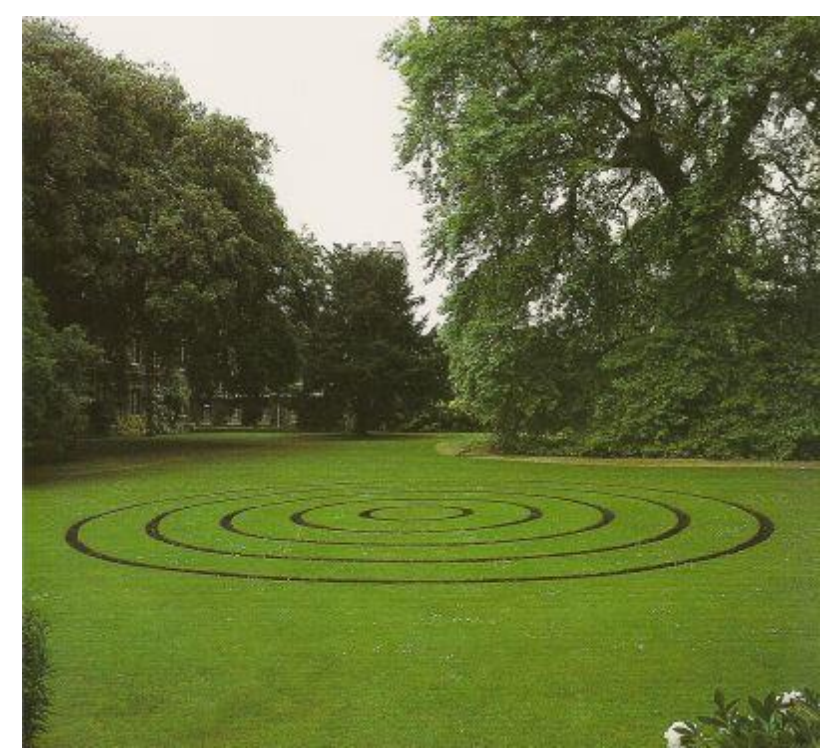

Figure 16: Perennial forms, art work by Richard Long, Jesus College, Cambridge (Renfrew 2003, 48). Photo by Colin Renfrew (used with permission). 


\subsection{Theatre/Archaeology (2001)}

In their collaboration that resulted in the book Theatre/Archaeology, performance artist Mike Pearson and archaeologist Michael Shanks worked to combine performance and archaeology. Their intention was to find a common interdisciplinary and methodological approach to performance and archaeology. This was undertaken through an examination of the interdisciplinary practice in three stages: the parallel ideas of archaeology and performance, the entwining of the two disciplines through representation of pasts in archaeological open-air settings and museums, and eventually what they call the 'interpenetration' of the two discourses (Pearson and Shanks 2001, chapter 1).

In a general sense they worked with concepts such as multiple temporalities of both performance events and archaeological sites. They introduced terminologies from one area, archaeology, into the other, performance. They also pointed out the value of work in progress, the fragmentary and partial (Pearson and Shanks 2001, 8).

As they work through the process it is obvious that they never really become one in a transdisciplinary sense. Instead they follow each other's work and intervene but are still separate actors approaching the themes of archaeology and performance from their different positions.

In the second part of the book they work particularly with concepts relating to war, body, sexuality, violence, blood, and weapons. General concepts in use throughout the book are landscape, body, site-specific work, sense of place, walking, palimpsest and deep mapping.

The work explicitly connects with the Performance Studies approaches of Richard Schechner and Peggy Phelan, and the archaeologists Fiona Campbell and Jonna Hansson Ulin, together with Christopher Tilley, are mentioned as working within the same fields.

\subsection{Borderline Archaeology (2004)}

In their joint dissertation, archaeologists Fiona Campbell and Jonna Ulin together explore and formulate a theoretical framework of a field in between art and archaeology that they call Borderline Archaeology (Campbell and Ulin 2004). They focus on the connection between archaeology and performance and point out the quality of subjective experience and alternative ways to approach archaeology and archaeological objects through a combination of archaeology and performative practice.

The case studies of their choice are both ancient and contemporary archaeological remains and their construction in the present. They look into a ruined cottage that once belonged to a relative of one of the authors. They walk the labyrinth, a feature interpreted as both ancient and more recent in time, a structure often seen as Bronze Age as well as contemporary (Figure 17). 


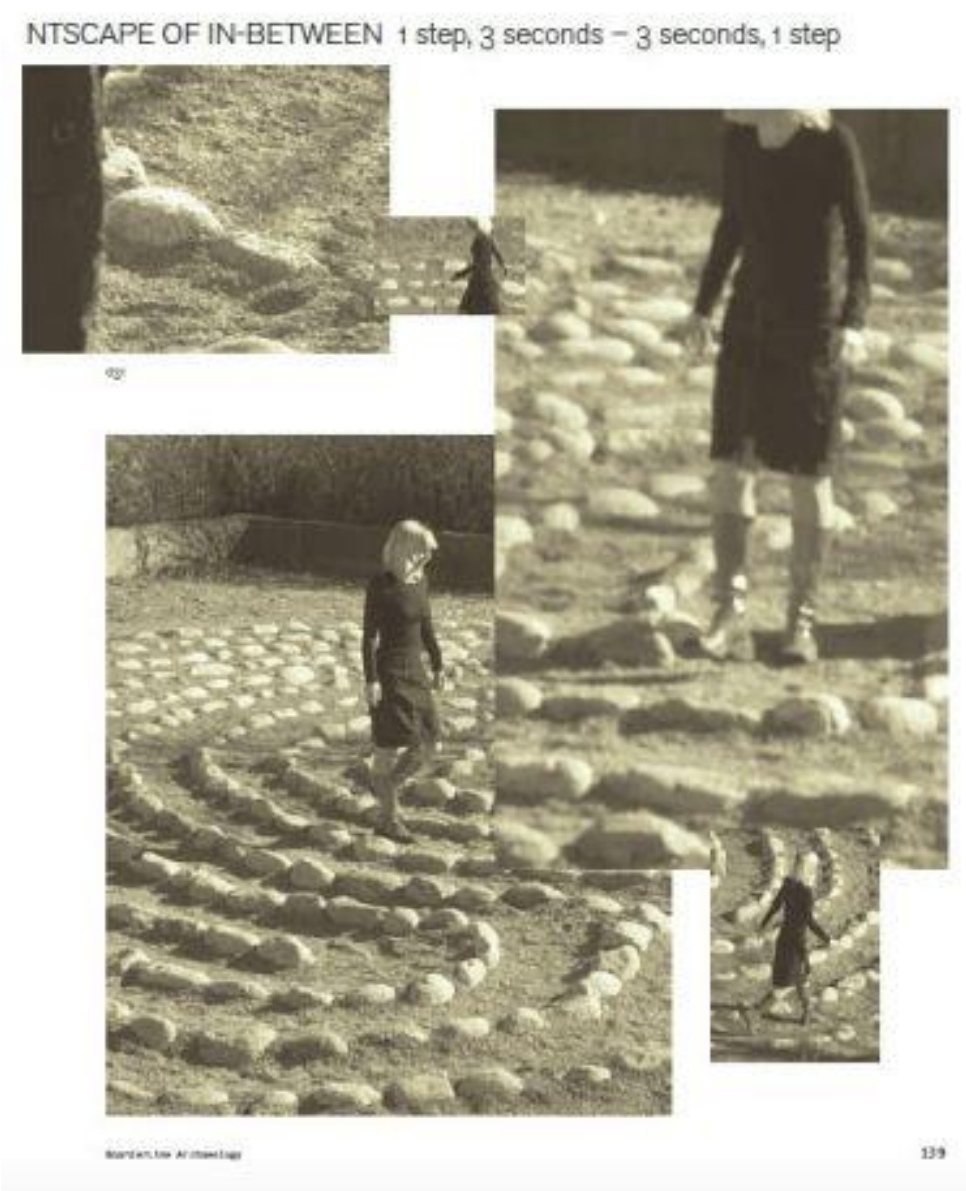

Figure 17: Walking the labyrinth, a theme within Borderline Archaeology, from the book of the same name (Campbell and Ulin 2004, 139)

Their work is inspired by performance artist Mike Pearson's work together with archaeological themes described by Michael Shanks, as mentioned above (Pearson and Shanks 2001). Campbell and Ulin discuss performative writing and the re-presentation of archaeology today. The body and movement are central in their explorations. Embodied practice and intersubjective processes are pointed out as key elements in their practice that they try to elaborate upon. They mention the crossing of borders and also the moving between the familiar and unfamiliar and how to get in touch with the silent and unspeakable.

The performative approach is core to their work. The authors point towards an act of performative writing as an alternative approach, and towards archaeology as performative cultural production. With this, the practice they advocate is significantly performance-based.

\subsection{Lines (2007)}

In his book Lines, social anthropologist Tim Ingold jumps outside traditional boundaries of academic subjects and his point of departure is the line. He sets out to 'lay the foundations for what might be called the comparative anthropology of the line' (Ingold 2007, 1). The lines he then considers are from different realms such as 
language, sound, music and the musical score; further to traces, threads and surfaces that are lined in one way or another. Mapping with spots and dots and considerations made concerning how they might be connected through routes and stories, genealogical lines and trees. At the end of his work of lines, the straight line is considered to belong to modernity, the fragmented line to postmodern dislocated Dystopia, and the meandering and wayfaring, circuitous line to Utopia. The conclusion on lines is that 'Lines are openended, and it is this open-endedness - of lives, relationships, histories and processes of thought - that I have wanted to celebrate' and 'as in life, what matters is not the final destination, but all the interesting things that occur along the way' (Ingold 2007, 170) (Figure 18).

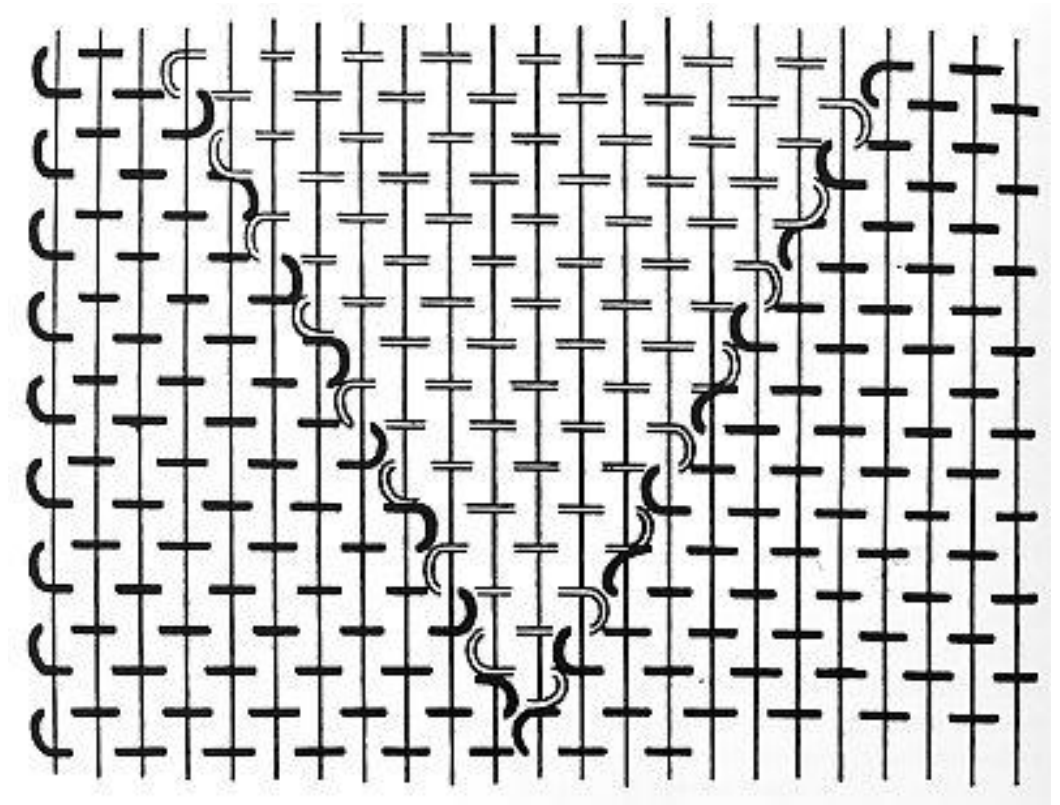

Figure 18: Image from Ingold 2007, representing weaving containing patterns of lines from a Navajo blanket, example reproduced from Gladys A. Reichard's book from 1936 with the title Weaving a Navajo Blanket

The work of Ingold is an individually performed thought experiment more than a joint effort with others. Of interest in this ground-breaking work are the perspectives from in between and across subject borders, so that the perspective presented leaves the subject-dependent thinking and instead follows the line as concept, meandering through history and into the present. The work does not depend on one specific discipline but transgresses borders and this character leads to a fruitful approach. In the same way as with the other examples of work performed between art and archaeology, there is an implicit wish to consider and explore the human condition in a kind of timeless manner, although there are some time-dependent perspectives present as well, such as when the line is seen as representing different views aboout the world, connected, for example, to the modern or the postmodern.

\subsection{Making (2013)}

Continuing in his attempts to cross disciplinary borders, Ingold made another contribution with his book Making (2013). His point of departure is thinking through the act of making, in relation to what he refers to as 'the 4 As': anthropology, archaeology, art and architecture (Ingold 2013, xi). The specific relevance of archaeology in his work 
is described as resulting from its connection with anthropology through shared perspectives on time and landscape, as well as a focus on both material and symbolic expression. The archaeological connection with art and architecture is through a shared interest in artefacts and buildings of the past (Ingold 2013, 10). The main perspective of the book is process and doing/creating, mirrored in the title, Making (Figures 19-20).

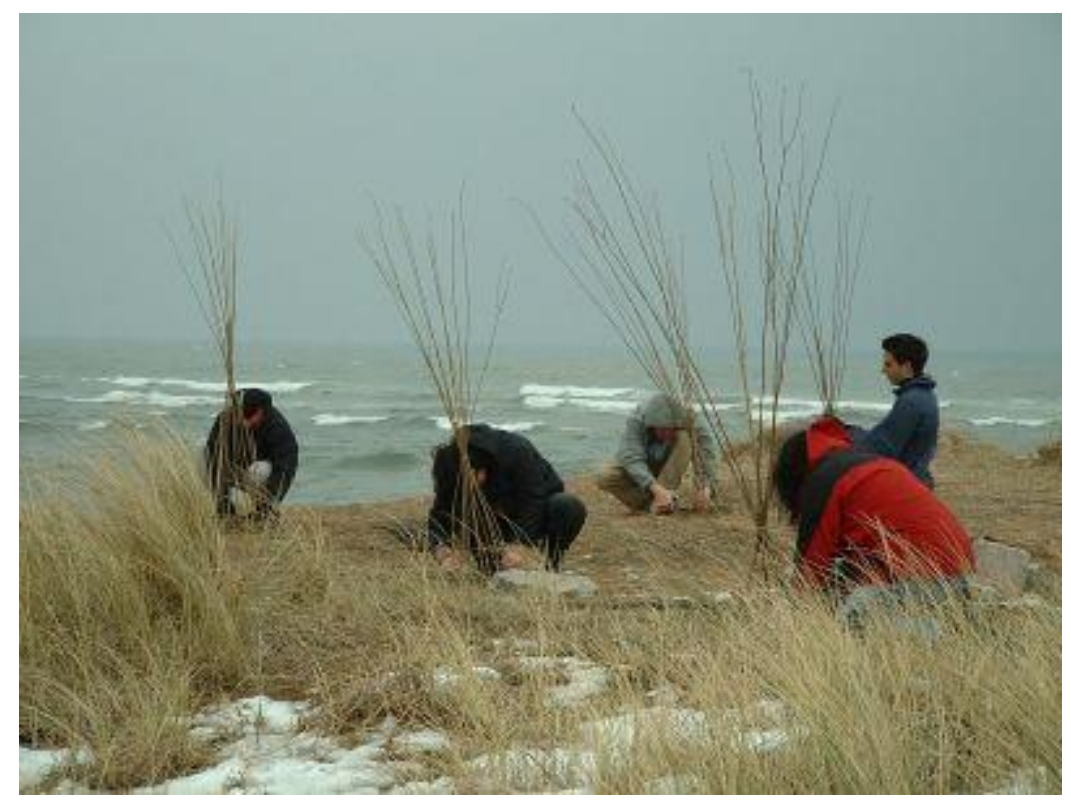

Figure 19: The making of baskets in the sand near Aberdeen beach in north-east Scotland. Photo by Raymond Lucas, previously published in Ingold 2013, 23

The thinking throughout Making is constantly anchored in, and returning to, process. At the same time the material world and the doings by hand are kept in focus and never left out of sight. The order of things is essential, as Ingold points towards a thinking through making, with reference to how, for example, a craftsman would go about an enquiry by beginning with the practice and then consider the theoretical aspects arising from that practice (Ingold 2013, 6). 


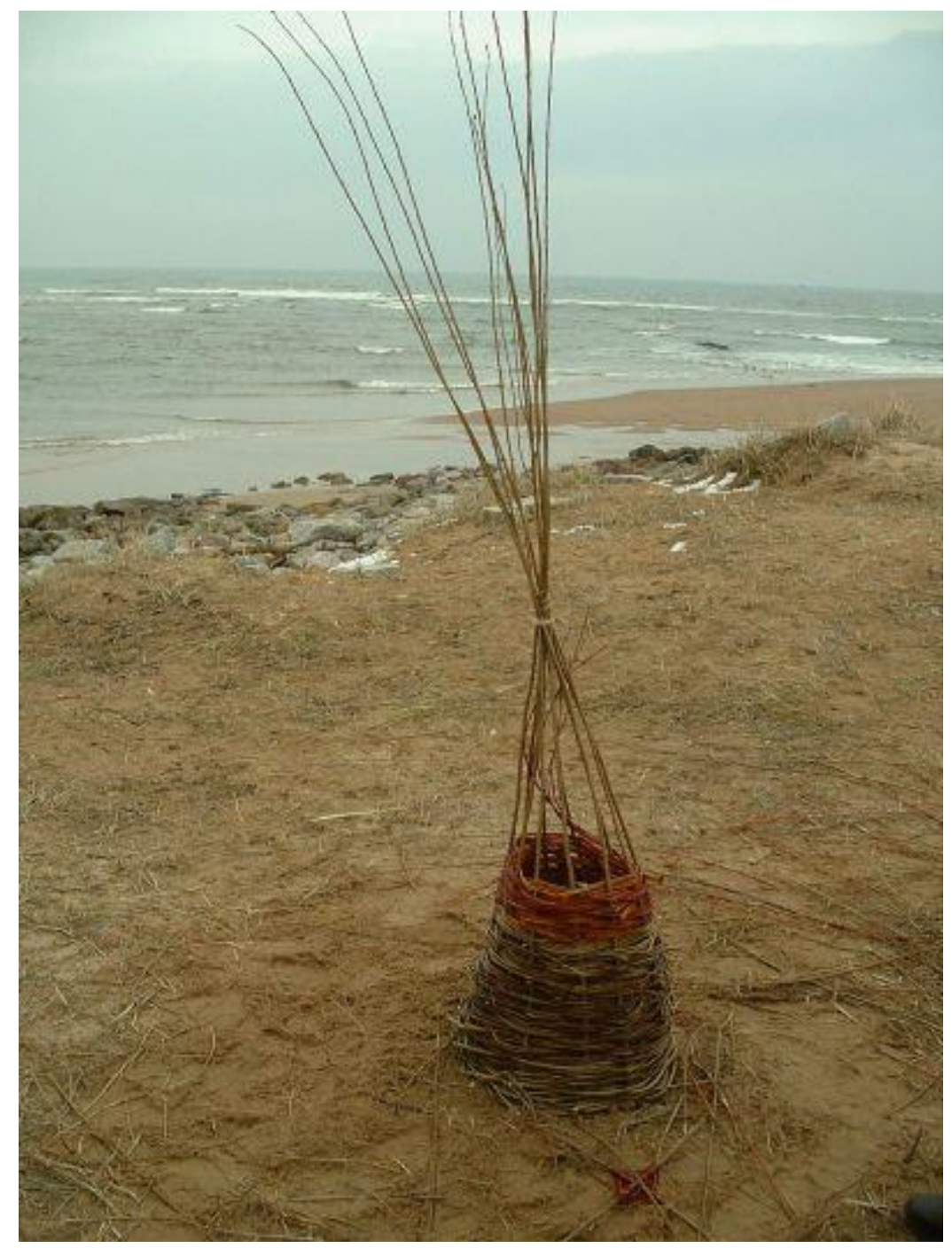

Figure 20: An almost complete basket. Photo by Raymond Lucas, previously published in Ingold 2013, 24

\subsection{History unfolds (2017)}

In a project formulated around the meeting between contemporary art and history, the Swedish History Museum in Stockholm invited ten artists to the museum to engage with research and collections in the museum. The main idea was to show how perceptions of history and heritage are shaped and used (Larsson Pousette 2017; www.historiska.se). The project resulted in an art exhibition intertwined with the existing exhibition on archaeology and history. It was a reflective process engaging artists, curators and researchers in the areas of archaeology, history and art history. The exhibition was launched at the end of 2016 and continued to be displayed during 2017. The project and its aims were not explicitly intended to intertwine work of different disciplines but is still of interest here as the project points towards common reflection among artists, museum curators and researchers on the theme of how heritage is formed and used.

One of the artistic works in the exhibition was a film, The Bell. It is described as inspired by a Kurdish entrepreneur who, after the Iran-Iraq wars and the Gulf wars, collected scrap metal from the wars such as remnants of landmines, bullets, bombs and parts of 
military planes and tanks, with the purpose of reshaping it for more ordinary use in daily life after the wars had ended. Stemming from the activities of this entrepreneur, the artist Hiwa K collected scrap metal from the war in Iraq and transported it to a manufacturer of church bells in Italy. There he had a bell cast incorporating motifs from Assyrian and Mesopotamian artefacts destroyed by ISIS. He reflects upon the fact that historically, church bells were used for the manufacture of cannons for war. This act of using metal from war objects in the production of a church bell is then a reversed transformation (Larsson Pousette 2017, 52). The relation with objects in the Swedish History Museum was that it had church bells on display in the medieval exhibition. Artefacts of a more distant past were thus related to artefacts of more recent times (Figure 21).

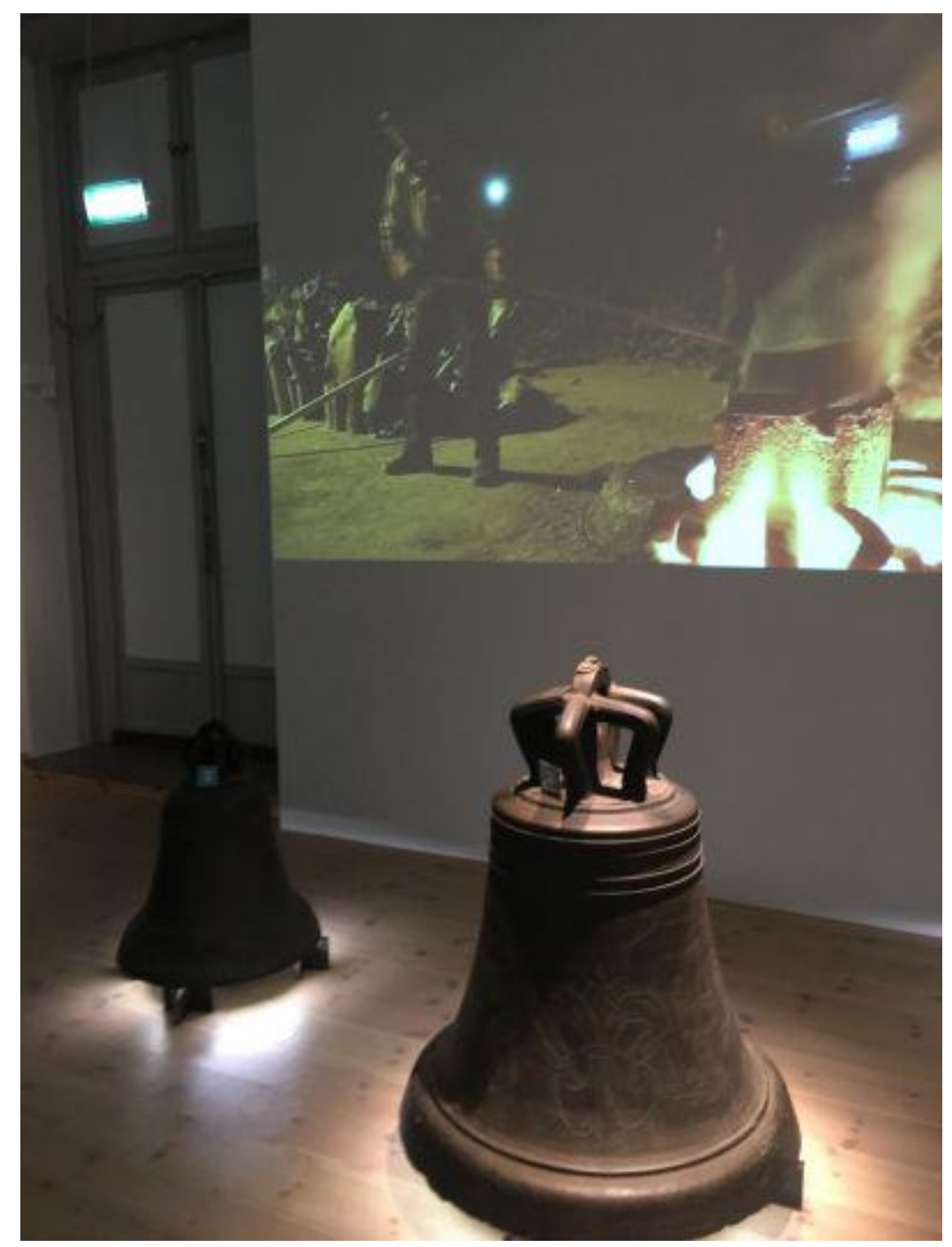

Figure 21: The Bell, film and the museum objects related to it. From the exhibition 'History Unfolds' at the Swedish History museum. Photo: Bodil Petersson 2017

Another art work by the Serbian artist Dusica Drazic was inspired by soil samples from archaeological excavations that are held in storage at the museum. The soil samples, weighing around 10 tons, originated from excavations undertaken in Sweden from the 19th century until the present, and their informative value is unclear. The artist draws attention to the fact that the soil samples might be labelled as 'Swedish' and that soil in itself carries notions of identity and belonging to particular nations. 


\subsection{Breaking the surface (2018)}

Using his experiences from excavating, archaeologist Doug Bailey reflects on the preconceptions of the archaeologist and how they affect and limit the possible interpretations made. Combining artists' and anthropologists' works with archaeological interpretation, he argues for alternative ways of seeing and interpreting the traces of human actions in the past. His point of departure is a specific archaeological feature named pit-houses, a common feature in central European archaeology (Bailey 2018, chapter 1).

Instead of asking in a traditional and mostly functional archaeological way about why a specific kind of house, in this case the pit-house, was built, and what it looked like and what it was used for, the question is turned in another direction: what was the meaning of breaking the ground, the act of digging a hole, of building a structure, and how do different groups of people conceive of and talk about the act of cutting?

One alternative perspective retold from Bailey's point of view is that of the artist Gordon Matta-Clark and his art work Conical Intersect, where he and his team are cutting through an old building in Paris in the 1970s. The focus of the art project is on the cutting through materials and also a focus on the created non-space of the intersect. A dialogue is created between the old building being torn down and a new building (the Centre Pompidou) being erected next to this old building that is supposed to be torn down when the artist's work is finished (Bailey 2018, chapter 5).

Another cutting project of art referred to is a performance project by performance artist Ron Athey where he cuts holes in another person's skin. The performance involves several connotations relating to, among other things, AIDS and relations between humans, but in Bailey's interpretation it also shows the transcendent act of cutting through something, in this case skin, that in a sense is equalled with cutting through building material as in the case of Conical Intersect or through the ground as in the case with pit-houses (Bailey 2018, chapter 2).

Bailey also refers to an anthropological study with a linguistic perspective. As a group of Maya people see an act of cutting vegetables recorded on film, they describe in their own language what is happening. Here, the anthropologist gets language-specific and culturally revealing answers when it comes to a specific group of people and their description of the act of cutting (Bailey 2018, chapter 6).

From this mixing of experiences from art, anthropology and archaeology, the interpretation of an archaeological site has the opportunity to become something completely different from what we are used to. The strict system of conventional archaeological interpretation is split up into more personal and diverse views on the past and how people lived their lives, used and interpreted their environments. One could argue that the focus shift from the pit-house as structure to the act of cutting the ground also means a shift of focus from the structure itself towards the embodied action by humans both in the past (those who dug the structure) and in the present (the archaeologists excavating the ground). This example shows how an archaeologist's mind and ways of working and thinking is actively changed by allowing the interweaving of artistic and anthropological practice with archaeological practice. 


\subsection{Unfolding inspiration}

The themes and projects referred to above (Comparative vandalism, Figuring it Out, Theatre/Archaeology, Borderline Archaeology, Lines, Making, History unfolds, and Breaking the surface) are just a few examples of ways of undertaking different forms of parallel or combined artistic and archaeological work: archaeologists inviting artists to work with and artistically interpret archaeology; artists inviting archaeologists; archaeologists working as artists; artists and archaeologists working together and/or individuals being both archaeologist and artist at the same time.

The link and inspiration between the projects Theatre/Archaeology and Borderline Archaeology is obvious and also mentioned in both publications. It is possible to discern a common way of working at the borderline in both projects. Still there are some differences in expression and choice of perspective in the narratives. While they all take their point of departure in material culture and traces of the past in combination with performative acts and the body, the narratives differ. As Pearson and Shanks in part focus on the body involved in war, sex and violence, Campbell and Ulin express the body in relation to family, house and culture. These possibly gender-related stories are interesting from a contemporary point of view. They probably represent a contemporary projection onto the bodies of the past. Of interest here is the mix of contemporary issues with the past through performance of the past filtered through the present. The multitemporal is made explicit throughout these two projects.

The History Unfolds narrative of the making of a church bell of war-related scrap metal is of a very elaborate kind, connecting the past with the present and also evoking stories of the past and putting it all into a present context: the church bell and its transformations goes back and forth in both time and space. The context of such recent war is explicitly political and also keeps the controversial aspect alive. This story is likewise explicitly multitemporal.

Breaking the Surface effectively shows how the scope of interpretation is widened through the active combination of artistic work and archaeology. It also highlights the possibility for collaboration between artists and archaeologists to combine art and archaeology with the purpose of changing focus from empirical explanation to experiential action.

\subsection{Purposeful connections and ever- present past}

When contemporary art and archaeology work together as in the above-mentioned examples, the question arises of having an audience or a group that might be the receivers of the efforts or even take part in the contents of these efforts. Some of the projects are probably performed between artists and archaeologists solely with the aim of developing new thoughts. Hereby the act itself is directed more inwards, towards a smaller group doing the research. At the same time, it might be of some importance for combined art and archaeology projects to find an audience and even a wider group of participants in the surrounding community. Academics find somewhat limited audiences in research networks and at conferences for example, and by writing in journals. Field archaeologists are often keen on finding an audience directly in the field and relating the 
communication efforts towards the local community. Artists often find their audiences in relation to institutions of different kinds, such as art museums and galleries and recurring art festivals. If art and archaeology are performed together and directly in the landscape outside established institutions, there is a unique chance of combining the abilities of archaeology to connect with the past, with artists' abilities to show what the past might mean to us, as focus is directed towards matters of living in the world beyond chronologies.

A fundamental idea for this project is how the past is actually ever-present in us, sometimes almost as contemporary matter. Thereby we need not separate the past from the present in practices solely defined as 'archaeology', 'history' or 'heritage'. Instead we need renewing practices, for example a practice of merging art and archaeology, that helps us understand in what ways the past is actually ever-present in our minds and bodies, which in turn makes the past meaningful and enriches our ways of being in the world. This is our aim as we combine art with archaeology and heritage in a landscape setting.

\subsection{Experimental renewal}

Now it is time to return to the Experimental Heritage project. The focus of the project is the combination of archaeology and contemporary art forms in a landscape setting. It also deals with the accompanying questions on how a transdisciplinary way of working together might contribute to this specific kind of landscape study, formed around themes such as stone and water, movement and time. There is also the Irish-Swedish context where the aim is to connect two separate rural areas of Europe and to find out how art, archaeology and heritage together might contribute to a renewed view of, and also active use of, archaeology and heritage today, to strengthen rural perspectives and ascertain if some actions might support a sustainable merging of these disciplines and approaches.

\section{Experiences from the Öland Experiments 2016-18}

\subsection{The Öland Experimental Heritage project}

The first steps of the now developing international Experimental Heritage collaboration between artists and archaeologists were taken on Öland, Sweden, where Bodil Petersson together with a group of artists in the Kulturell Tankesmedja (Cultural Think Tank in English) in winter 2014-15 elaborated upon a concept of archaeologists and artists working together with heritage sites in the landscape. The chosen sites were well known, previously explored or excavated by archaeologists and defined as heritage sites in the eyes of the local people, authorities and tourists alike.

The project group consisted of around 30 people. The group defined four themes with four related heritage sites that they decided to work with. No funding had been obtained at this point. Initially there was some economic support from the municipalities of Mörbylånga and Borgholm on Öland and from Kalmar county authorities. Additional funding was granted from Linnaeus University for the purpose of community involvement 
and collaboration. In 2015 the group decided to apply for funding from the Kamprad Family Foundation (www.familjenkampradsstiftelse.se), which supported entrepreneurial development projects in rural areas. A two-year project was grant-aided during a period from 1 September 2016 until 31 August 2018.

\subsection{Some results}

The project initiated some interesting discussions and processes in the local setting that created engagements relating to the project idea of activating heritage in the local society. The sites and themes were chosen as they carried meanings relating to both the past and the present. In some cases it was obvious that the use of heritage in this experimental setting was challenging the concept of how the past is usually handled in the present. The strands of this project will be briefly presented and discussed here and the experiences eventually transferred to the ongoing Irish-Swedish explorations.

\subsection{Sandby fortress - life and death}

Life and death are appealing categories and were the first to be put forward by the group. Four of the artists decided to work with archaeologists on the topic of life and death, and two of them explicitly chose to work in relation to the archaeological site of Sandby fortress, an Iron Age fortified village roughly dated to between the 3rd and 5th centuries CE and situated on the south-east coast of Öland (www.sandbyborg.se). The artists had a free choice on how they wished to approach the site. The preparatory work was arranged so that the topics of the artists' choice were processed in a series of workshops where both artists and archaeologists took part. Both groups contributed their perspectives on the site and its contents, both past and present.

Anne Hamrin Simonsson performed a land art project named LIV No. 8 (LIFE No. 8 in English). It entailed the use of soil to create mounds and the act of cultivation through sowing and eventually harvesting. By creating the three big letters LIV as mounds in the rural Öland landscape, the artist represented the cycle of life-death-life. The letter mounds were erected in an area intended to host a local art museum, but since the museum was not built, it was possible for Simonsson to access the land and make alternative use of it. She started her project in early spring, when the mounds were erected with the aid of an excavator. Then she prepared for sowing with a special kind of traditional wheat called Ölandsvete (Öland wheat in English) that was sown on the mounds by a group of school children from the island. The wheat grew and was harvested in late summer. After a full year life cycle the mounds were transformed into ground for grazing sheep (https://experimentelltkulturarv.se/liv-dod-anne-bildspel/; Sandell 2018, 42ff) (Figure 22). 


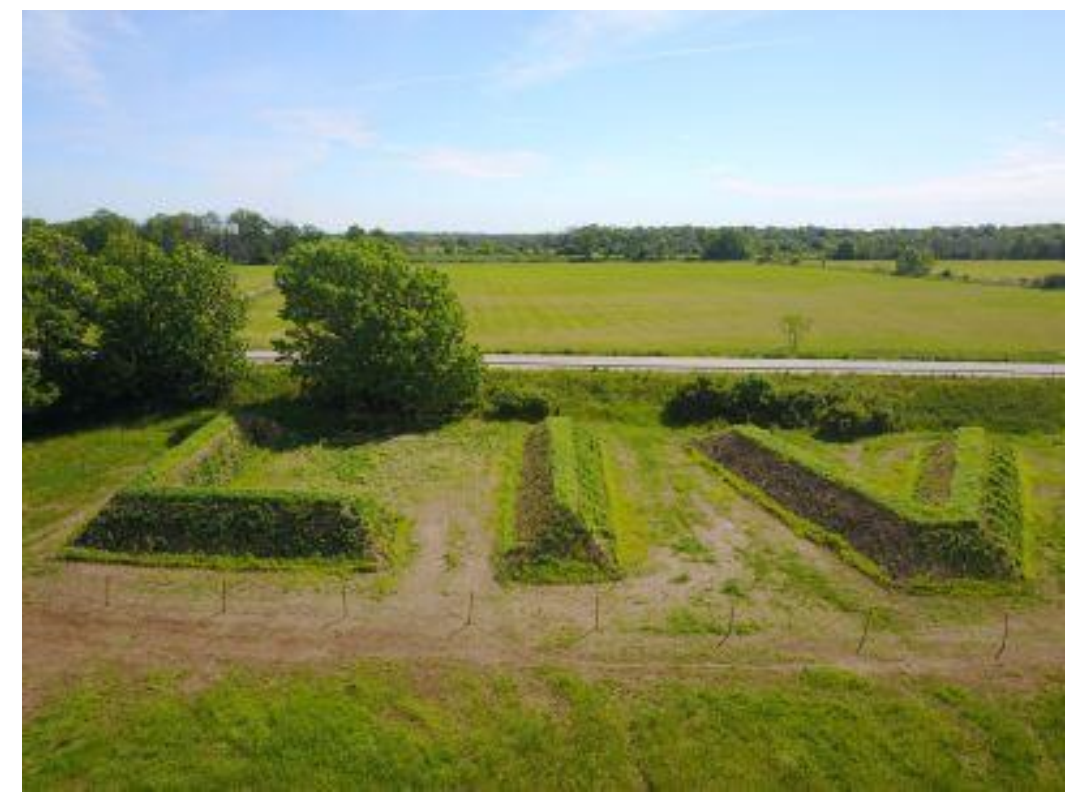

Figure 22: LIV no. 8 (LIFE no. 8 in English) aerial view of Anne Hamrin Simonsson's land art installation near Algutsrum, Öland. Photo by Nils Hamrin, (CAnne Hamrin Simonsson

Bodil Magnusson and Frances Gill took their point of departure in the archaeological site of Sandby fortress and the excavations relating to the massacre that took place there in the year around $470 \mathrm{CE}$. The inhabitants of the fortress were brutally killed during an assault. The whole fortress was left to decay without anyone coming back to bury the dead or even take the valuable objects, which were left in situ for the archaeologists to discover. Magnusson wrote poems and processed photographs of the fortress for display as an installation, Budskap i vinden (Messages in the wind in English), accessible both via a smartphone app on site and through a museum exhibition at the Kalmar county museum (Figure 23). 


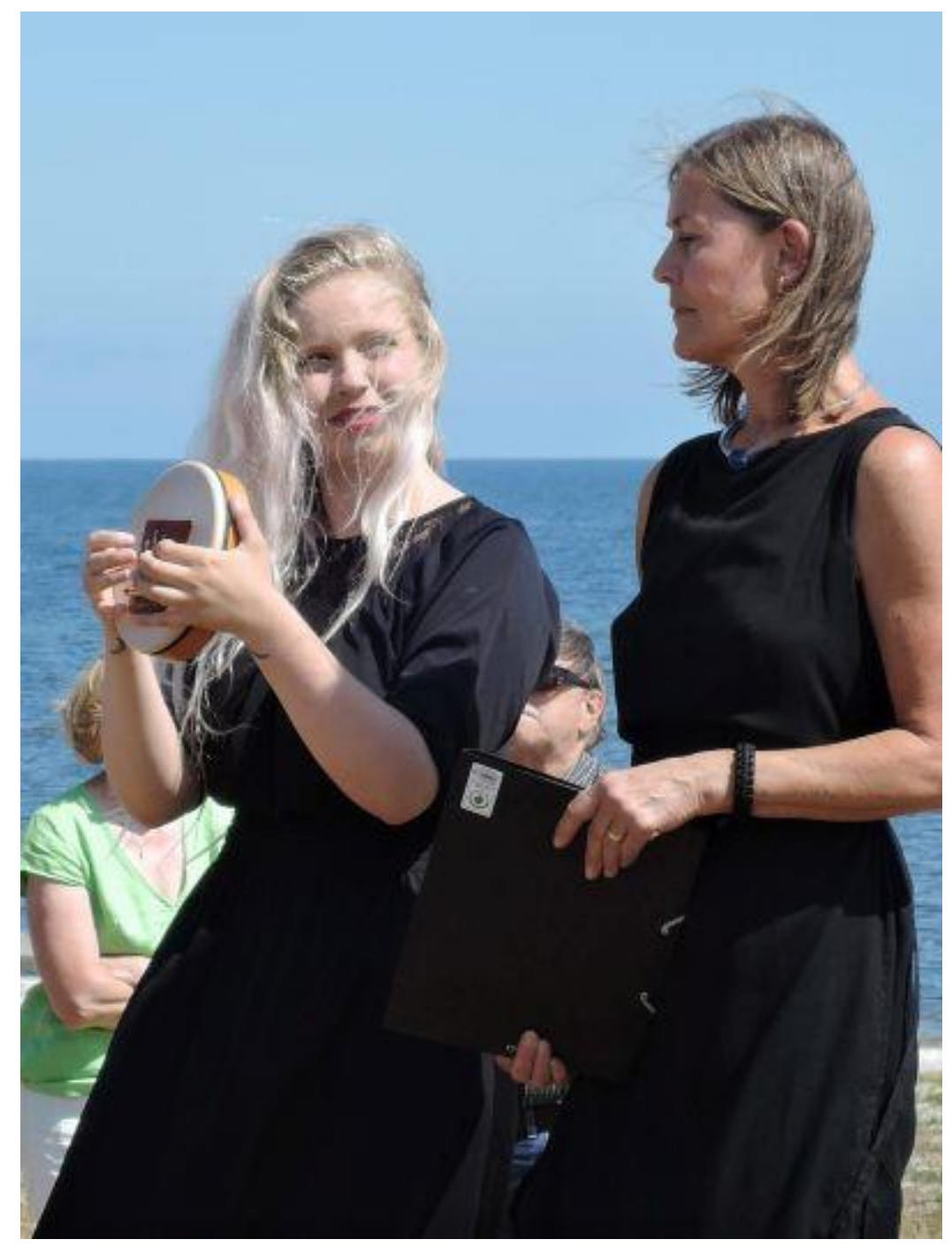

Figure 23: Saga Björling and Bodil Magnusson performing together at Sandby borg summer 2018: music, song/recitation and poetry. Photo by Magnus Ekenstierna 2018

Gill made an art installation, SOUNDmound, and constructed sound sculptures that change character as the visitor moves around inside the fortress. The sounds were created by groups of people during gatherings who were instructed by Gill to create sounds of different kinds, either using objects in the environment, their own bodies, or instruments they had at hand. Gill recorded the sounds and afterwards edited the sound sculptures together. When all the recordings were combined with the layout of the Sandby borg fortress, the visitor walks across the different soundscapes created through each sculpture. The sound changes as visitors walk through certain invisible but audible sculpture areas inside the fortress. The installation can be accessed via a smartphone app on site. Both Gill's and Magnusson's projects take their starting-point in the presentday situation of refugees coming to Europe from war-torn regions in other parts of the world but being denied a full human life and destined to be refugees for most of their lives. The purpose was explicitly to use this specific archaeological site of conflict and difficult heritage to discuss the present-day situation with similar difficulties regarding assault, warfare and persecution (Gill 2020, 81ff) (Figure 24). 


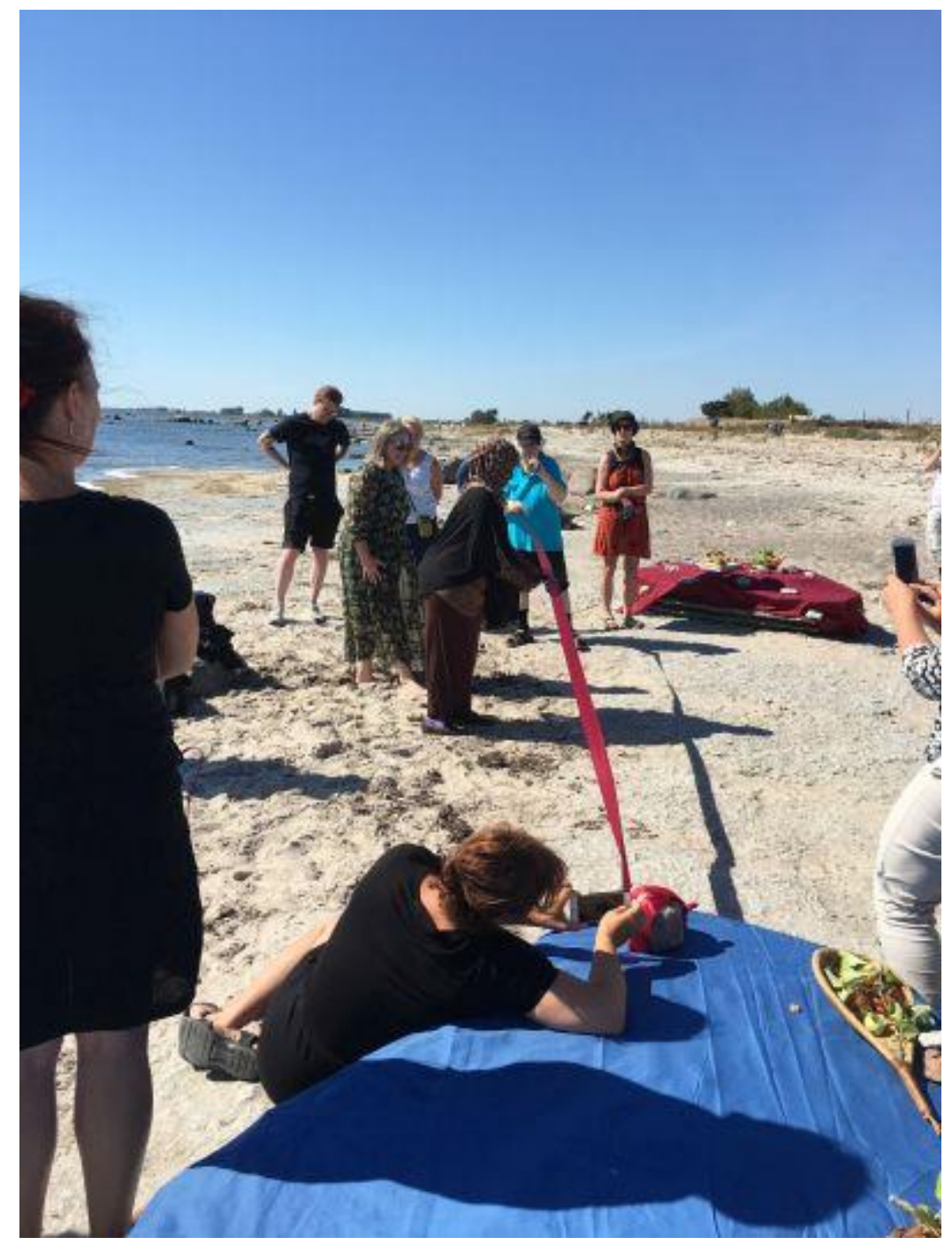

Figure 24: The opening of Frances Gill's SOUNDmound at Sandby borg summer 2018. Photo by Bodil Petersson 2018

Ylva Magnusson made a film project called Konstattack (Art Attack in English) where she used the in situ reconstructed fortress Eketorp as a stand-in for Sandby fortress, as they are similar in structure and layout. Magnusson staged an assault on the fortress, made by artists equipped with brushes, palettes and paint. They painted the walls of the fortress in different colours and with different messages on the importance of art and culture for society. In the film there were two contrasting themes, one with an academic historian, Peter Aronsson, discussing why heritage in general is important for society, the other being the artist Frances Gill, contemplating the mistake she had made by throwing red paint on the wall of the reconstructed fortress while the art attack was performed and filmed. She says it was not right to do so, but that she anyway felt it was justifiable to have done it in order to question and challenge the concepts of archaeology, authenticity and heritage (https://experimentelltkulturarv.se/ylvamagnusson/) (Figure 25). 


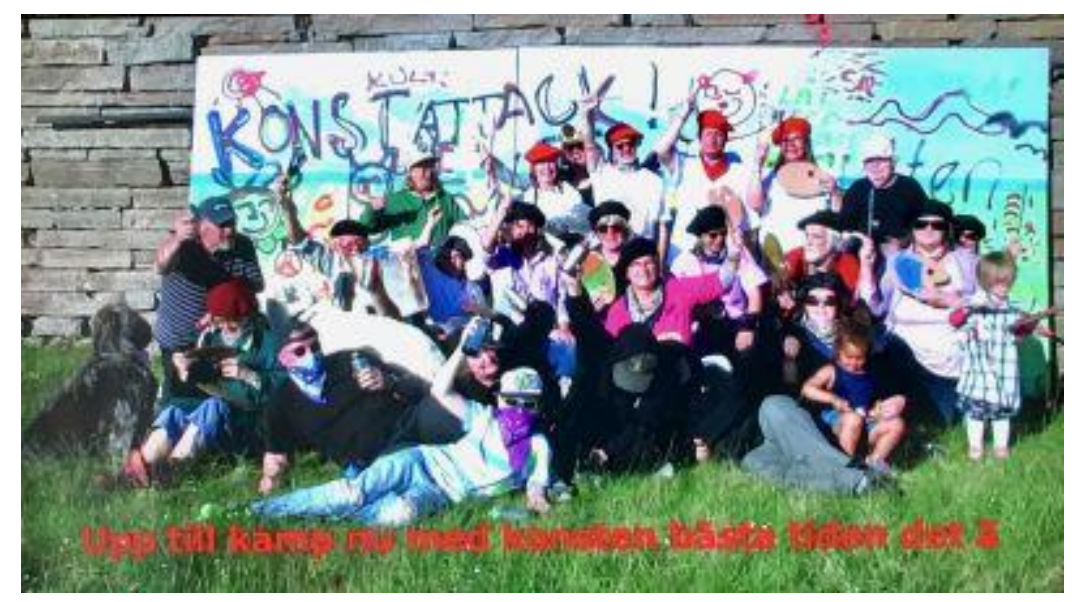

Figure 25: Still from the film Art Attack, with the army of artists attacking the Eketorp fortress with paint. Photo by Ylva Magnusson 2018

\subsection{The Sandby fortress art, archaeology and heritage challenge}

To work consciously in a transdisciplinary way between archaeology and art at a site like Sandby fortress, with its ongoing archaeological excavations, proved a challenge for both the archaeologists and the artists, as well as for the authorities, represented by the county administrative board, whose role is to protect and maintain ancient sites for future generations. Legislation as well as practice and not least a sense of ownership of heritage seemed to collide with the visions of the artists.

During the preparatory collaborative workshops including artists and archaeologists it was hard to convince the archaeologists to take part in embodied workshops where performance was in focus instead of talking, presenting and answering questions. The archaeologists left the workshops when the performance practices commenced. In the same way, the artists felt too much time was devoted to oral presentations and discussions and not enough time to performing. The difference was that the artists took part in the archaeological presentations. As the pattern developed, the project tried to intertwine presentations and performances so that they came in a sequence one after another, so that neither of the groups could escape.

To do artistic work within the framework of a protected archaeological site had its own difficulties. One of the artists, Bodil Magnusson, had the idea of creating a wind shelter made of plexiglass and a bench of limestone, with poems carved into the wall of the shelter or into the stone itself. This idea proved impossible to realise because of the legal rules for protection of cultural heritage sites. The artist had to accept a peripheral location for the artwork, otherwise it would not be possible to erect anything at all near the site. Magnusson decided she wanted her interpretation to be closer to the site. Therefore, the non-intrusive electronic app format was eventually chosen since it could be used in the fortress without leaving any intrusive marks. Another issue developed since the artist wanted to put up a small sign with the app instruction on it, but that was not allowed either, since the county administrative board didn't allow any signs nearby or in the fortress despite having accepted another kind of sign put up by the Swedish National Heritage Board just a few years earlier in the form of an 'information pavilion'. Additionally, the idea of a shelter and a bench wouldn't work because cattle grazing in 
the area would be likely to scratch themselves against the structures and thereby destroy the art work.

The artistic interpretations by Magnusson and Gill were prepared during the years 201618 and eventually presented during summer 2018. The inaugurations attracted local people as well as people visiting the island. The visitors were curious about the archaeological site that had been presented in media as the site of an Iron Age massacre. They wished to take part in the explorations of the artists as well as getting information about the excavations by the archaeologists. Since the artistic and archaeological events didn't happen on the same occasions, people returned to the site several times to inform themselves about both the excavation results and the artistic interpretations.

The technology with the app format in smartphones was an interesting way of working non-intrusively with the site, but the technique was not completely successful. It actually became an obstacle for many people because of the lack of a stable internet connection on site. There were several visitors that didn't manage to access the presentations in the app (Figure 26).

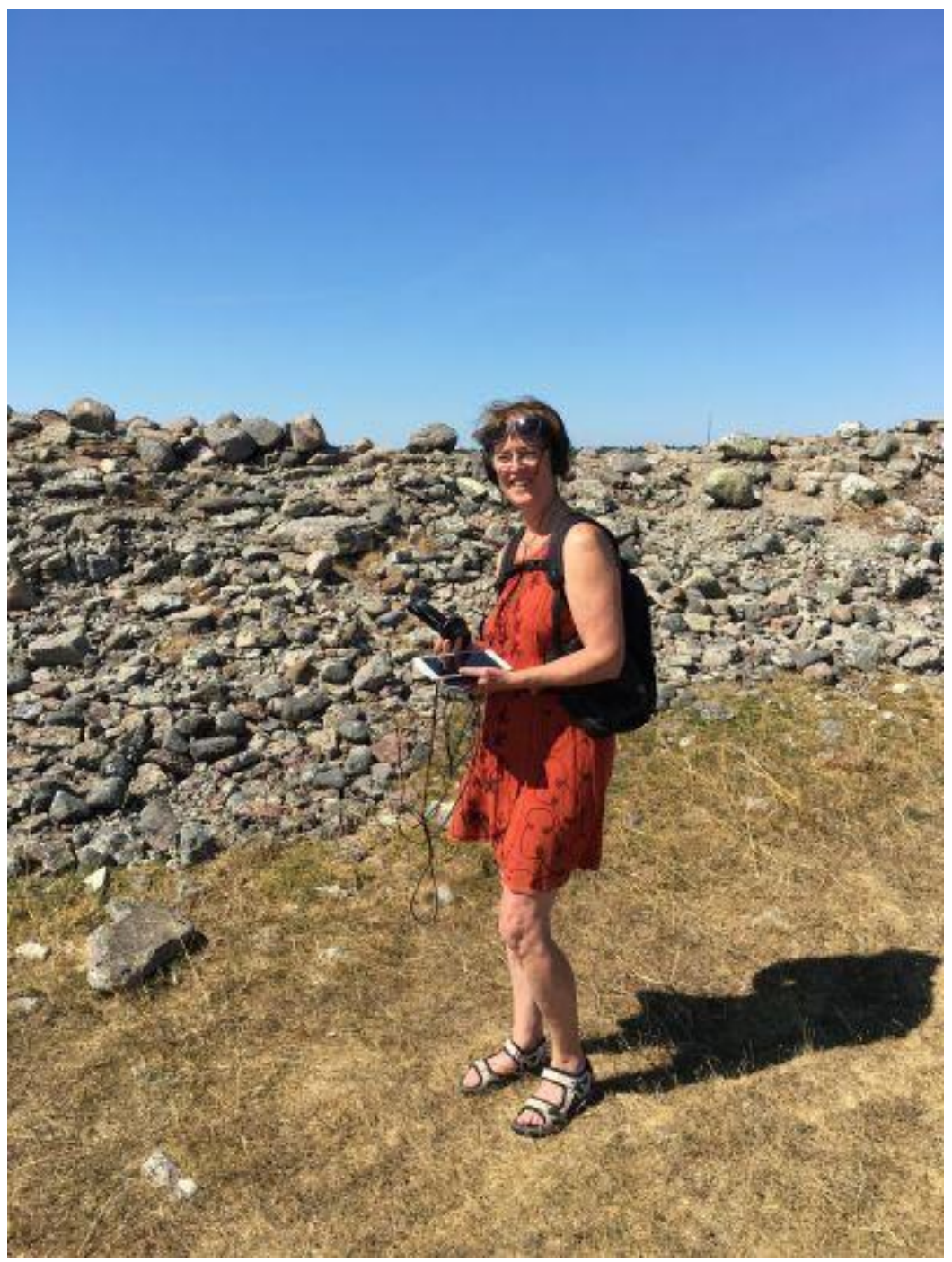

Figure 26: Visitor to Sandby borg with full digital gear taking part of SOUNDmound sound installation. Photo by Bodil Petersson 2018 
There was also an issue about the Sandby fortress 'trademark'. Sandby fortress was, and is, seen as the logo of the Kalmar county museum that they want to protect and use in their marketing campaigns. There was some concern that the artistic interpretations would ruin this.

At the Kalmar county museum where Bodil Magnusson's artwork eventually was also displayed adjacent to the exhibition about Sandby fortress, it was primarily the educational department at the museum (a separate unit not connected with the archaeology department) who realised that an artistic interpretation of the site within the museum could enhance the story of the massacre in the fortress by emotionally connecting the events in the past with what happens here and now in our times. The archaeologists agreed on the addition to the exhibition.

\subsection{Ismantorp fortress - meetings and reconciliation}

The Öland artists' collective Sisters of Sättra initiated the performance of the Filtprojektet (The Blanket Project in English) at Ismantorp fortress, an Ölandic ring fort dating from the Roman Iron Age and Migration period, between the 3rd to mid-6th century CE. The theme connected with this archaeological site was meetings and reconciliation. Ismantorp fortress has been excavated by archaeologists at different periods in the 20th and the early 21 st century. It has been difficult for archaeologists to interpret the fortress and its use. Its use as a fortification has been questioned since it has nine entrances. The number nine further suggests a relation to ritual practice, since the number nine is a holy number in Nordic Ásatrú religion. The most common interpretation of the fortress is a combination of ritual and military function (Andrén 2014 , 102).

Sisters of Sättra were attracted to the site as it brought to mind the idea of a mandala to be coloured by someone. The first depiction of the site that meets the visitor on the way to the fortress is a sign with a drawing made from an aerial viewpoint (Figure 27). 


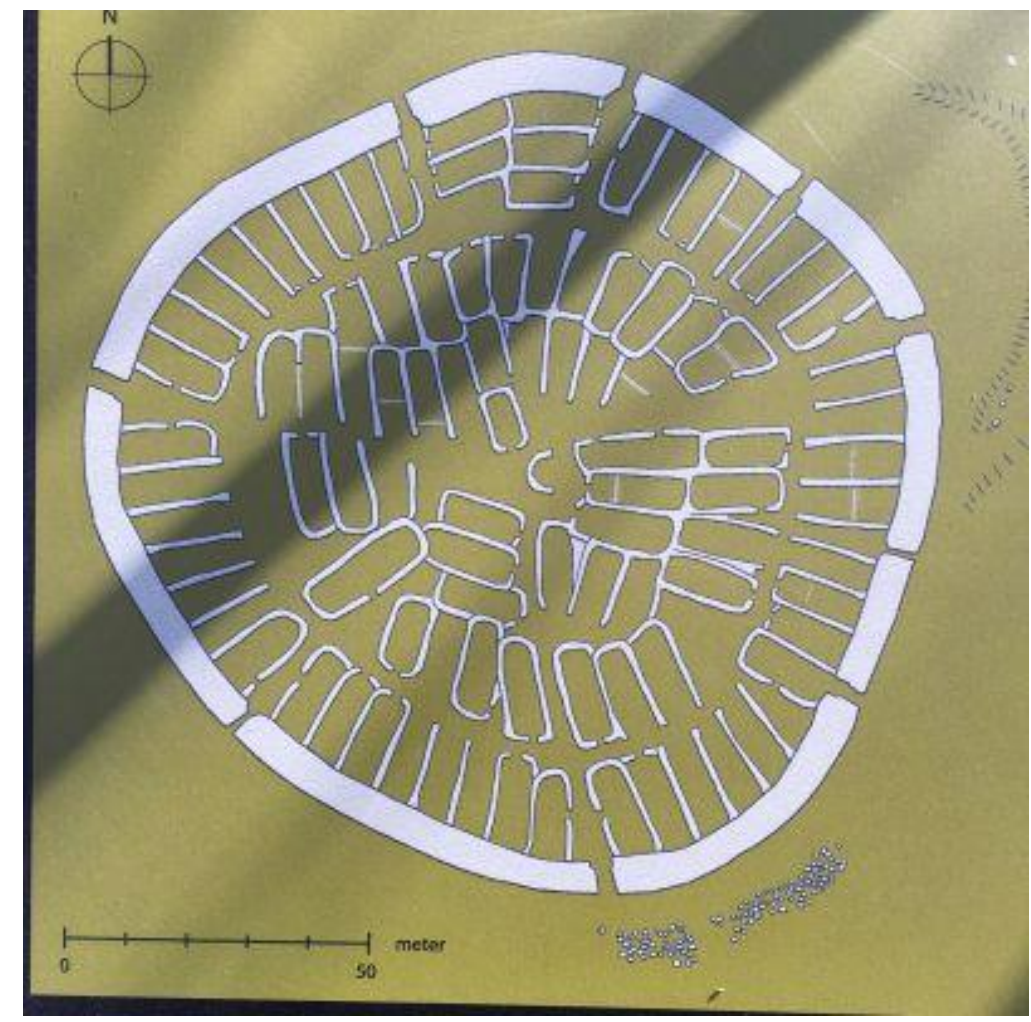

Figure 27: The layout of the fortress as depicted on the information sign nearby Ismantorp fortress. Photo by Bodil Petersson 2018

This aerial view was used by the artists, and eventually a plan to colour the fortress itself was formed (Figure 28).

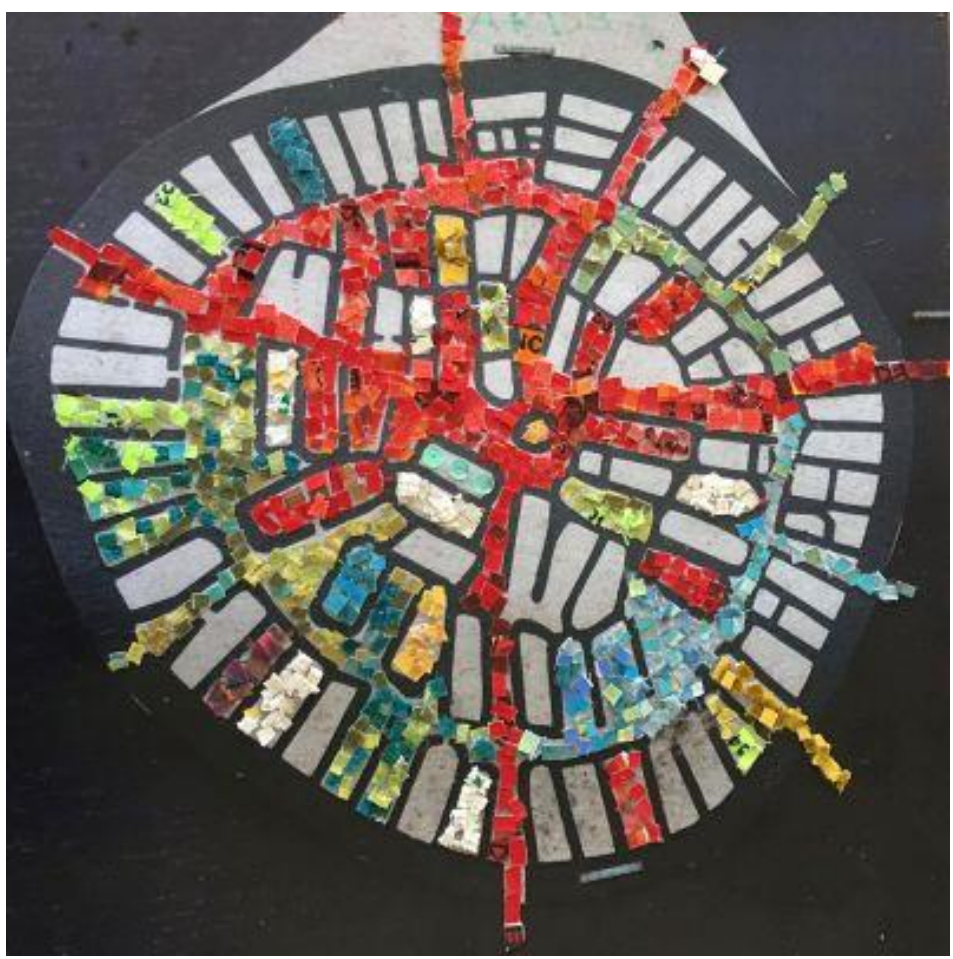

Figure 28: Sisters of Sättra and Kristina Jeppsson's sketch of Ismantorp fortress coloured. Photo by Bodil Petersson 2017 
But how would it be possible to do so without destroying or affecting the site? The solution was to use textiles, specifically blankets. During winter and spring 2016-17, blankets were donated by local people willing to contribute to the project. On a rainy day in the summer of 2017 the performance took place with a hundred participants (Petersson 2019). The idea was to come together at this meeting place and perform an act of reconciliation with a picnic on the blankets, and music (Figure 20).

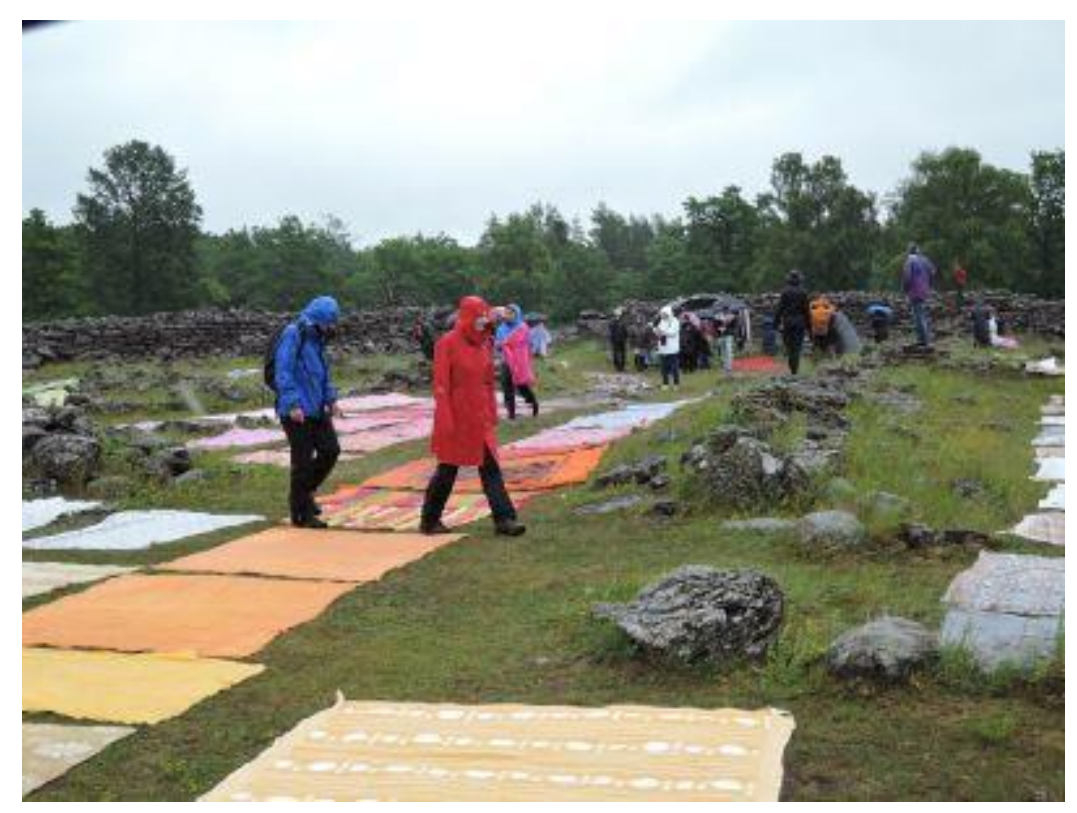

Figure 29: Photo from the blanket project performance day 1 July 2017 . Photo by Jes Wienberg

After the event the blankets were donated to an aid organisation for distribution to anyone in need of blankets. In the same way as the Sandby fortress art and archaeology project connected to today's situation with warfare and refugees scattered over the world, there were thoughts in the same direction in this project. It was not equally emphasised though, because of the somewhat different character of the site and landscape. Ismantorp fortress didn't have the excavated evidence of violence found at Sandby Borg so that aspect wasn't expressed. The site has an aesthetic attractiveness owing to the natural environment, with its rare orchids and trees that reach towards the sky giving character to it in the present.

\subsection{The Ismantorp fortress art, archaeology and heritage challenge}

At Ismantorp fortress there was no ongoing archaeological investigation and therefore no obvious conflict between the practices of archaeologists and artists. Instead, archaeologists connected to the Experimental Heritage project could more freely contribute directly to the art project without having difficulties with an individual sense of 'ownership', with museum branding or protection of interpretations. The ground of Ismantorp was literally less loaded with conflict. The site has also been used frequently for different purposes involving music, theatre and performance. Therefore the ground was already prepared for further cultural activities; the place wasn't in itself foreign to events of a cultural and artistic character. 
The act of having a picnic in the landscape was a way for the involved artists and archaeologists to reload the site with new content. It was a revival of the site as a meeting ground for people from different places and cultures. The idea of being in times of migration both then, in the Iron Age, and now, in our present times of migration, was an undercurrent to the project. The project can be seen as a creation of a ritual that connects past and present traditions and where the site is central to the idea.

\subsection{Blue Maiden, island of myths}

Artist Linda Persson focused her work on the island Blå Jungfrun (Blue Maiden in English), an island of myths situated between Öland and mainland Sweden and said to be the place where the witches and the devil meet every year at Easter time to party and do all kinds of unspeakable things. It is also an island known for stormy waters and many sunken ships throughout history. Persson's explorations resulted in a film, Astral women, about three generations of women witches on the island (Figure 30).

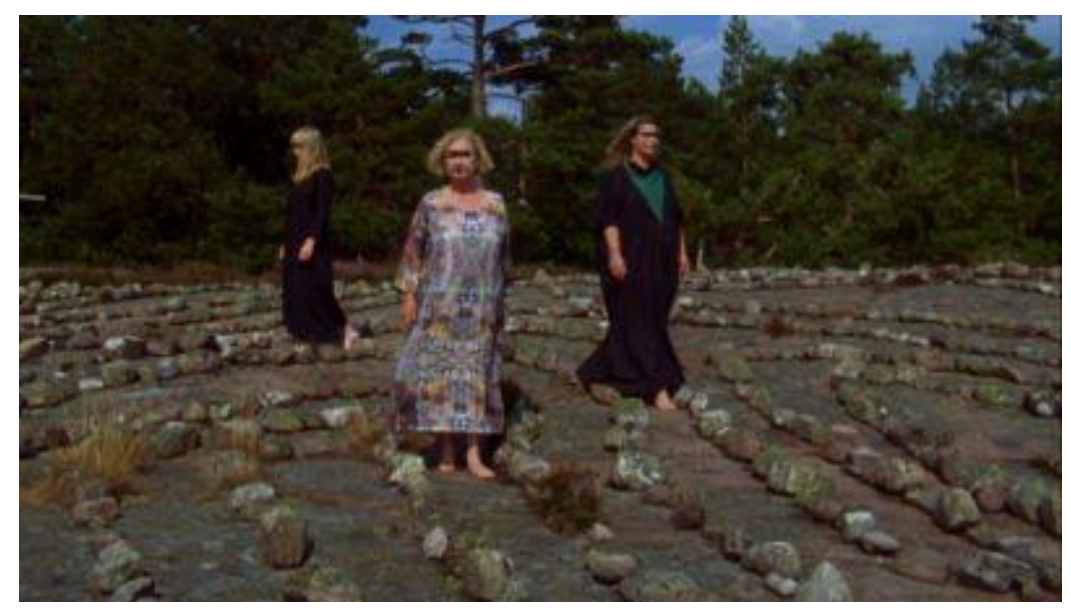

Figure 30: Still from Linda Persson's film Astral Women, recorded on the island Blå Jungfrun with three generations of women representing the tradition of females being connected to the island. Photo by Linda Persson

It also resulted in stories about the actual giving back of stones to the island, stones that are said to bring bad luck to the owner since they are brought away from this bewitched island. Most of the stones returned are accompanied by letters that describe the effects of the bad luck of the stones. The municipality of Oskarshamn takes care of the stones and letters, and one of the skippers that brings tourists to the island has a special responsibility to return the stones (Figures 31-32). 


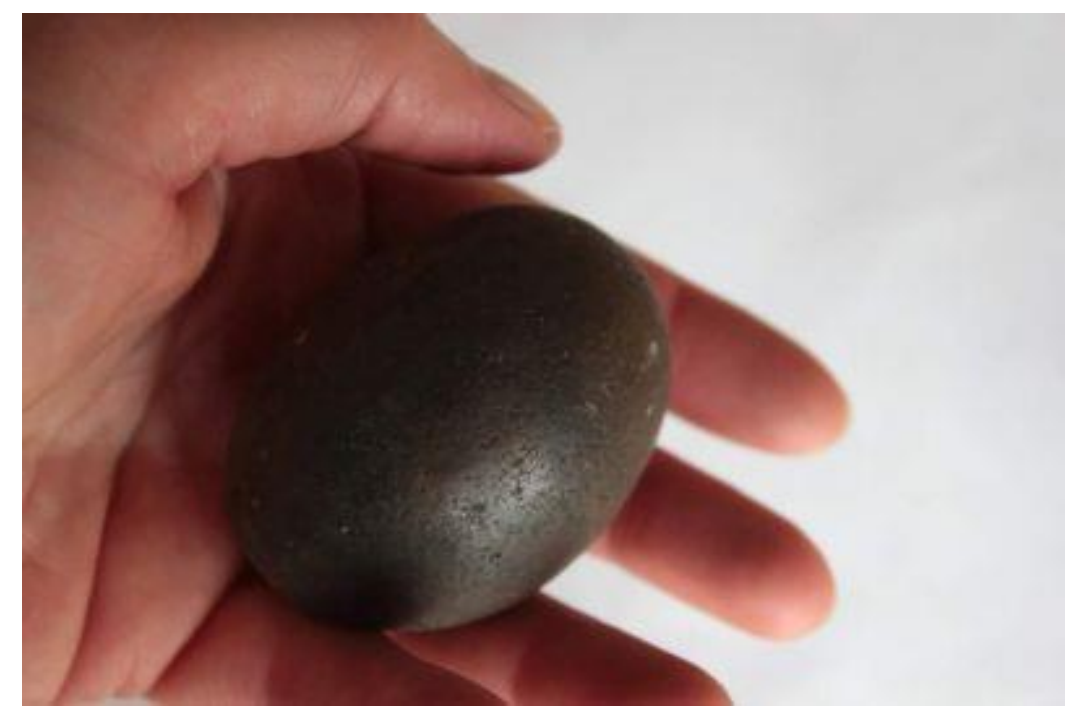

Figure 31: Photo of a returned cursed stone to Blå Jungfrun. Photo by Linda Persson

Parallel to Linda Persson's efforts there were ongoing research excavations on the island made by archaeologists Anna-Karin Andersson, Ludvig Papmehl-Dufay and Kenneth Alexandersson from Kalmar county museum. The archaeologists focused on the early phases of the island, with some seasonal settlements from the Mesolithic. They also found evidence of seal hunting (Alexandersson et al. 2014). Since archaeologist Anna-Karin Andersson is also an author of books for children and young people, rather than competition concerning interpretation there was instead an interest in storytelling that unfolded itself between artist and archaeologists. Andersson has published a book on Blå Jungfrun as well, with the title I skuggan av Blå Jungfrun (In the shadow of the Blue Maiden in English). In the network there was another author, Anna Winberg, who had written a novel about Blå Jungfrun with the title Jungfruön (The Maiden Island in English). The myths of course preceded archaeology on the island, and that fact itself probably made the archaeologists aware of a slightly different situation than the one at Sandby fortress, where the story of the massacre unfolded as the archaeologists' work proceeded. 
Scilla.

Heals me; att attar limn

dennis stem till

Blu jungfurn. Toy den fer

naigra air sedan, utah lav,

och all has basra blivet

eft elende. Snälla hide mi;

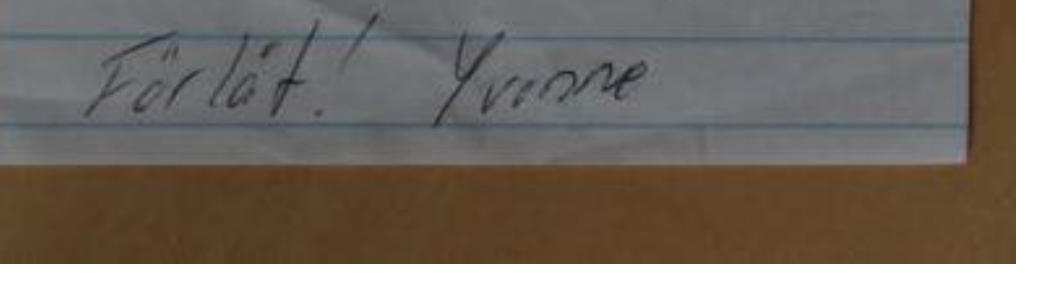

Figure 32: Photo of letter attached to the returning of a cursed stone to Blå Jungfrun. Text as follows: 'Please! Help me return this stone to Blå Jungfrun. Took it some years ago, without permission, and everything has just turned into misery. Please help me. I am sorry! Yvonne'. Photo by Linda Person

5.8 Blue Maiden art, archaeology and heritage challenge

As an interesting contrast to the Sandby fortress collaborations, the work between archaeologists and artists in this more mythologically orientated setting was somewhat more flowing. It was as if the archaeologists involved found it easier to accept and agree upon the concept of mixing art and archaeology in a setting already permeated by myth. And there seemed to be no conflict of interest concerning interpretations, since the archaeologists contributed with interpretations from a period that probably was 
conceived of as preceding the phase of the witches that was the main interest from the artist's point of view.

When it comes to Blå Jungfrun as representing archaeology or being a more general heritage site, it is clear that it is conceived of as the latter. The mythological status of the island has made it well known not only among archaeologists. Therefore, the archaeologists have no exclusive right to interpretation. This might also contribute to the different reactions and discussions concerning the island within the project. In this respect it differs in an obvious way from, for example, the site of Sandby Borg that in a sense became an archaeological trademark.

\section{9 Öland water and springs}

Annika Grünwaldt Svensson was one of the artists focusing on Öland water bodies and springs. Svensson decided to make some kind of artistic interpretation of the mythic creature called the brook horse, known in parts of European mythology as an animal that enticed children to come near water and then he took them on his back and drowned them. She made a metal sound sculpture in the shape of a horse. The placing of the sculpture was contested both among the group of artists in the project and by the county administrative board. The first place chosen by the artist was located by a spring within a nature reserve, but the siting of the sculpture there couldn't be allowed because it is a protected area. The second place suggested for the sculpture was next to Gärdslösa church on eastern Öland. The church-council and the vicar were eventually convinced that it was a good idea to put the sculpture in a park south of the church. There was already a memorial stone to the poet Erik Johan Stagnelius, who once wrote a poem on another attractive water creature, Näcken, who sits in the water and plays the violin, thereby enticing young women to get into the water where they are drowned.

An unexpected discussion started as the local Stagnelius literary society strongly opposed the brook horse sound sculpture. The artist and the Experimental Heritage project were attacked in letters to the editor in the local newspaper Ölandsbladet (Järnegard 2017). The brook horse was described as something odd and alien to the island of Öland and its local mythology. The poet Stagnelius grew up in the vicarage by Gärdslösa church and the horse was therefore seen as an intruder on his home ground. The horse, and its placing south of the church, was described as an 'attack'. The horse was described as a foreigner belonging to the landscape of Skåne in the very south of Sweden. The project was accused of bringing foreign matter to the island. However, throughout the whole turbulence the vicar and the local church council supported the brook horse sculpture (Figure 33). 


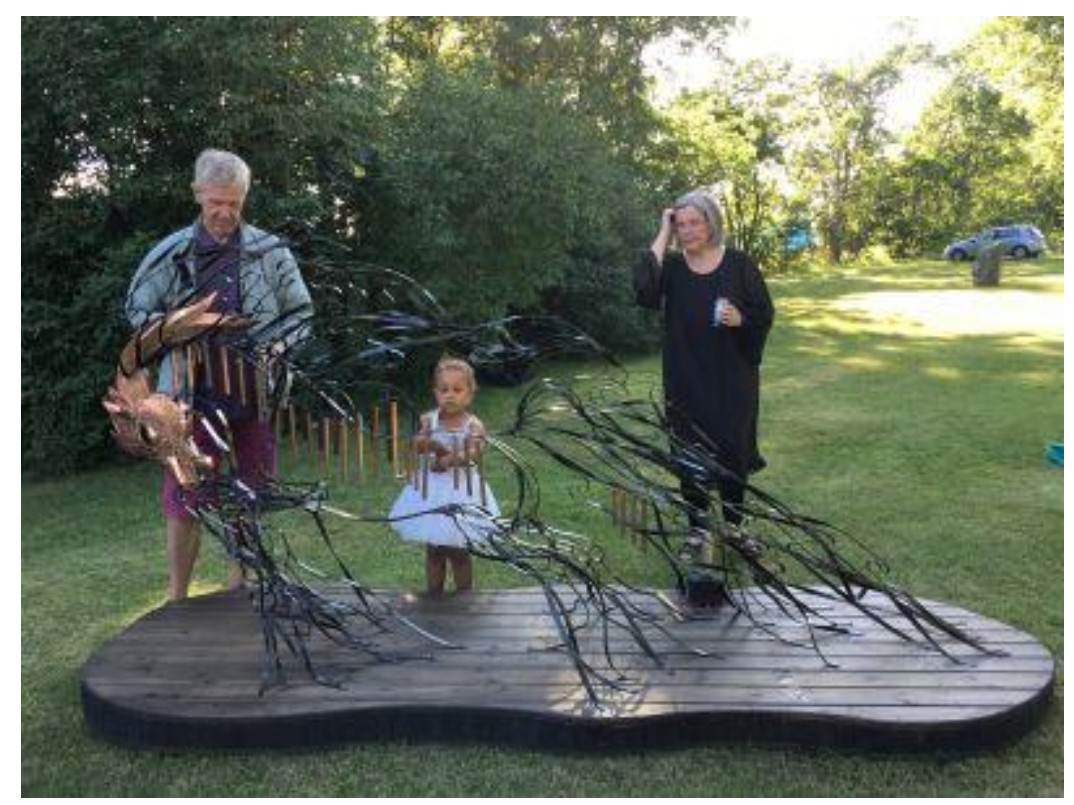

Figure 33: The brook horse south of Gärdslösa church, Öland. Photo by Bodil Petersson 2017

Anita Andersson initiated the project Från källa till källa (From spring to spring in English) within the water and springs theme. She performed a textile-based interpretation of the spring and its contents of history and heritage interwoven with our present need of water in the context of climate change and recurring lack of fresh water on the island of Öland in recent years. With her project, performed both in the landscape near the Sjukällorna springs on Öland and at the local history museum of Himmelsberga, she and a group working with her discussed the water situation both past and present. The work with springs integrated local history, the hydrology on Öland and artistic work, history, archaeology and biology. Thereby this project came to be the one that actually combined the most diverse fields of interest and also the one that had a natural connection with interests of the local community. As a consequence of the engagement, questions were raised about present-day handling of springs and water and discussion on why we should preserve these ancient culture environments, and who is supposed to do it (Figure 34). 


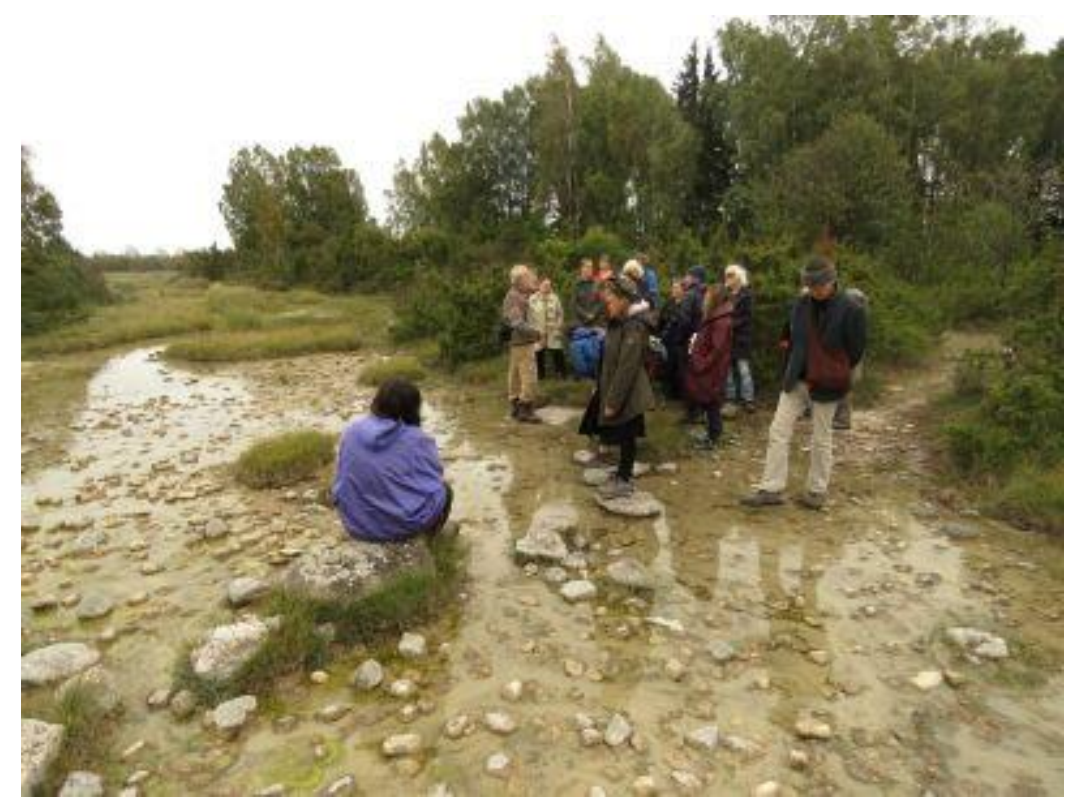

Figure 34: Irish-Swedish Experimental Heritage visit to Sjukällorna, Öland. Photo by Michael Walsh 2018

\subsection{0 Öland water and springs art, archaeology and heritage challenge}

In relation to the brook horse there was little or no discussion between archaeologists and artists since very few archaeologists in the project felt any ownership of the water creatures, poems or to the sites relating to water and springs, even if several of the water sites also contain archaeological remains. There was no tension between archaeologists and artists, so the transfer of traditions between art and archaeology worked out in a good way. Even the county administrative board were involved with a hydrologist, and she contributed her own knowledge to the project as a whole.

As part of the general interest from the participants in the project working with water and springs on Öland, there was a tendency to feel that the responsibility for protecting and preserving the springs lay with the bureaucracy. The project group focusing on the Öland water and springs decided to work with the idea of protecting and preserving the specific area of springs called Sjukällorna. The county administrative board was generally positive towards the initiative, but when it came close to implementation there was some undefined resistance to the public engagement. Lack of money to fund the activities was one explicit reason mentioned, but it was obvious that the county administrative board responsible for the nature reserve containing the springs was sceptical, since the initiative came from outside the board itself, and it was not a municipality-led activity either. Since the protection and preservation of this kind of area actually is a responsibility of the county administrative board, they couldn't completely ignore the initiative either: they could on the other hand choose to do nothing, and that was what seemingly prevented things from happening despite the fact that there were artists, culture workers, hydrologists and archaeologists involved, and the skills needed were available. 


\subsection{Transferable experiences}

The description and discussion of this work on Öland are made for the purpose of transferring experiences from the Öland project to the Irish-Swedish ongoing collaborations. There are some conclusions that can be drawn regarding transdisciplinary work that are of interest. These conclusions have to do with relationships in different contexts such as:

- between artists and archaeologists and the transdisciplinary ambition from both sides

between the project and authorities such as museums and the county administrative board

- between the project and the local community

\subsubsection{Artists and archaeologists}

One experience from the Öland-based project was that the connection between artistic and archaeological thinking was not subsequently analysed or deepened sufficiently. One hindrance was some of the archaeologists' loyalty to their institutional perspectives and practices, so that they couldn't really free themselves from institutionalised thinking. Another reason for the somewhat shallow collaborations in some parts had to do with the financing of the archaeologists. The artists got a fixed amount of money to do their artistic interpretations, but the archaeologists were paid only now and then for shorter contributions and participation in workshops. There would have been more incentive for deepened collaboration if the archaeologists had also been paid continuously for their work throughout the project. This shows how the socio-economic system plays an important role in a project like this, as it makes it difficult to create an equal situation between artists and archaeologists. Financial expectations also differ between the groups of archaeologists and artists respectively, and on an individual basis depending upon the degree of establishment of the individual.

Surprisingly, as the practices of both artists and archaeologists in some sense are embodied practices, the workshop collaborations didn't always succeed in integrating practices between the groups. One reason for this might have been that artists are more aware of the process, while the work archaeologists do is just their path towards an ultimate end result and reporting of the act of excavating and the interpretation of the past. The archaeologists' sharing was preconceived by themselves as being the sharing of end results of, for example, an excavation.

The most successful collaborations that could keep an open-ended attitude towards a partly unknown process were those where the archaeologists had no knowledgeprestige to lose and where there was a common interest in the myths and rituals connected with a site (for example Blå Jungfrun). It was also definitely helpful when the archaeologists and/or artists involved had some experience of the other practice either themselves or in relation to their previous work.

As a reflection relating to the difficulty of integrating archaeological and artistic work, archaeologist Doug Bailey's observation might be of some importance. He sees the 
reluctance of archaeologists to enter artistic work as a consequence of the critique that is and has been directed towards archaeologists that have entered into some kind of artistic practice. The expectations placed upon archaeologists are to do something archaeological, not to be artists:

I took the opportunity that the project offered to explore the challenges and opportunities that might come from recording and working on emptiness and absence through the medium of photography. I was happy with the results, though in the follow-up seminar where participants presented their work, the most frequent comment I received was: "Why didn't you do something archaeological?". Labelled as archaeologist, I was expected to perform with trowel and Harris Matrix. (Bailey 2017, 248)

\subsubsection{Project and authorities}

There was some suspicion as a consequence of the project statement to stand outside established institutions and work directly in the landscape. The museums probably felt this statement as a critique towards established actors in this field of art and heritage, and it was. At the same time several artists within the project had ambitions to be accepted by and be exhibited at the art institution involved, so there was a kind of ambivalent relationship between institution and individuals the whole way through. There was a proud feeling that the project actually managed to stand free from institutions and despite this attract their interest, but at the same time a certain delicacy was demanded from both parts, and in fact that was successful with both Kalmar art museum and Kalmar county museum.

The relationship with the authorities responsible for aspects of preservation and care for the natural and cultural heritage that was in focus in the different parts of the project was obviously problematic. Even if the signals in meetings and other contacts from authorities such as the county administrative board were generally positive ones, there must have been some underlying suspicion since practically all initiatives to start a process of caring engagement from the group of artists and archaeologists together with community groups were prevented by 'non-support'. What this means is that the involved authorities agreed that the initiatives were good and interesting but when it came to allowing action or grant money, it just didn't happen. Money seemed to go primarily to initiatives where people already had connections - for example, the municipalities of Mörbylånga or Borgholm or if the county administrative board was already involved through some of their employees. As this project was in a way disconnected from the authorities it might have affected how the different project strands were understood. Even when those involved had lots of meetings and engagements with the authorities, it didn't really change this attitude.

\subsubsection{Project and local communities}

In the relationship between the project and the local communities, the project was in a way predestined to be connected to a certain group of very active cultural workers and local artists formed as a group called Kulturföreningen Karneval (The Culture Association Carnival in English) and a sub-group of this association in a collaboration with Kalmar art museum and Linnaeus University called Kulturell Tankesmedja (Cultural Think Tank in English). The local network of $c$. 200 people was located primarily on the southern part of the island, so the connection with the north was less successful, even if several of the project collaborators were based in the northern part of the island. This 
also had to do with the island being divided into the two municipalities of Borgholm in the north and Mörbylånga in the south, where Mörbylånga had somewhat more engagement in matters concerning culture and heritage than Borgholm. Possible explanations might be that more artists choose to live in the southern part of Öland, and that southern Öland contains the world heritage site. In general regarding the island then, the fact is that the southern part is more artistically orientated in a sense than the northern part.

As a consequence of the collaboration with Kulturföreningen Karneval, the project didn't connect with other groups of somewhat younger artists organised in other associations. Instead it developed rather good contacts with several local history societies that took part in the activities and also contributed with local stories and knowledge about places and events, as well as helping to get in touch with people who knew a lot about place names.

We now turn to the ongoing research at the intersection of art and archaeology in an Irish-Swedish setting.

\section{Ongoing Irish-Swedish Explorations}

\subsection{Landscapes and the Irish-Swedish connection}

The Clare and Öland areas of Kilshanny and Karum chosen for the Irish-Swedish explorations are introduced below. Here we explain why these specific areas are the focus of this project. They are geographically separated but in spite of this they carry similar traits such as the presence of limestone and a location close by the sea, as well as a long history. Stone and water are themes of the project. The rural character of the landscapes is an important point. The chosen landscapes have retained their features representing different periods of time just because of their rural and therefore in part unexploited character. Traces of different eras are present in the form of ancient monuments and archaeological landscapes. The areas have been more added to, layered rather than reshaped in their character. The richness of the multitemporal is possible to access as a consequence of the rural character.

\subsection{Kilshanny: a place between}

The road from the main market-town of North Clare, Ennistymon, to the Victorian spatown of Lisdoonvarna passes through Kilshanny, a small village as well as a civil parish in County Clare (Figure 35). 


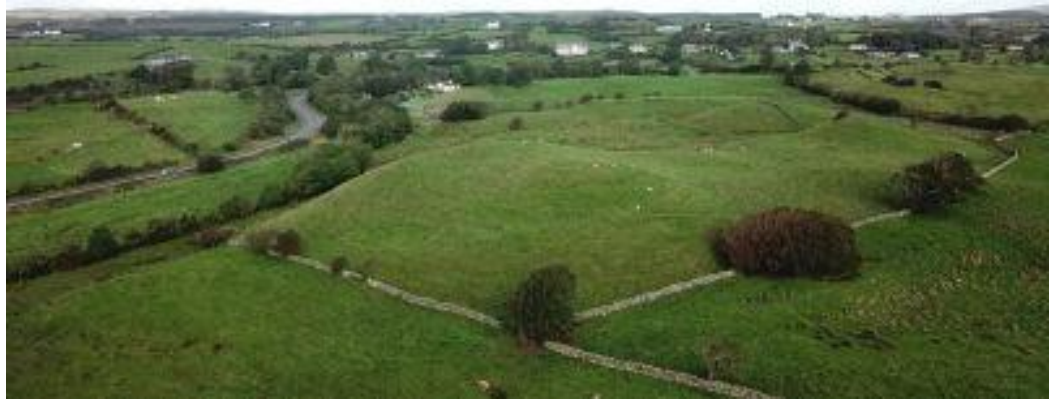

Figure 35: Aerial photo overview of Kilshanny parish and the road, with a ring-barrow visible in the foreground. Photo: Matthew Kelly 2019

There is a pub by the side of the road (Figure 36), and formerly there was a shop. A church built in the 1890s and the parish national school are on side roads off the main road; it would be easy to pass through Kilshanny without being aware of it.

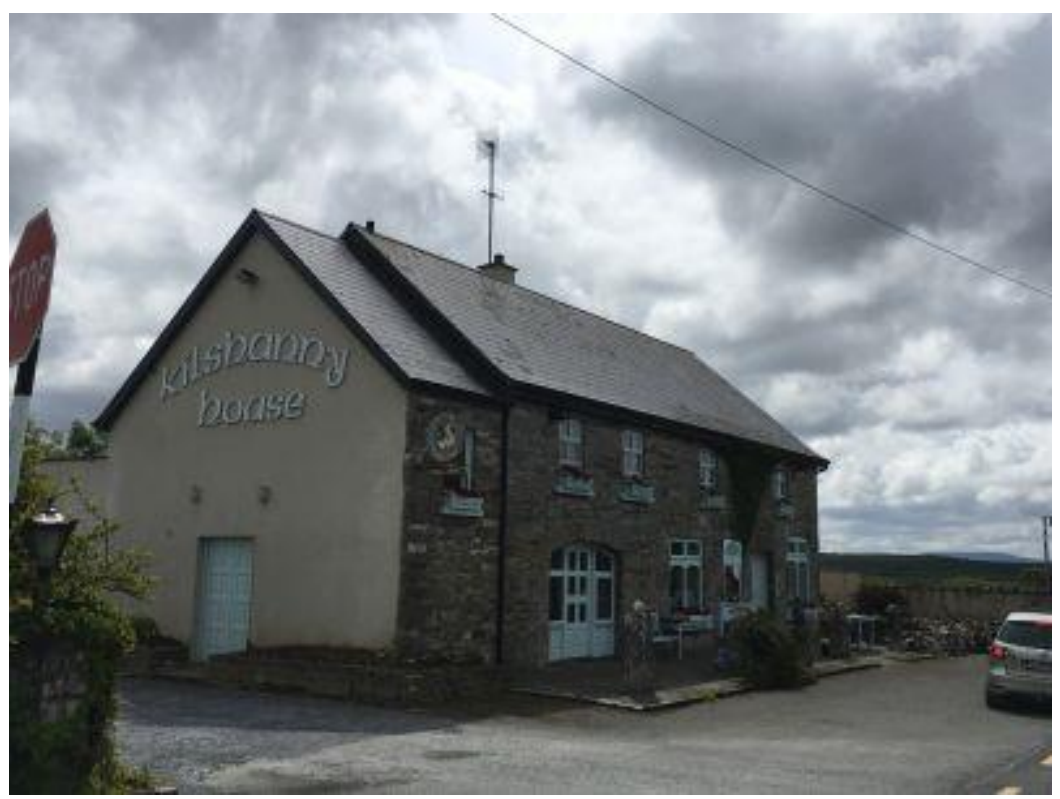

Figure 36: The pub in Kilshanny. Photo by Bodil Petersson 2019

The River Dealagh flows through the parish (Figure 37), connecting Lough Goller on the northern boundary of the parish with the sea in Liscannor Bay just to the west, so the parish, as well as being on the road between the two main towns of North Clare, lies between lake and sea. 


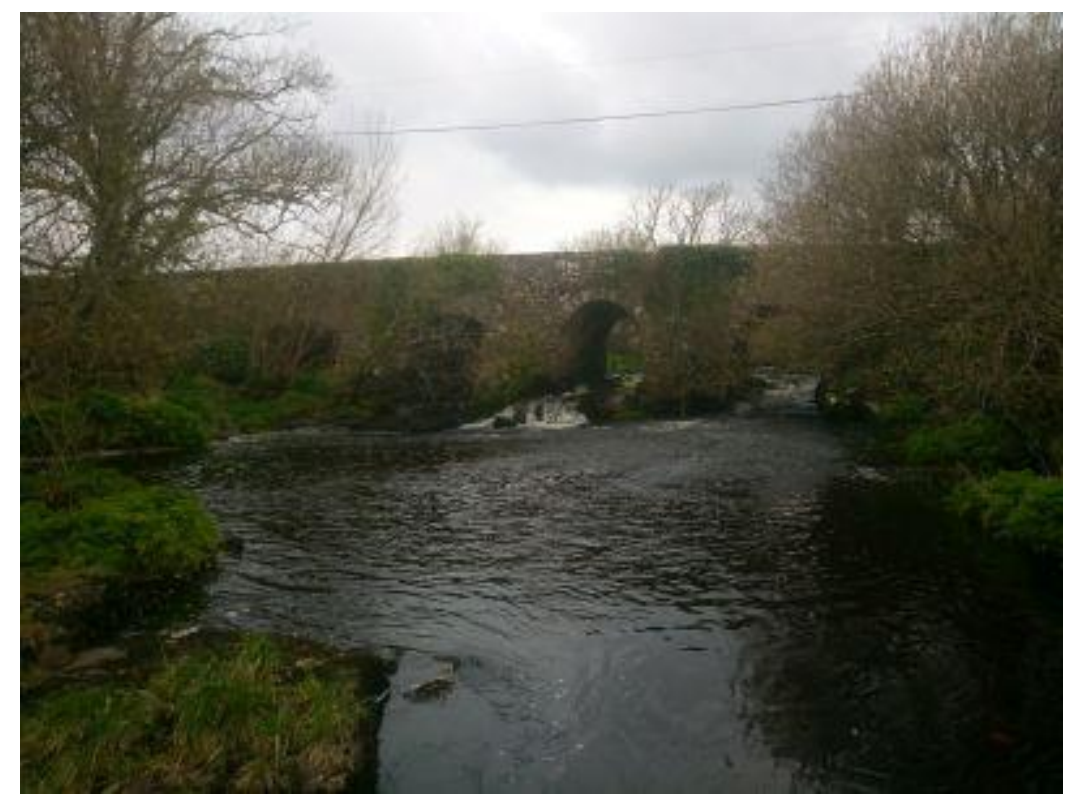

Figure 37: The River Dealagh at Derry Bridge near Kilshanny. Photo: Danny Burke 2019

Kilfenora diocese, in which the parish of Kilshanny is located, was established in 1152 and the boundaries of this diocese are thought largely to coincide with those of the former Kingdom of Corcomroe. The cathedral of Kilfenora is located in the parish just east of Kilshanny, while Dough Castle, seat of the rulers of the Corcomroe, is to the west on the estuary of the Dealagh. Again, we see that Kilshanny is located between, in this case between the seat of the religious ruler and that of the secular ruler.

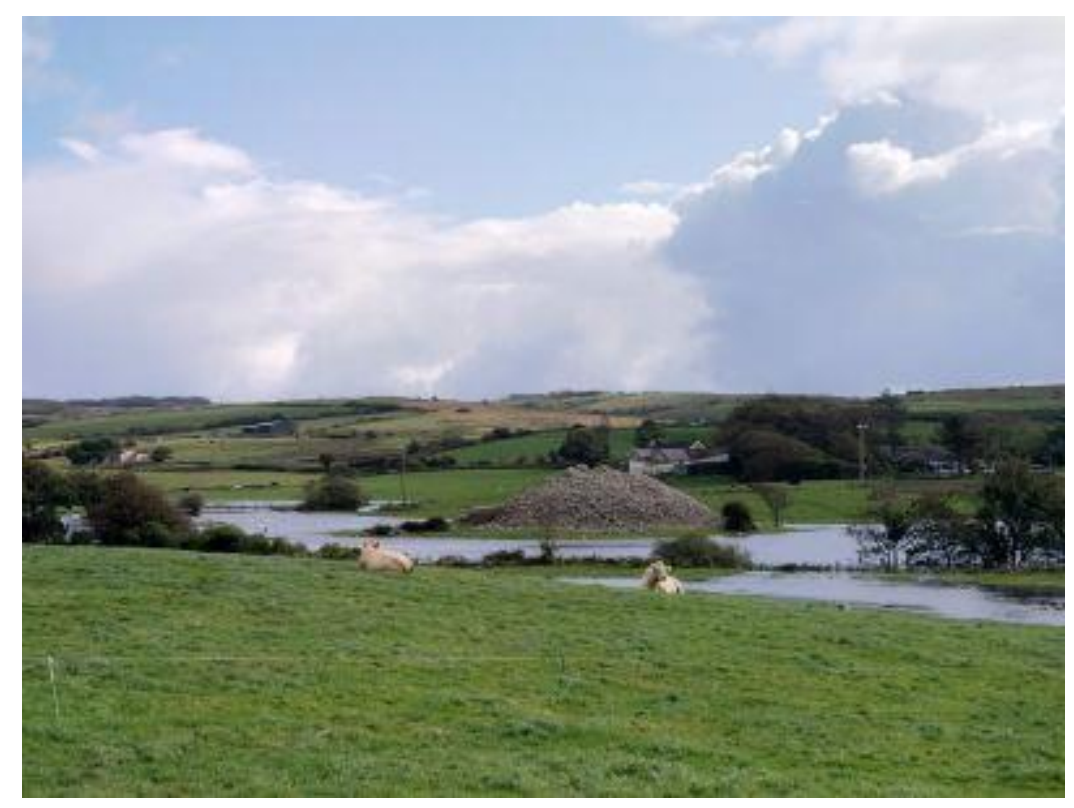

Figure 38: The large Carn Connachtach centrally placed in the middle of Kilshanny parish. Photo by Danny Burke 2019

As well as these in-between elements, Kilshanny is rich in archaeological monuments: a very large cairn (Figure 38), several ring-barrows (Figure 39), a monastic settlement and a holy well (Figure 40): the ensemble amounting to what could be interpreted as a ritual landscape. As well as these ritual monuments there are secular monuments: several 
ringforts and a tower-house and inhabited dwellings of differing ages. So, as well as being a place between places, Kilshanny is a place stretching between times: given its good agricultural land and its range of monuments we can be sure that this piece of land lies between us in the here-and-now and the Irish Neolithic, and probably even the Mesolithic given the presence of salmonid fish species in the Dealagh river.

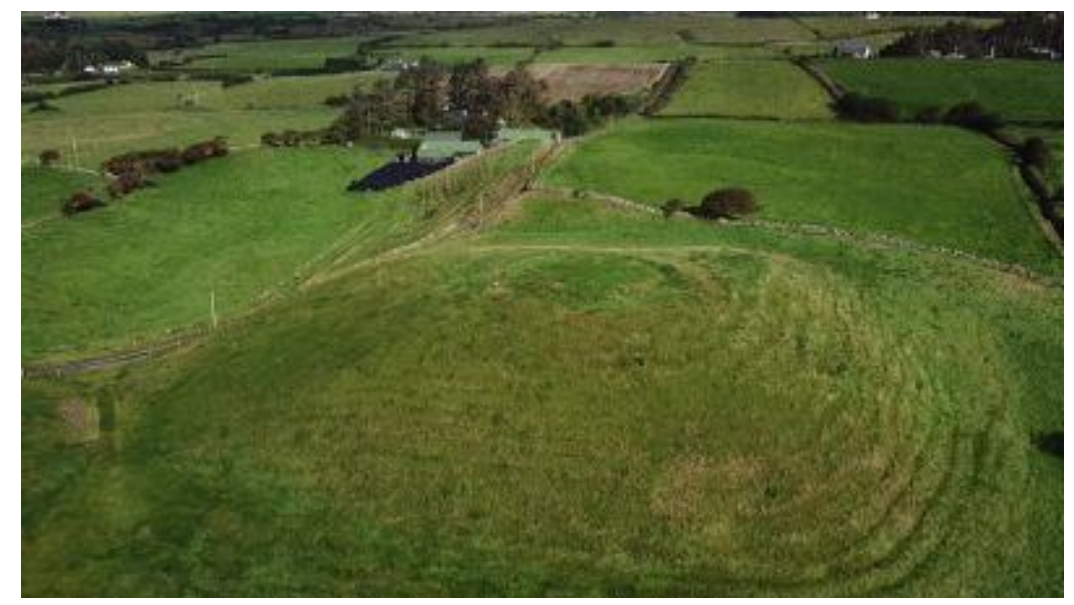

Figure 39: A ring-barrow in Kilshanny parish. Photo by Matthew Kelly 2019

It has been suggested that the cairn in the heart of the parish was the site of the inauguration of the kings of Corcomroe, and the same cairn is also noted in stories as the location where a mythological péist, a sea-snake or perhaps a giant eel, conceivably a symbol of the pre-Christian religion, was killed next to the Dealagh river after being hunted from the sea through the green hills of the parish. So finally we can see Kilshanny as being a place between realities, between the historical and the mythic.

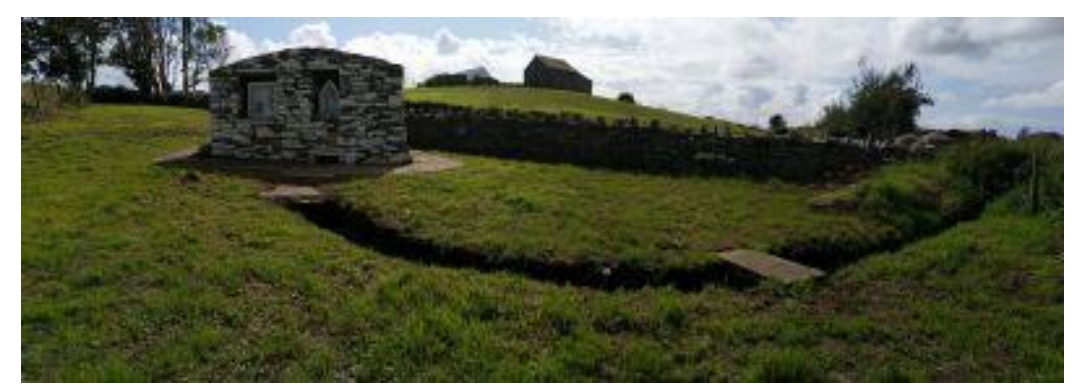

Figure 40: St Augustine's holy well in Kilshanny parish. Photo by Danny Burke 2019

\subsection{Karum: from inland to sea}

About halfway along the north-south axis of the island of Öland it is possible to leave the north-south west coast road at the supermarket of Rälla and drive further inland into the landscape of Karum, situated close to the municipality of Sättra. Karum is the name of a part of the alvar-type landscape on Öland, the place name indicating an open area or room. It is also the name of a nature reserve covering almost the same area. Sättra was only established around the year 1900 and developed thereafter following industrialisation and the establishment of the railway on the island. It contains the remnants of a mechanical workshop, a motorised mill, an old school building now turned into an arts centre, and an old dairy converted into a combined restaurant and B\&B. Sättra is both a farming community and an attractive village for artists who have settled 
there during the last decade or so. The contrast is obvious between the formerly industrial Sättra on the one hand, and on the other hand its surrounding alvar landscape of Karum containing traces and monuments from the Bronze Age and onwards, indications of settlement in this area for a very long time.

At the entrance to the Karum landscape from the west, the first thing to be seen is a group of characteristic Öland standing stones named Odins flisor, meaning the stones of Odin (Figure 41).

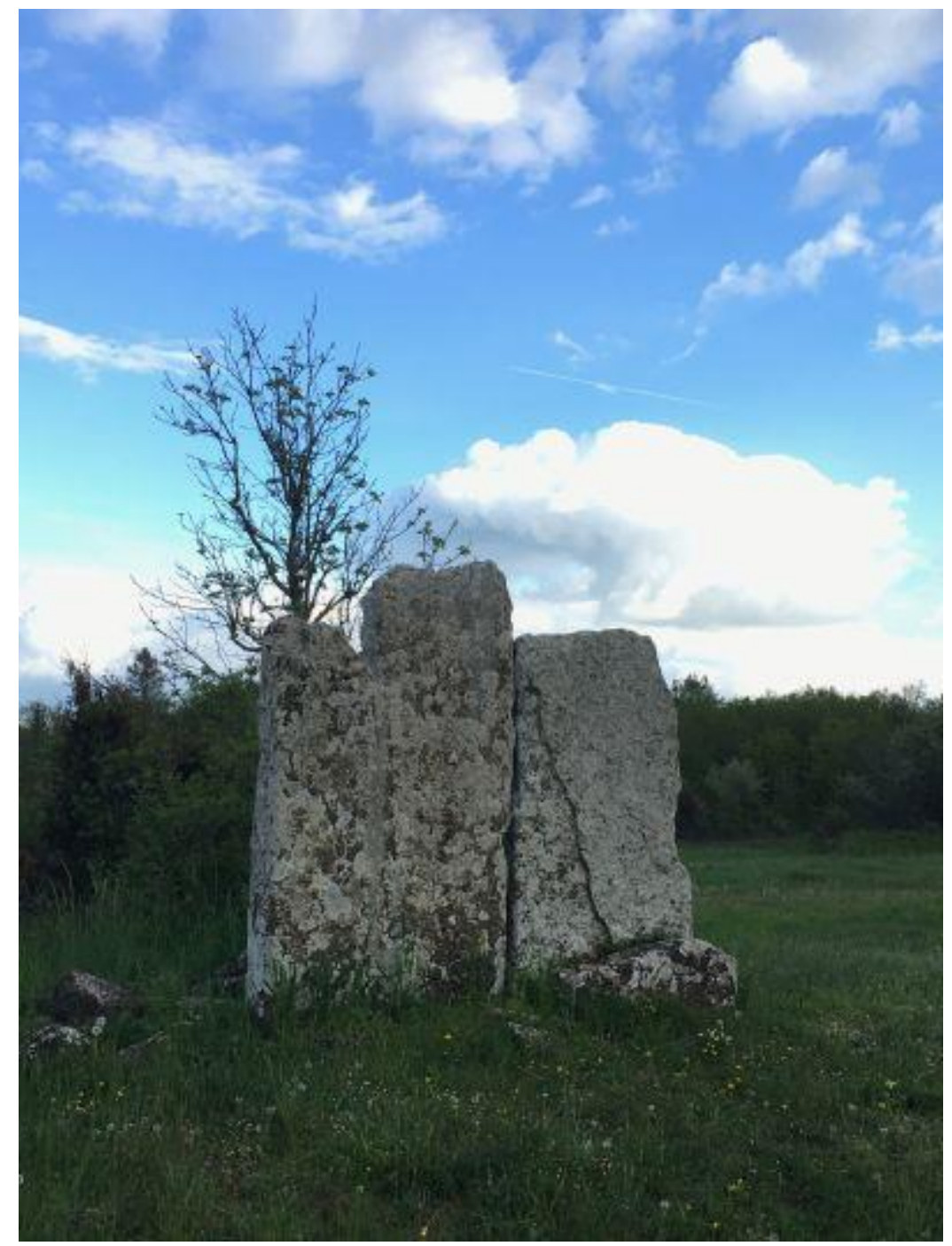

Figure 41: Odins flisor near Karum grave field. Photo by Bodil Petersson 2019

The mythology relates that it was here the main god worshipped in the Germanic and Old Norse worlds tied his horse Sleipnir when he was visiting the area. The stones are placed at one end of a burial ground from the Bronze Age and the Iron Age. The most prominent feature of the burial ground is a stone ship, which from its morphology probably dates from the Bronze Age and is now called Noah's Ark (Figure 42). 


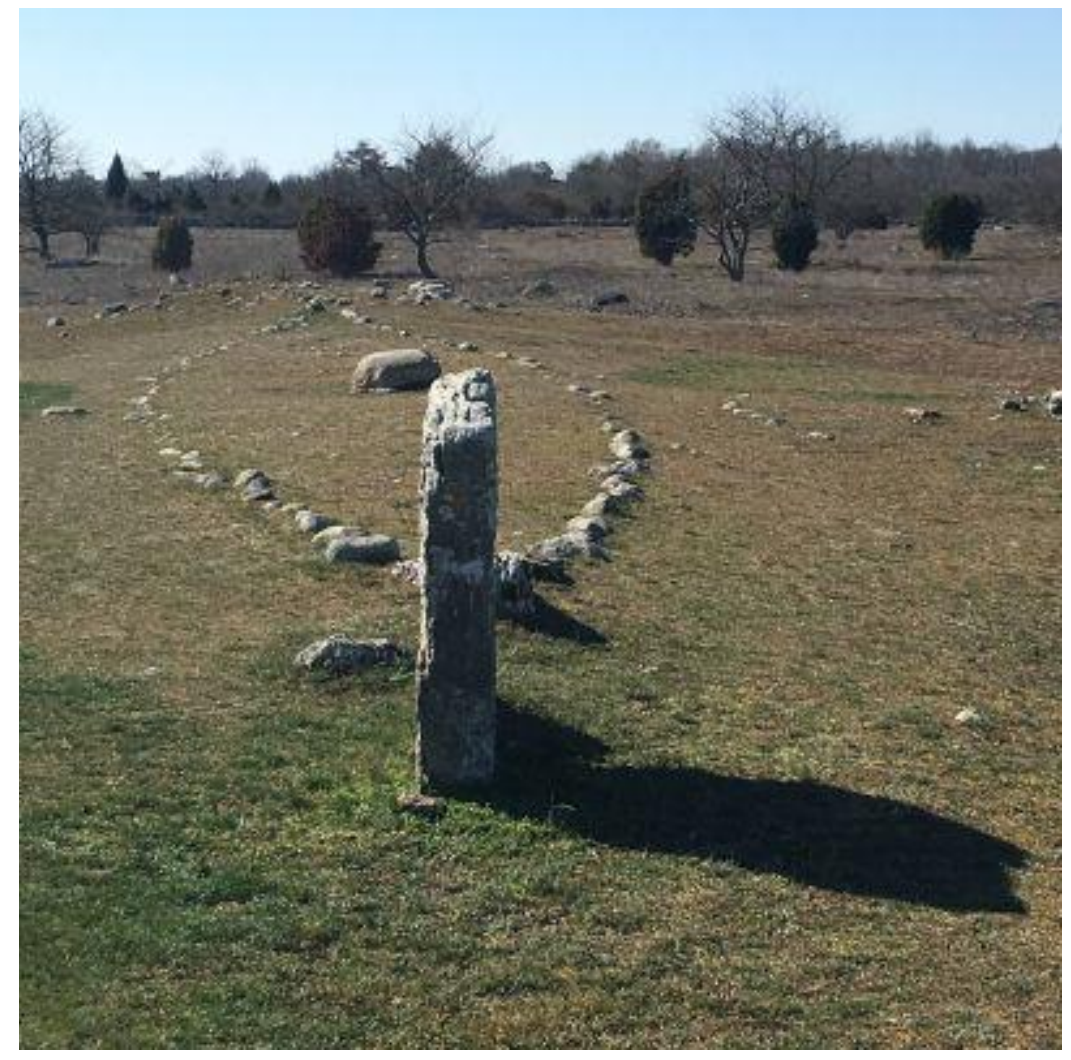

Figure 42: The Karum stone ship as seen from the north. Photo by Bodil Petersson 2019

Continuing the road through Karum and Sättra to the north-east, there is Gärdslösa medieval church, first founded in the 12th century and then expanded and changed during the 13th century. It is considered the best-preserved medieval church of Öland.

If instead you choose the other road at the entrance of Karum and go to the south-east, the road passes by Ölands Museum Himmelsberga, a combined open-air and art museum with buildings representing old farm life of Öland in historic times (Figure 43).

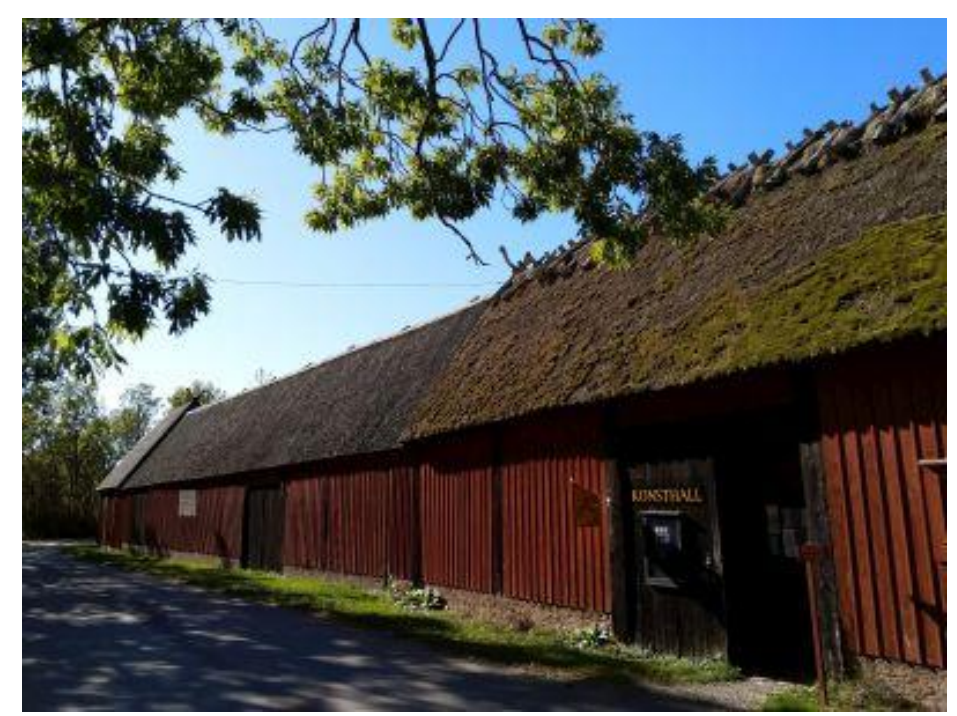

Figure 43: Traditional old farm buildings at Ölands Museum Himmelsberga, nowadays containing art exhibitions. Photo by Danny Burke 2019 
To the south of Karum burial ground and nature reserve it is possible to walk through the mittlandsskogen, the central forest of inland Öland, to Ismantorp fortress (see Section 3), a large ancient ruin that may have been a central place of the Iron Age communities of Öland, where people gathered for purposes both ritual and worldly. Near Ismantorp fortress the Ingeräll stone is located, that is said to have been the meeting place of three parishes (in Swedish: socknar) in more recent historic times. The landscape of Karum and its surroundings is interesting because of its connections from inland to coast, in between stone and water, myth and history, long time occupation and eventually also the connecting of long-standing traditions with change.

\subsection{Translocalities}

Within the project the artists and archaeologists from Ireland and Sweden work together not only on the topics of their own landscapes but also in a translocal manner. We connect the Irish and Swedish landscapes and their content with each other, based on observations of similarities as well as differences. The advantage of working in this way between the two rural landscapes is the invitation to the gaze from outside. To have only the local perspective on the well-known might hinder attention being directed towards structures that are hidden to the all-too-accustomed experience. Translocal work has the ability to highlight the hidden and taken for granted.

\subsection{Moving the ship}

As a translocal effort of art and archaeology between Sweden and Ireland, we have together created a performance in the landscape that assumed the form of a ritual of symbolically moving a ship from Öland in Sweden to Clare in Ireland. It was an idea that arose as a collective action between the countries because of the idea and its obvious connection to the concepts of stone, water, movement and time, the multitemporal. Preparations to move the ship began in March 2019. A farewell ceremony and launching of the ship in the Baltic Sea took place in the beginning of April, and after its voyage across the Baltic Sea and through the Atlantic, the arrival and ceremonial reception of the ship and its crew eventually took place in western Ireland in June.

The moving of the ship has two explicit aims. The primary aim is to explore in an experimental way how today we both are affected by and ourselves affect places where we know rituals have been performed. The idea is that the embodied performing itself might elucidate the needs and uses of rituals in several ways. The second aim is to document the experimental act in the landscape and use it for display in the local communities of Karum, Öland, and Kilshanny, Clare, so that we create the opportunity to present and discuss the experiences we get from the translocal ritual act in between Sweden and Ireland, and also to explore dimensions of transdisciplinary work between art and archaeology.

We don't have any detailed knowledge about what actually took place at a site like Karum grave field hundreds or thousands of years ago. Karum grave field with the ship that we are symbolically moving is dated to the period $1800 \mathrm{BCE}-800 \mathrm{CE}$. The ship structure is considered to date to the Swedish Bronze Age (1800-650 BCE) and it has a form that is quite unusual for the Nordic area, with features interpreted as benches for rowers in it (Figure 44). 


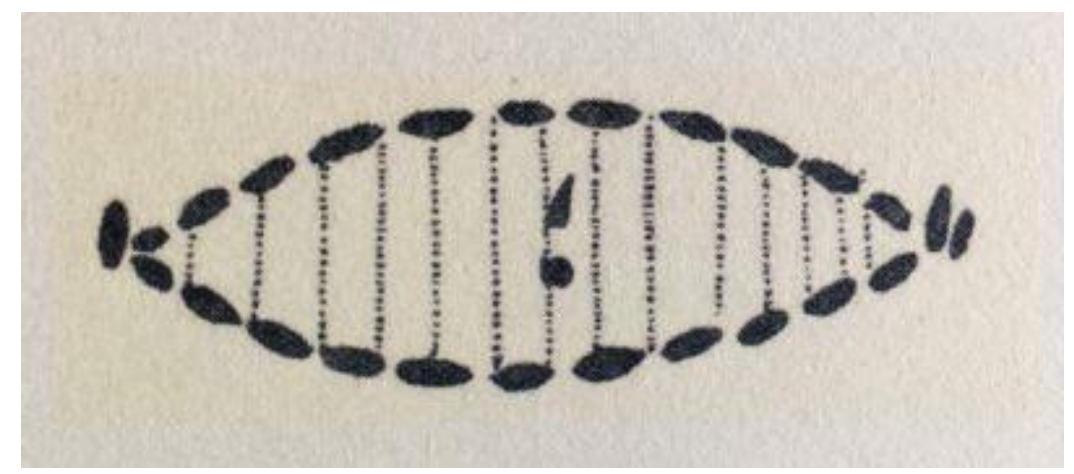

Figure 44: Carl Linnaeus' depiction of Noah's ark from 1741 after he made his Öland journey. The supposed benches and the mast stone, that at the time might have been two stones, are visible in this sketch (from Linnaeus 2005, 162 [New edn])

The bench features could alternatively be interpreted as frames of a wooden ship. In the middle of the ship is a large boulder which has been interpreted as representing a mast.

The idea of performing at Karum emanates from the fact that the ship is built of stone and in one way or another is intended for a symbolic voyage at sea, probably sending the deceased to the world beyond. The stone ship of Karum was probably, already in the Bronze Age, symbolically brought to the sea and put into the water and made to sail (the tradition of ship and sea-related burials continued in Scandinavia well into the Viking Age). In turn, the sea water is what connects Öland with western Ireland in a physical sense, and thereby the sea also connects the groups within the project as well. The symbolic idea of moving the ship was well received by the groups, and the idea could easily be connected with local communities, among others, artists residing and working in the vicinity of both Karum and Kilshanny. The planned performance was therefore proven to be a good way to connect with parts of the local communities.

The Karum event started with some preparations for the symbolic launch of the stone ship from the grave field and into the Baltic Sea. On the actual day of moving the ship, in early April, a smaller group started the day wandering and sensing the surrounding landscape, locating a natural spring in the vicinity, a way to connect the ship structure as well as the group with water and with the landscape features of stone, hazel and juniper bushes that surround the ship. The sun was shining from a light blue early spring sky and we were surrounded by the typical almost dazzling light of Öland springtime.

The preparations at Karum progressively led into the performance that spontaneously took on the form of a ritual, where a group of fifteen people moved together around the ship to symbolically lift it with our bodies, and then transport the ship to the Baltic Sea in the east. The group started with moving around the ship in a specific choreographed pattern together while singing the sea-related Finno-Swedish folk song Vem kan segla förutan vind (Who can sail without wind in English). At a certain moment the group was urged to use their hands to follow the rail of the ship and thereby sense and take into their bodies the actual ship and its contours and qualities. The act of bringing the ship into the body of the group was both an individual and a group act. It happened right at the junction of bodies and landscape (Figure 45). 


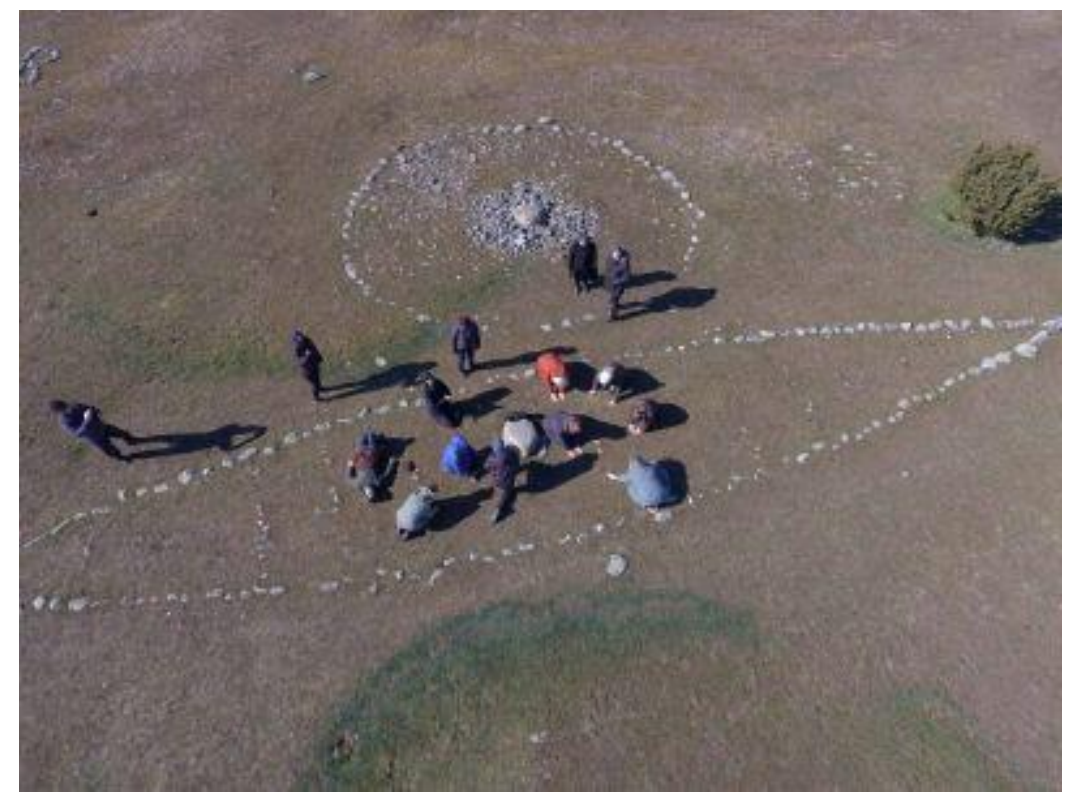

Figure 45: Drone photo of the group moving around the Karum ship. Adjacent to the ship is a circular grave structure. Photo by Jan Hagelin 2019

As this movement was performed and finished, the group continued making sounds with stones collected locally at the Karum grave field together with stones collected in Ireland and brought to Karum for this specific occasion. Each participant in the making of the sounds was equipped with one stone from Sweden and one from Ireland (Figure 46).

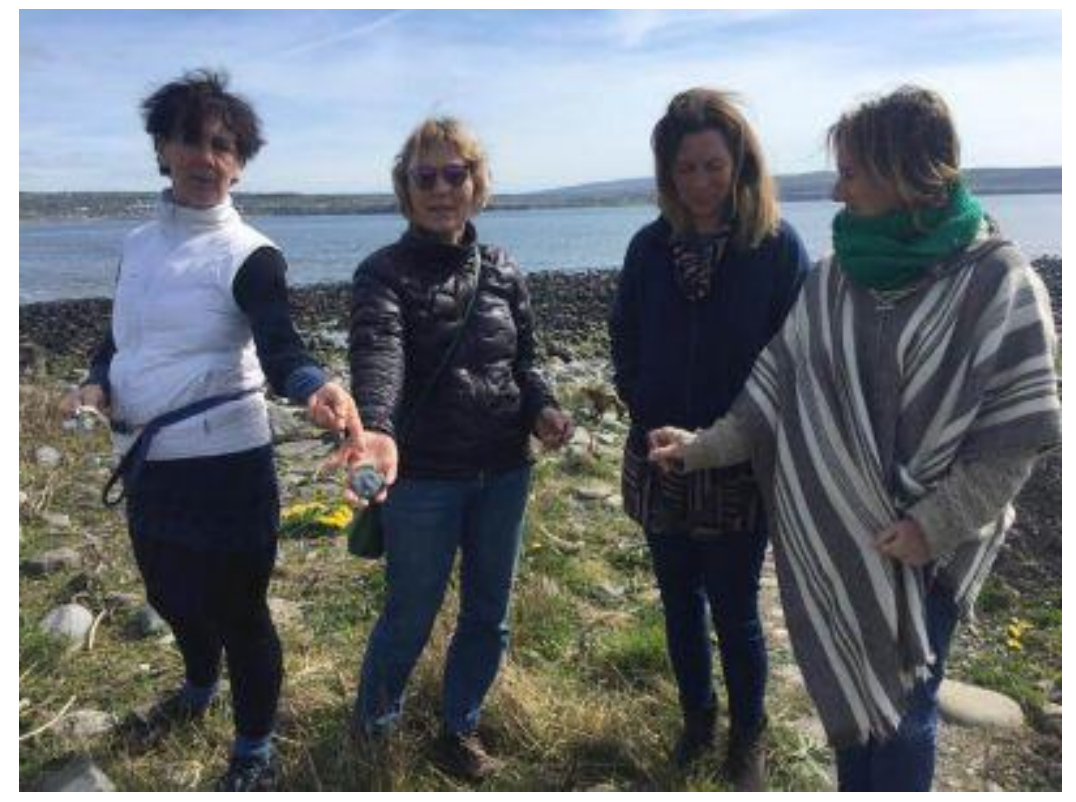

Figure 46: A group of artists (Jackie Askew, Sheila Vollmer, Ilse Mikula and Anna Park) in Ireland collecting stones at the estuary of Liscannor to be brought to the performance at Karum grave field in Sweden. Photo by Maria Kerin 2019

The sounds were recorded to be used in a forthcoming exhibition as well, as it works as documentation of the translocal and transdisciplinary work. Artists, archaeologists and those of the local community who were interested took part in the event. 
After the performance at the Karum grave field, the group made their way to Gärdslösa village, east of Karum, from where the group then walked to the Baltic Sea and the small harbour east of Gärdslösa. The group was spread out on both sides of the harbour and then the song was sung again. There were accompanying sounds from the sea as the wind was strong and the waves occasionally hit the harbour with splashing sounds and the spray of sea water was felt on our skin (Figure 47).

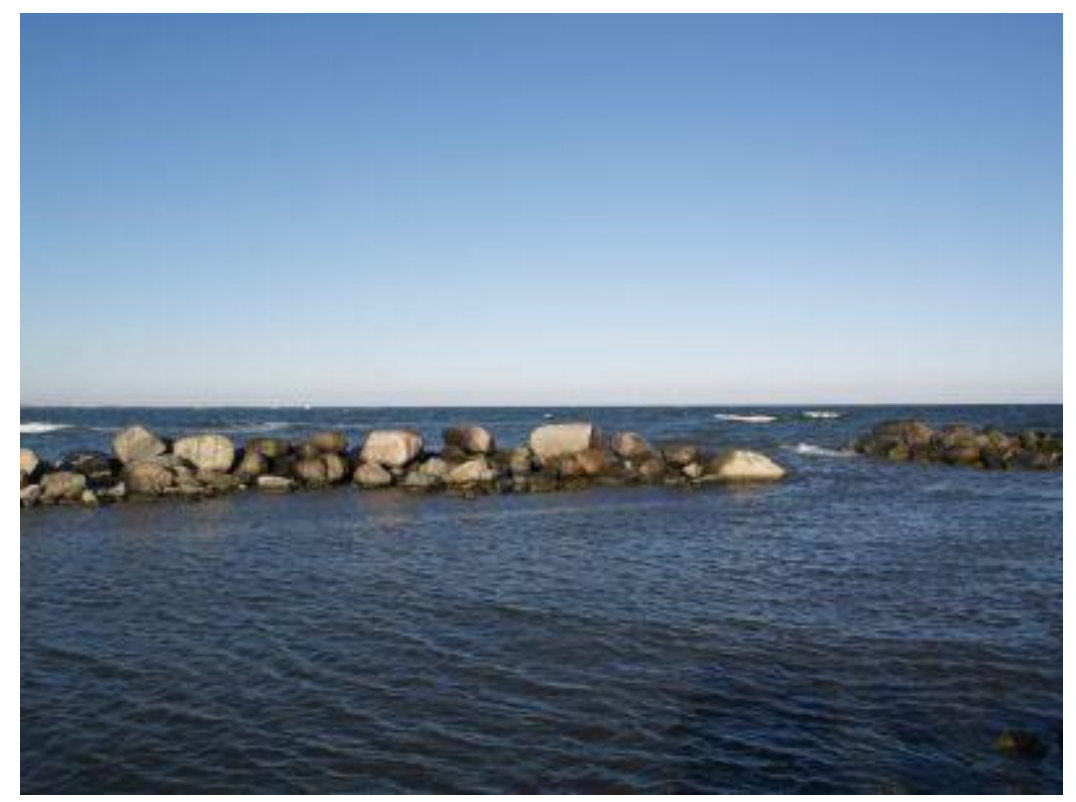

Figure 47: Gärdslösa harbour by the east coast of Öland, where the Karum ship was launched after the performance at the grave field. Photo by Bodil Petersson 2019

At the small harbour of Gärdslösa the ship was symbolically launched, rowed and sailed to western Ireland, where a ceremony was prepared to welcome and receive the ship and its crew. The actions at the grave field of Karum as well as at the harbour of Gärdslösa were performed together with the above-mentioned folk song, which made up the rhythm of the movement and contributed to the atmosphere of leaving.

In mid-June, some ten weeks after the launching of the ship at Gärdslösa harbour on eastern Öland, the Karum ship reached its Irish destination, the estuary by Liscannor, western Clare, where the River Dealagh after flowing through the parish of Kilshanny reaches the Atlantic. Such places, where rivers meet the sea, were often the first places where humans settled because of their qualities of being in between different kind of areas such as sea and freshwater, pasture, meadows and more forested areas, giving access to different biotopes that provide a range of possibilities for subsistence. In addition these waterways were important points to control and defend as they were obvious points of access to the hinterland for potential seaborne invaders (Figure 48). 


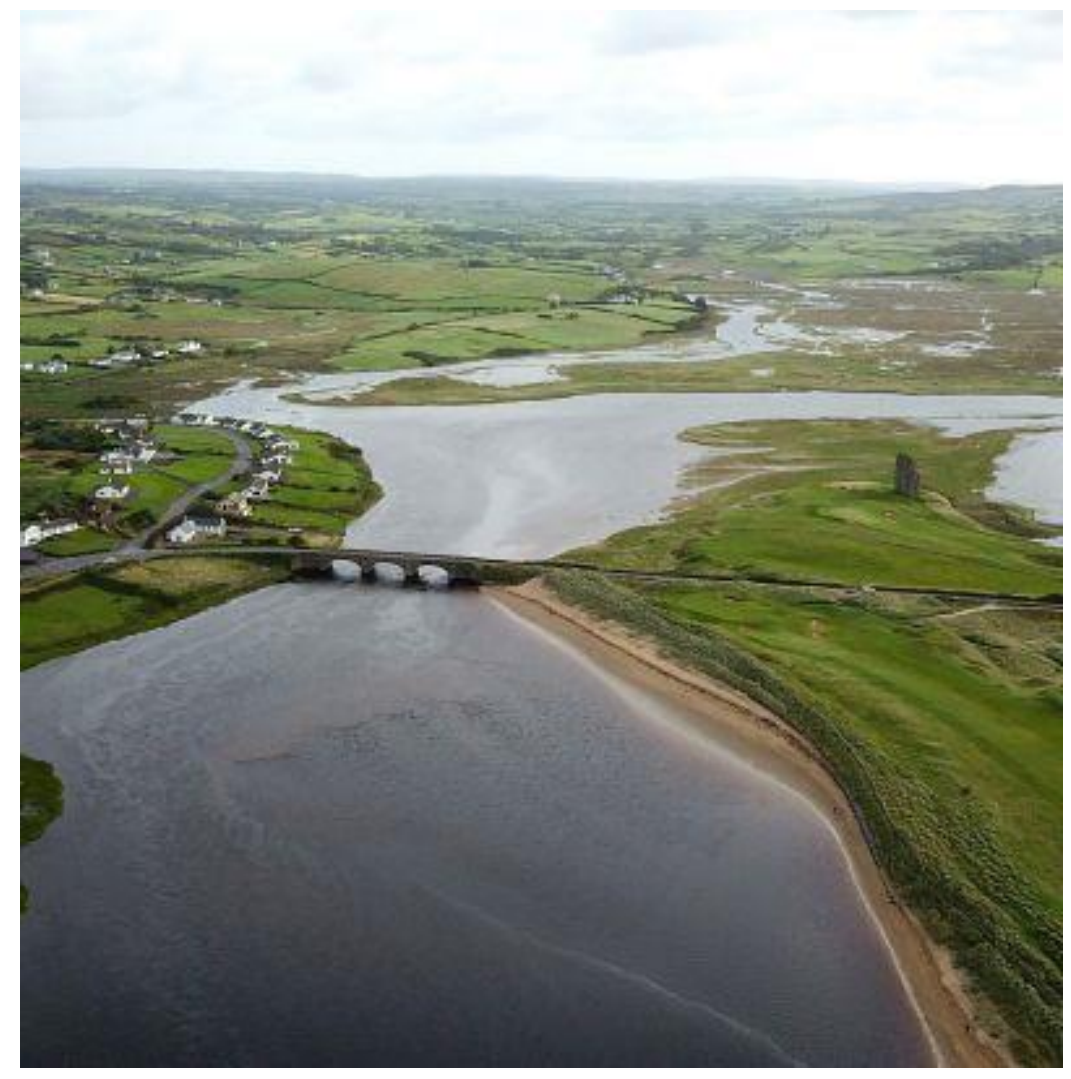

Figure 48: Drone photo of the estuary of the combined Dealagh and Inagh rivers looking inland up the Dealagh towards Kilshanny. The ruins of Dough Castle, the seat of the O'Connors, former kings of Corcomroe, can be seen to the right of the bridge. Photo by Matthew Kelly 2019

A group of ten Irish and Swedish artists and archaeologists gathered at the estuary as the tide turned and together performed a ritual of welcoming the Karum ship. The welcoming was performed by repeating through movement the structures of the Karum ship on the sandy shores of the estuary. The movements were performed through walking together with a rhythm underlined by spoken words in Swedish, Irish and English relating to water and stone. The walking movements of the group created visible traces in the sand in the form of a ship, which then continued with a circle (Figure 49).

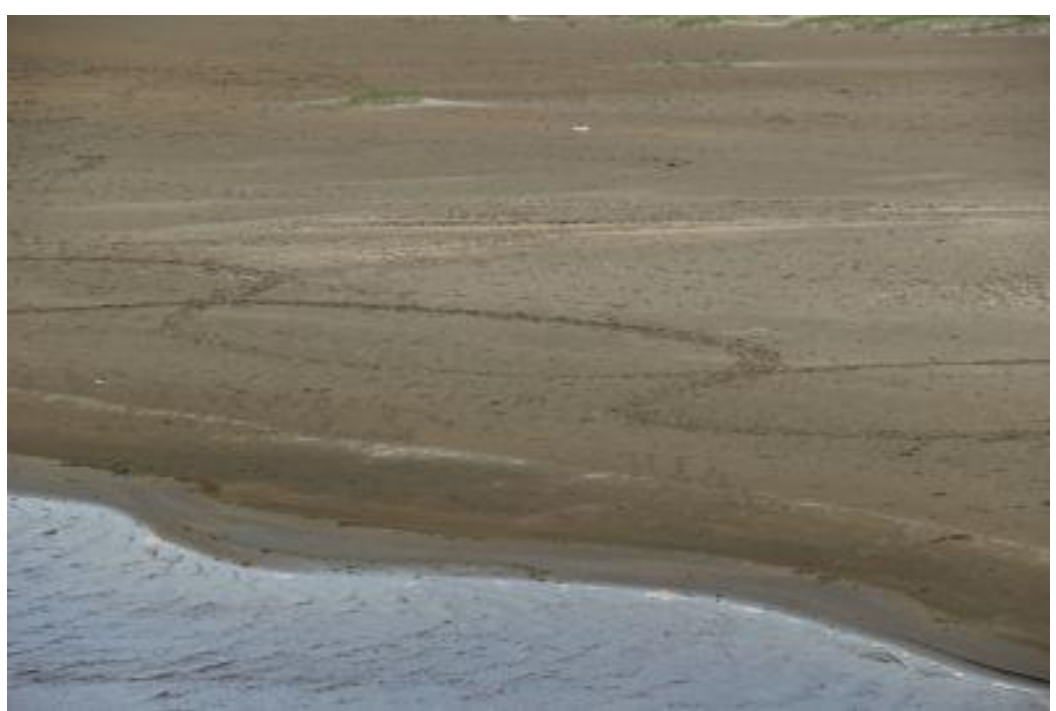


These patterns were picked up from the movements performed at Karum grave field, where the Karum ship and a circular stone setting are placed next to each other.

Another movement pattern brought from Karum was the use of hands as if they touched the rail of the ship as we walked the contours of the ship and circular form on the sandy shores of the estuary. A tune was performed on a flute as the group arrived to the part of the estuary where two rivers from inland Clare meet, the woodwind instrument evoking the wind in the ship's sail as it voyaged from Öland.

The group then slowly moved back towards the sea, once again following and thereby filling in the outlines of ships and circles, and at the very end the group formed a circle symbolising the ultimate transformation of the Nordic ship into the local coracle, a kind of boat traditionally used for fishing on the rivers of Ireland (Figure 50).

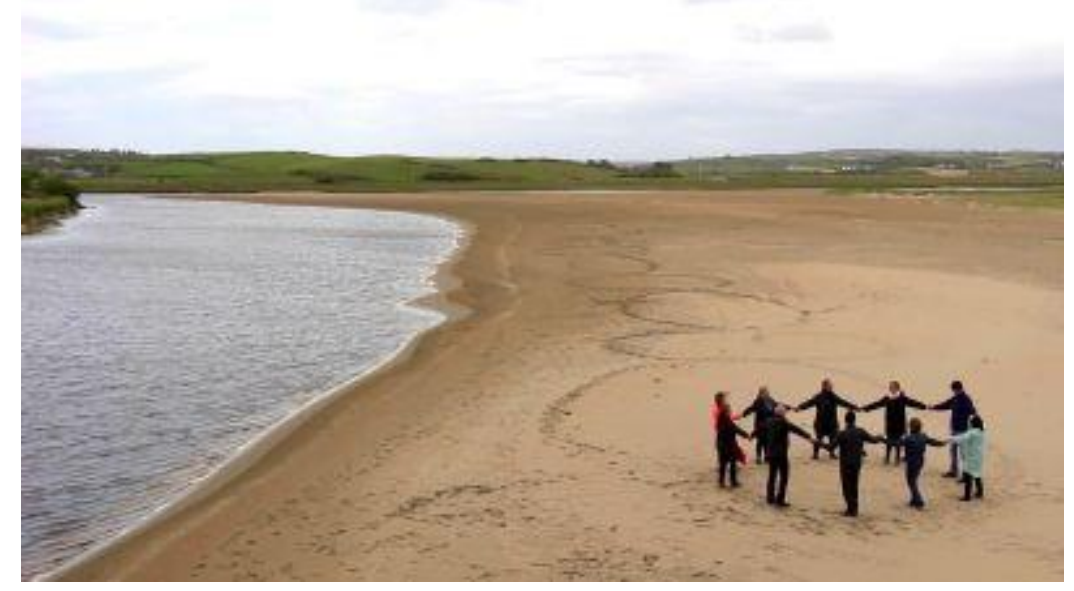

Figure 50: Participants in the performance/ritual by Liscannor estuary forming a circular shape resembling the coracle. Photo by Jackie Askew 2019

Performing the ritual at the estuary was documented through filming and photos, with the purpose of creating material to be used together with the documentation material from Karum in exhibitions both in Ireland and Sweden. The connection between Sweden and Ireland with the moving of the Scandinavian ship, the sending on its way and the receiving of the ship and its final transformation into an Irish boat, shows in action the possibility of a performing practice that might turn into a ritual where the local places and people of Öland and western Clare are connected in both translocal strivings and transdisciplinary ways.

The embodied experience in the landscapes of Karum and Kilshanny and as a group added immensely to the performance that progressively took on the form of a ritual. The usual distance that is created between observers and the viewed was replaced by the embodied participation of sharers situated within the chosen environments of performing the ritual. The urge to actively use the senses to reach an understanding of what happened, combined with the active embodied listening to the group and environments, contributed to an experience where it was actually possible to transcend physical and mental borders and distances and be immersed in the act itself.

The being in between nature and culture, Sweden and Ireland, Karum and Kilshanny, art and archaeology, past and future, became obvious during these efforts. We were doing 
this outside institutions, in rural environments and landscapes relating to both stone and water by their content and neighbouring seas and rivers. The performance and ritual emanating from the group effort was moving between the past, via the present, into the future. The ship from the past was prepared and launched for travel into the future to arrive at a distant shore in western Ireland. We actually had no filter between the landscapes where it all happened and our own sensuous experiences. It wasn't an individual experience; it wouldn't have been possible to perform this act without the group participation. We worked consequently outside the interpretative and streamlining frameworks of art and archaeology museums and galleries. All this taken together contributed to a fully embodied landscape-based ritual performance.

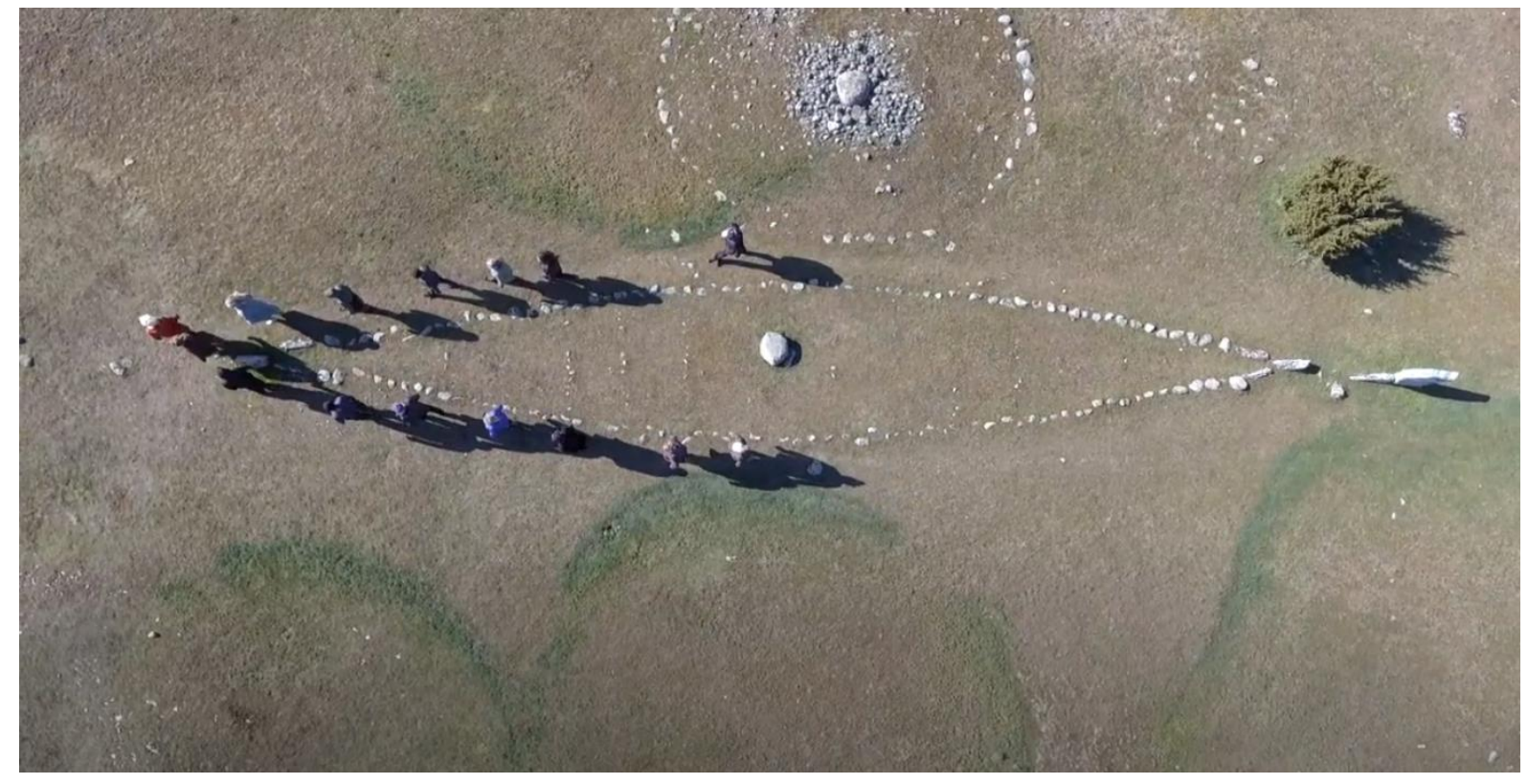

Moving The Ship on Vimeo.

\section{Experimental Heritage as Practice 7.1 Return to enquiries}

In what ways do the efforts described, past and ongoing, on Öland, Sweden, and in Clare, Ireland, elucidate and explain why the specific combination of art, archaeology and heritage might enhance our understanding and use of the past in the present and contribute to future needs?

\subsection{Merging perspectives}

One of the main questions in this work concerns the effect of the merging of perspectives from art and archaeology and how it might affect the joint effort to examine landscapes, structures material and immaterial, and people over time. 
One effect is a general change in the thinking about and perception of the world, a striving to go beyond the taken for granted. The transdisciplinary and embodied work is a key to a holistic way of conceiving the world. The ongoing collaborations between artists and archaeologists provide new and merging perspectives on past and present. The conventional perception of time is loosened in favour of a movement back and forth between times without strict linearity. Similarly, the dualistic categories of nature and culture are released in favour of a combined understanding of the world as constantly combining these non-separable categories. Explorative methods and ways of communication, with focus on the in-between art and archaeology, the in-between times, and the in-between nature and culture, reveal new perceptions of relations between the present and the past. When artists and archaeologists work without such conventional boundaries, they affect the thinking in the surrounding world by contributing alternative ways of seeing things.

Archaeologists could, in principle, be the most suitable mediators and facilitators between past and present through their obviously embodied work practice and encounters with the physical remains of past times, in parallel with insightful considerations about life in other times. In the current situation of scientific rules and restraints, though, most archaeologists are caught in a paradigm of scientific standards that prevent them from fulfilling the possibilities of embodied practice that actually would require a changed approach. Through transdisciplinary work together with artists, archaeologists are given the possibility to develop this part within their own practice and find new ways to understand the world between past and present.

\subsection{Multitemporal view}

Another element that has been examined within this project is the multitemporal view of things, to actually leave the timeline view behind and instead focus upon moments in time and the multitemporal content and discern how that approach affects how the past occurs at every given moment in the present.

The process of working with art, archaeology and heritage in a landscape setting contains a different cycle and time frame of afterthought. Ways of life and relations with the landscape are tested in relation to past-present-future and back again. The process itself is allowed to take a year or even more. We allow enough time for the group to enter real environments on-site instead of artificially created and explained ones in museums or through computers or VR gear. The landscape experience is different to the museum and technology-based experience, since it is not directed or consciously filtered in the same way as presentations intended for public display. The embodied experience in the landscape in-between times, places, nature-culture and art-archaeology triggers thoughts and actions relating to a boundless human experience of past, present and future at one and the same moment in time. When entering real environments, it is possible to both understand and learn more about the contents of the multitemporal in the landscape.

\subsection{Translocal efforts}

The translocal way of working is an important part of this collaboration. The two different parts of Europe involved, Öland and Clare, are clearly separate but also share several 
unifying concepts such as stone and water, movement and time, and we work with the ways these concepts are useful for connecting the areas.

The translocal effort is here a relational and intercultural one, taking its departure in two separate areas. The areas are interconnected in a way through lines and threads created within the framework of this project. The translocal is then a way to uphold, and also inspire, diversity in a globalised world. This project, in actively spanning these two areas, is in addition connecting them through specific actions.

Interestingly, as culture can separate places and people of different areas in the world, the chosen themes of landscapes, stone and water, movement and time, rural and peripheral, are instead, in this project, working in the opposite direction as unifying forces. It is good to have these two ways existing in parallel: the separating and the unifying. It makes the overall experience more dynamic and open to interpretation through artistic work.

Through translocal practice, the experience of meeting the foreign can effectively be held up as a metaphor for our experiences of meetings with past places, cultures and peoples. Through translocal interconnection, the foreign in a sense comes to represent the past in our present experience and reminds us of our distance from our antecedents.

The Moving the ship strand of this project relates to landscapes, stone and water, movement and time, rural and peripheral. The Karum ship is a ship from the past moving in the present, moving between the two chosen landscapes, containing a crew of both times and places, of the living and the dead, The ship, made of stone, is consciously intended for and also consequently placed in the element of water, itself cradled in the stone of the earth, seabed and coast, and the ship is then moved in both space and time, connecting two areas of the world, foreign to one another but bridged in this process.

\subsection{Rural approach}

From an experimental point of view the combined rural-peripheral approach in this project is a challenge for artists, archaeologists and the participating local communities alike. The practices of art as well as archaeology are often embedded in urban mentalities in different ways. The arenas of artistic expression are in many cases located in bigger cities where there is an abundance of people already with the habit, time, and possibility to take part in and engage in art as performed in alternative ways through galleries, in the streets and at art museums. Archaeology today is very much an effect of planned human exploitations of landscape, of expansion and reshaping of the world in dramatic ways through building roads, cities and industry as well as transport and infrastructure features. Consequently, archaeology is a direct effect of the urban in most cases and therefore smoothly adapted to the system. The reasons for doing art and archaeology as a transdisciplinary, translocal, rural and peripheral act need to be considered thoroughly and formulated as separate from the traditional urban-centred formats known and practised. The idea of outreach and local engagement of this project also needs to be considered. The position of rural and peripheral is in this case a strong one that might provide alternative views to the established ones and thereby attract interest and engagement in a local and translocal setting. 
In several archaeological interpretations the sites being excavated are described as 'central', 'urban', as important places where the elite resided, essential things occurred and networks were created and upheld (cf. Nakoinz 2012; Christophersen 2015). If rural is mentioned, it is often in the context of being the urban 'hinterland', supplying the urban areas with food and goods (Hall and Kenward 1994). And if archaeological sites are not qualified for this story, they are actually mostly treated as insignificant and laid to rest in magazines and archives. It is as if there is no place for archaeological sites that the urban present cannot identify itself with. Archaeology as a profession often takes the role of finding the extraordinary and spectacular. This might lead the understanding of the past away from, for example, interpretations concerning rural and village life, and towards the interpretations and stories that contain the urban life as norm. What this project, contained in rural landscape, contributes, is a possibility of a perspective that maintains a relation to the rural past through the project and its direct presence in the landscape. By being and performing in the landscape, the qualities of the landscape itself - in-between nature and culture, past and present, and its meaning to the people inhabiting the landscape through the ages - comes to overshadow the strivings of archaeologists and historians to fit the archaeology or history into the dominant story of development from rural to urban.

The staging of the above-mentioned combined art/archaeology efforts in the landscapes of Öland and Clare has, with its landscape-related approach, the advantage of being in the middle of the immediate rural surroundings. These environments have consequently affected the contents of the work performed, as have the people from the areas: artists and archaeologists as well as communities. When actions are taken locally in a rural setting, they are not filtered through the urban demands of art and archaeological institutions connected to towns and cities, where the performing norm often lies elsewhere, in the case of Europe often in Berlin, Paris, London or Rome, where large and influential art and archaeology institutions are situated. Throughout the project there have been comments that the art performed could just as well have been shown in, for example, Stockholm or Berlin (Walle Dickson pers. comm.). This is probably intended as a compliment to the work done, but our wish is instead to point towards being and performing within the rural and peripheral, not to maximise the audience by adapting to urban structures and hierarchical institutional systems. The work performed is intended to stay with and enrich the communities and areas it emanates from.

\subsection{Landscape experience}

The project is working consciously with the multitemporal approach. We explore how landscapes and their contents might be conceived and expressed through a joint and integrated effort of artists, archaeologists and surrounding communities. We have together created happenings in the landscape, that in a way evoke ritual acts and ceremonies, thereby filling landscape and place with intangible contents, projecting embodied events upon landscape and places and relating to the past through acts in the present.

The different strands of the project in the Swedish and Irish setting performed so far have contributed to an understanding on both an individual and group level of how we are embedded in the multitemporal if we only consider it and allow ourselves to enter the past as who we are in the present. We consciously avoid the timeline filtering of events, allowing ourselves to take part in travels and thoughts emanating from landscapes, from archaeologists and historians, and from ourselves as artists and archaeologists in the 
present. The collaboration between artists and archaeologists in turn help especially the archaeologists among us to release the concept of time into something more unknown and thereby somewhat more temporally unpredictable and even reversible in a sense.

The project provides processes of caring for and developing landscapes with new methodologies of how to approach the unknown and undefined contents that in our time are hidden mainly because we do not apply interdisciplinarity but stay within the limits of singular research traditions. Eventually the consideration of different times might enhance the understanding of the need for a slowed-down process. The project thus works towards finding alternative views on time and the passing of time also in relation to present-time working processes.

\subsection{Process as result}

We have together begun to explore the relationship between process and result. The enquiry concerns the relationship between the two, and also questions the concept of end results in favour of seeing the process itself and what it reveals as a main result of the project.

The act of moving the ship between Karum and Kilshanny is an explicit example of translocal movement and exchange and likewise an example of the process itself as result. It is through performing together that the contents of the act are revealed. It was actually not known beforehand what was going to be the effect of this effort. The intention was to allow for a process without a definite goal formulated in advance.

Throughout the process and along with the preparations and the carrying through of the act of moving the ship, the intended performance progressively became transformed into something of a ritual, with the consequence of bringing the group closer to what was obviously conceived of as a common meaningful effort of connecting across time and space. The process explains itself through the actions of the group in different ways and reveals some contemporary aspects of the relevance of archaeology and heritage today.

One obvious effect of this way of working, focusing on process, is revealing. It is primarily the ways in which the group works, in between subjects, landscapes, countries, materials and times, that reveal how the process actually changes the thinking and perception among those involved. The next step of that process is to engage wider communities beyond the artists and archaeologists immediately involved. That process has just begun. But as the example of the community involvement around moving the ship has shown, the communities received the intention and ideas evolving from that experience well. The moving of the ship, as an example of this way of working, can thereby be used as a model in the developing Irish-Swedish Experimental Heritage explorations.

\subsection{Emerging needs}

It is possible to discern some emerging needs as we work our way through transdisciplinary and translocal projects. One is the need for a well-thought through set of concepts and expressions, the need for a shared language to be able to better describe to ourselves and to others outside the collaboration what we are doing. It is likewise important to use language that is not obscuring but instead clarifying our 
actions. We need to be conscious how we express what we are doing, also in relation to our community-related work, so that we can be understood by groups we collaborate with, both within and outside an academic setting.

We come from different backgrounds, and as an effect of that we have different ways of approaching practice, forming methods and developing theoretical standpoints. As we consider a shared language, we need to consider its clarifying potential, so that our activities are not obscured by how we describe them. It is not a matter of simplifying what we are doing and performing, instead it is a matter of awareness and conscious consideration of the effects of how we express things.

To create a shared language and develop profound community interaction and collaboration, paired with true transdisciplinary and translocal work, enough time is needed, possibly a time horizon of, for example, six years would be suitable for this kind of enquiry. It is obvious that this kind of process-led work takes extra time, since it contains efforts of integration and collaboration between subjects and communities. To interact in a sincere way and partly independent of existing institutional frameworks demands much more consideration and planning than is usually expected in these times, when projects are expected to happen at a very rapid pace, often within one or two years, thereby forcing reliance on existing theoretical frameworks and with very limited scope for reflection and integration of new insights into developing frameworks across subject borders and social groups.

\subsection{On arts, humanities and sustainable life forms}

With this project we aim to find paths towards how to be human in this world, caring for material and immaterial aspects of lives and life forms both past and present. In the very beginning of this text we stated the wish to provide new tools to create alternative futures rooted in respect and need for diversity. The focus therefore consciously moves away from urban-led capitalist ideals of continuous development, growth and consumption. We wish to cherish the slowed-down pace and to create a respectful awareness of material as well as mental processes, human and nonhuman, that need time to understand and develop. It is our hope that this project with its combination of art and archaeology might contribute to a more sustainable way of being in the world. One important role for the arts and humanities in the world of today might be specifically this approach: to create a holistic, deeper and embodied, intellectual, sensuous and sensory understanding and awareness, grounded in a wish to find alternative and more sensitive ways of being in the world. 


\section{Glossary}

Alvar

The alvar landscape is flat, open and located on limestone bedrock. As a consequence of its exposure to wind, summers are dry and winters are frosty. Another characteristic is a very thin layer of soil, and the limestone is often bare without any soil cover at all. Owing to the harsh conditions the flora and fauna of these areas have developed their specific traits of adaptation to the environment. Alvar is found in Scandinavia, for example on the islands of Öland and Gotland in the Baltic sea but also in other regions of the world with similar conditions (Eriksson and Rosén 2008, 1).

Embodied practice

The concept of embodied practice suggests that we experience the world through our bodies and the bodily perception of the world via the senses, emotions, and movements in both space and time (Tiwari 2010).

Harris Matrix

The Harris Matrix is a graphical way of visualising relationships between stratigraphic units in archaeological excavations. It shows for example how a pit is dug through older layers and then filled with younger materials. Each action of digging a pit, and creating a layer of some kind, is seen as one single stratigraphic unit to be documented in the matrix (Darvill 2002, 170).

Parish

As the concept of parish is mentioned in the text in relation to Sweden, the translation is from the Swedish word socken, an early church-based as well as administrative division that has been in use since the Middle Ages, from around the year $1100 \mathrm{CE}$ onwards. It might even have pre-Christian origins in some parts of Sweden. The church-related socken had functions relating to rural/village decision making by medieval times, a division that lasted well into the 20th century. It was replaced in 1952 by 'kommun' as administrative unit, but the socken has lasted as a concept especially within cultural heritage management since it contains important information for understanding old structures and divisions of land. Source: NationalEncyklopedin.

Townland

A townland is the smallest administrative unit of land in Ireland, with over 60,000 on the island. Until the creation of Eircode postal codes in 2015, townlands were the only means of identifying rural postal addresses in Ireland. They are thought for the most part to be at least as old as civil parishes, many of which date to the establishment of the diocesan structure of the Roman Catholic church in Ireland in the 12th century. 


\section{Acknowledgements}

We wish to thank Karum-Creevagh Experimental Heritage group for creative work together on this text. We would also like to thank the wider network of Experimental Heritage in Sweden, Ireland and the Netherlands for inspiring exchange, with a special thanks to all the participants of the performance Moving the Ship in both Sweden and Ireland during 2019.

We are especially grateful for the efforts by Maria Kerin and Hans Gurstad-Nilsson concerning the choreography, composition, sound production and editing of the film. We would as well like to mention the efforts by Jan Hagelin, Jackie Askew and Michael Walsh who provided the necessary visual material in the form of drone footage, film sequences and photos. Thanks to Danny Burke, Ann Elkjär Gustafsson and Thomas Wiegert for contributions to the sound worlds of Moving the Ship.

This article relies upon rich illustration material, and we wish to thank all contributors to the varied and multifaceted character of that material. Thanks also to Matthew Kelly for allowing the use of his drone images. A generous grant from Hainska Stiftelsen made research work leading to this publication possible. Linnaeus University, Sweden, has through its program for funding open access publication generously contributed with the money needed to cover the cost for publishing. Finally, thanks to Internet

Archaeology editor Judith Winters and to Gavin MacGregor for help with enhancing and enriching this text and its contents.

\section{Bibliography}

Abram, D. 1996 The Spell of the Sensuous: perception and language in a more-thanhuman world, New York: Pantheon Books.

Alex, R. K., Deborah, S.S., Cheruvalath, R. and Prakash, G. (eds) 2017 Ecocultural Ethics: Critical Essays. Lanham, Maryland: Lexington Books.

Alexandersson, K., Andersson, A-K. and Papmehl-Dufay, L, 2014 Fornlämningar på Blå Jungfrun. Arkeologisk inventering och provgrävning 2014, Kalmar läns museum Arkeologisk rapport 2015:04.

Andrén, A. 2014 Tracing Old Norse Cosmology. The world tree, middle earth, and the sun in archaeological perspectives, Vägar till Midgård 16. Lund.

Arbenz, T. (ed) 2012 Cave Pearls of Meghalaya. Vol.1: Pala Range and Kopili Valley, Matzendorf: Thomas Arbenz.

Atalay, S. 2012 Community-based Archaeology: research with, by, and for indigenous and local communities, Berkeley: University of California

Press. https://doi.org/10.1525/9780520953468 
Bailey, D. 2017 'Art/Archaeology: what value artistic-archaeological collaboration?', Journal of Contemporary Archaeology 4(2), 24656. https://doi.org/10.1558/jca.34116

Bailey, D. 2018 Breaking the surface - an art/archaeology of prehistoric architecture, Oxford University Press.

Beausoleil, E. 2014 'The Politics, science and art of receptivity', Ethics \& Global Politics 7(1), 19-40. https://doi.org/10.3402/egp.v7.23231

Berry, J.W. 2003 'Origins of cross-cultural similarities and differences in human behavior: an ecocultural perspective' in A. Toomela (ed) Cultural Guidance in the Development of the Human Mind, London: Ablex Publishing. 97-110.

Bradley, R. 2000 An Archaeology of Natural Places, New York: Routledge.

Brickell, K. and Datta, A. (eds) 2011 Translocal Geographies: spaces, places, connections, Farnham: Ashgate.

Brigstocke, J. and Noorani, T. 2016 'Posthuman attunements: aesthetics, authority and the art of creative listening', GeoHumanities 2(1), 1-

7. https://doi.org/10.1080/2373566X.2016.1167618

Brodsky, J. 2002 'How to "see" with the whole body', Visual Studies 17(2), 99112. https://doi.org/10.1080/1472586022000032189

Burke, D. 2014 'Jingkynmaw: memories written in stone' in J. Hazarika and M. Hazarika (eds) 50 Years After Daojali-Hading: Emerging Perspectives in the Archaeology of Northeast India, New Delhi: Research India Press. 360-375.

Campbell, F. and Ulin, J. 2004 Borderline Archaeology: a practice of contemporary archaeology - exploring aspects of creative narratives and performative cultural production, Unpublished dissertation. Göteborgs

Universitet http://hdl.handle.net/2077/16211

Cancienne, M. and Snowber, C.N. 2003 'Writing rhythm: movement as method', Qualitative Inquiry 9(2), 237-53. https://doi.org/10.1177/1077800402250956

Christophersen, A. 2015 'Performing towns. Steps towards an understanding of medieval urban communities as social practice', Archaeological Dialogues 22(2), 10932.

Cinthio, E., Franceschi, G. and Jorn, A. 1995 Skånes stenskulptur under 1100-talet, København: Borgen.

Crehan, K.A.F. 2011 Community Art: an anthropological perspective, Oxford: Berg.

Darvill, T. 2002 The Concise Oxford Dictionary of Archaeology, Oxford/New York:

Oxford University Press. 
Davoudi, S., and Stead, D. 2002 'Urban-rural relationships: an introduction and a brief history', Built Environment 28(4), 269-77.

Ehn, B. 2012 'Between contemporary art and cultural analysis: alternative methods for knowledge production', InFormation, Nordic Journal of Art and Research 1(1), 418. https://doi.org/10.7577/information.v1i1.214

Elwin, V. 1943 The Aboriginals, Bombay: H. Milford, Oxford University Press.

Eriksson, M.O.G. and Rosén, E. 2008 Management of Natura 2000 habitats. 6280 Nordic alvar and precambrian calcareous flatrocks, European Commission.

Gibbs, L. 2014 'Arts-science collaboration, embodied research methods, and the politics of belonging: "SiteWorks" and the Shoalhaven River, Australia', Cultural Geographies 21(2), 207-27. https://doi.org/10.1177/1474474013487484

Gill, F. 2020 'Ears to the ground: on Cajsa Lund's legacy and moving movements' in G. Kolltveit and R. Rainio (eds) The Archaeology of Sound, Acoustics and Music. Studies in Honour of Cajsa S. Lund, Publications of the ICTM Study Group on Music Archaeology 3, Berlin: Ekho Verlag. 55-96.

Gkartzios, M. and Crawshaw, J. 2019 'Researching rural housing: with an artist in residence', Sociologia Ruralis 59(4), 589-611. https://doi.org/10.1111/soru.12224

Guha, R. 1999 Savaging the Civilized: Verrier Elwin, his tribals, and India, University of Chicago Press.

Hall, A.R. and Kenward, H.K. (eds) Urban-Rural Connexions: perspectives from environmental archaeology, Association for Environmental Archaeology. Symposium, 1994, Oxford: Oxbow Books.

Hayles, N.K. 1999 How we became Posthuman: virtual bodies in cybernetics, literature, and informatics, Chicago, III: University of Chicago

Press. https://doi.org/10.7208/chicago/9780226321394.001.0001

Ingold, T. 2007 Lines: a brief history, New edition, London:

Routledge. https://doi.org/10.4324/9780203961155

Ingold, T. 2013 Making: anthropology, archaeology, art and architecture, London:

Routledge. https://doi.org/10.4324/9780203559055

Jorn, A. 1964 Signes Gravés sur les Eglises de l'Eure et du Calvados with photographs by Gerard Franceschi, Copenhagen: Borgen.

Järnegard, S. 2017 'Ett attentat mot Silverbäcken', Ölandsbladet, 13 July 2017, https://www.olandsbladet.se/asikter/ett-attentat-mot-silverbacken

Larsson Pousette, H. (ed) 2017 History Unfolds. Contemporary Art Meets History, Stockholm: Swedish History Museum. 
Lepecki, A. 2006 Exhausting Dance: performance and the politics of movement, Abingdon: Routledge. https://doi.org/10.4324/9780203012871

Linnaeus, C. 2005 Carl von Linnés Öländska resa, New edition, Stockholm: Natur och Kultur.

Lund, H. 1993 Impressionism och litterär text, Stockholm: Brutus Östlings bokförlag Symposion.

Merleau-Ponty, M. 2002 Phenomenology of Perception, London: Routledge (in French, Merleau-Ponty, M. 1945 Phénoménologie de la perception). https://doi.org/10.4324/9780203994610

Mouffe, C. (ed) 2008 Art as a Public Issue: how art and its institutions reinvent the public dimension, Rotterdam: NAi Publishers.

Nakoinz, O. 2012 'Models of centrality' in W. Bebermeier, R. Hebenstreit, E. Kaiser and J. Krause (ed) eTopoi Journal for Ancient Studies, Landscape Archaeology Conference (LAC 2012) Special Volume 3, 217-23.

Narmo, L.E. 2011 'The unexpected' in B. Petersson and L.E. Narmo (eds) Experimental Archaeology: Between Enlightenment and Experience, Lund: Lund University. 195-226.

Nelson, R. 2013 Practice as Research in the Arts: principles, protocols, pedagogies, resistances, Basingstoke: Palgrave Macmillan. https://doi.org/10.1057/9781137282910

Østergaard Pedersen, T. 2015 Sammenlignende vandalisme: Asger Jorn, den nordiske folkekunst og arkæologien, Højbjerg: Moesgaard Museum.

Pascoe, B. 2018 Dark Emu. Aboriginal Australia and the birth of agriculture, Magabala Books.

Pearson, M. and Shanks, M. 2001 Theatre/Archaeology, London/New York: Routledge.

Petersson, B. 2019 'Experimentellt kulturarv - Ismantorp mellan arkeologi och konst' in C. Ljung (ed) Tidens landskap - en vänbok till Anders Andrén, Lund: Nordic Academic Press. 259-261.

Phelan, P. 1993 Unmarked: the politics of performance, London: Routledge.

Renfrew, C. 2003 Figuring it Out: What are we? Where do we come from? The parallel visions of artists and archaeologists, London: Thames \& Hudson.

Sandell, J. (ed) 2018 Kon: samtidskonst och kulturarv på landsbygden 1, Kalmar: Kalmar Art Museum.

Saratsi, E., Acott, T., Allinson, E., Edwards, D., Fremantle, C. and Fish, R. 2019 Valuing Arts and Arts Research, Valuing Nature Paper VNP22. https://valuing-nature.net/valuingarts-and-arts-research 
Schatzki, T.R., Knorr-Cetina, K. and von Savigny, E. (eds) 2001 The Practice Turn in Contemporary Theory, London: Routledge.

Schechner, R. 2013 Performance Studies: An Introduction, 3rd edition, London/New York: Routledge. https://doi.org/10.4324/9780203715345

Schön, D.A. 2003 The Reflective Practitioner: how professionals think in action, Aldershot: Arena.

Schulting, R., Sheridan, A., Clarke, S. and Bronk Ramsey, C. 2008 'Largantea and the dating of Irish wedge yombs', The Journal of Irish Archaeology 17, 1-17.

Smith, L. and Waterton, E. 2009 Heritage, Communities and Archaeology, London: Duckworth.

Thrift, N. 2004 'Intensities of feeling: towards a spatial politics of affect', Geografiska Annaler, Series B, Human Geography 86(1), 57-78. https://doi.org/10.1111/j.04353684.2004.00154.x

Thrift, N. 2008 Non-representational Theory: Space, politics, affect, London/New York: Routledge. https://doi.org/10.4324/9780203946565

Tilley, C. 1994 A Phenomenology of Landscape: places, paths, and monuments, Oxford: Berg.

Tilley, C. 2008 Body and Image: explorations in landscape phenomenology 2, Walnut Creek, Calif.: Left Coast.

Tilley, C. 2016 Interpreting Landscapes: geologies, topographies, identities (ebook), Explorations in Landscape Phenomenology 3, London:

Routledge. https://doi.org/10.4324/9781315426297

Tilley, C. with Bennett, W. 2004 The Materiality of Stone: explorations in landscape phenomenology 1, Oxford: Berg.

Tiwari, R. 2010 Space - Body - Ritual. Performativity in the City, Lanham, New York: Lexington Books.

Tunbridge, J.E. and Ashworth, G.J. 1996 Dissonant Heritage: the management of the past as a resource in conflict, Chichester: Wiley.

Unwin, B.C. 2008 Phenomenology and Landscape Experience: A Critical Appraisal for Contemporary Art Practice, Unpublished PhD Thesis/Portfolio. University of Hertfordshire. https://core.ac.uk/download/pdf/1638219.pdf

Vakoch, D.A. and Castrillón, F. (eds) 2014 Ecopsychology, Phenomenology, and the Environment - The Experience of Nature, New York:

Springer. https://doi.org/10.1007/978-1-4614-9619-9

Wahlberg, M. (ed) 2016 Svenskt ortnamnslexikon, Second revised edition, Uppsala: Institutet för språk och folkminnen. 
Willim, R. 2013 'Out of hand: reflections on elsewhereness' in A. Schneider and C. Wright (eds) Anthropology and Art Practice, London: Bloomsbury.

\section{Websites}

Burren Geopark https://www.burrengeopark.ie/ [Last accessed: 12 January 2019]

Experimental Heritage https://experimentalheritage.com/ [Last accessed: 19 January 2019]

Experimentellt Kulturarv https://experimentelltkulturarv.se/ [Last accessed: 17 February 2019]

Kamprad Family Foundation https://familjenkampradsstiftelse.se/ [Last accessed: 13 March 2019]

Moderna Museet/Modern Art Museum in Stockholm, Sweden https://www.modernamuseet.se/stockholm/en/ [Last accessed: 9 July 2019]

Sandby fortress website https://www.sandbyborg.se/en/home/ [Last accessed: 15 March 2019]

Swedish History Museum https://historiska.se/home/ [Last accessed: 19 March 2019]

UNESCO World Heritage List https://whc.unesco.org/en/list/ [Last accessed: 24 April 2019] 